\title{
Análise cinética da locomoção aplicada á técnica de transposição do músculo semitendinoso na reparação de hérnia perineal bilateral em cães
}

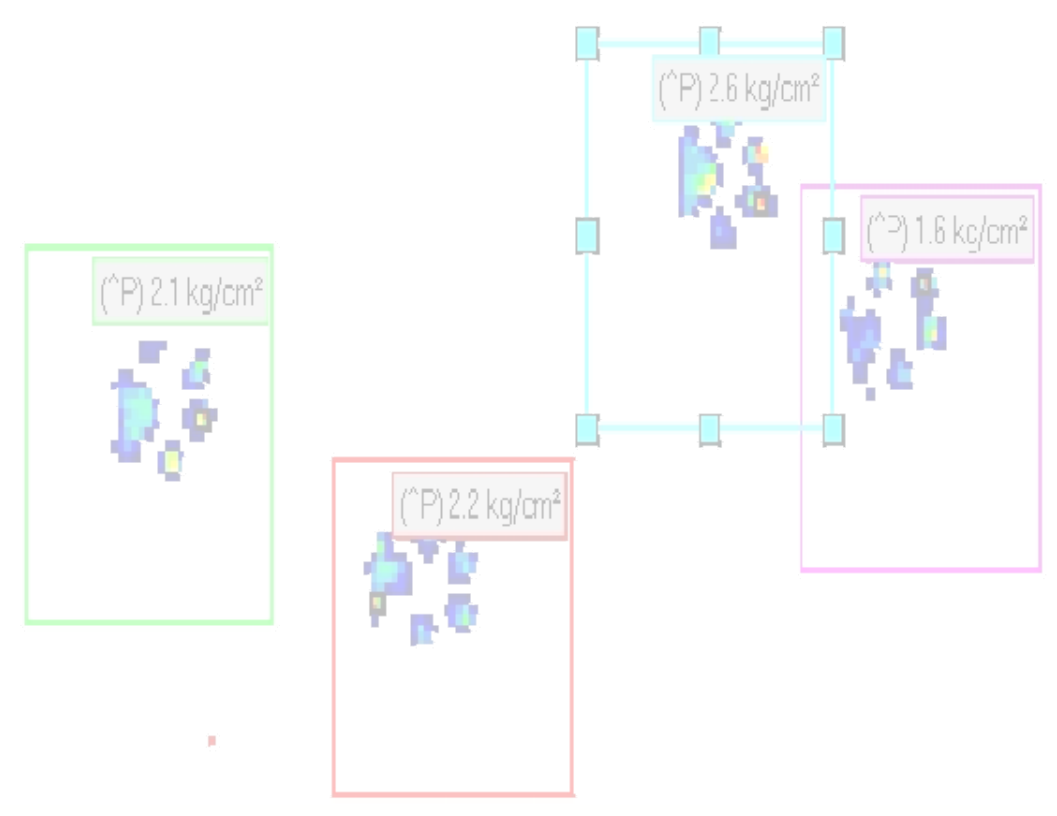

São Paulo 
PROCÁSSIA MARIA LACERDA BARBOSA

Análise cinética da locomoção aplicada á técnica de transposição do músculo semitendinoso na reparação de hérnia perineal bilateral em cães

Tese apresentada ao Programa de Pósgraduação em Clínica Cirúrgica Veterinária da Faculdade de Medicina Veterinária e Zootecnia da Universidade de São Paulo para obtenção do título de Doutor em Ciências.

Departamento:

Cirurgia

Área de concentração:

Clínica Cirúrgica Veterinária

Orientador:

Prof. Dr. Angelo João Stopiglia

\section{São Paulo}


Autorizo a reprodução parcial ou total desta obra, para fins acadêmicos, desde que citada a fonte.

DADOS INTERNACIONAIS DE CATALOGAÇÃO-NA-PUBLICAÇÃO

(Biblioteca Virginie Buff D’Ápice da Faculdade de Medicina Veterinária e Zootecnia da Universidade de São Paulo)

Barbosa, Procássia Maria Lacerda

Análise cinética da locomoção aplicada á técnica de transposição do músculo semitendinoso na reparação de hérnia perineal bilateral em cães / Procássia Maria Lacerda Barbosa. -- 2010.

100 p. : il.

Tese (Doutorado) - Universidade de São Paulo. Faculdade de Medicina Veterinária e Zootecnia. Departamento de Cirurgia, São Paulo, 2010.

Programa de Pós-Graduação: Clínica Cirúrgica Veterinária.

Área de concentração: Clínica Cirúrgica Veterinária.

Orientador: Prof. Dr. Angelo João Stopiglia.

1. Hérnia perineal. 2. Músculo semitendinoso. 3. Análise cinética. 4. locomoção. I. Título. 


\section{FACULDADE DE MEDICINA VETERINÁRIA E ZOOT ECNIA}

\section{Comissão de Ética no uso de animais}

\section{CERTIFICADO}

Certificamos que o Projeto intitulado "Análise cinética da locomoção aplicada à técnica de transposição do músculo semitendinoso na reparação de hérnia perineal bilateral em cães", protocolado sob o n 1138/2007, utilizando o mínimo de 10 cães, sob a responsabilidade do Prof. Dr. Angelo João Stopiglia, está de acordo com os princípios éticos de experimentação animal da "Comissão de Ética no uso de animais" da Faculdade de Medicina Veterinária e Zootecnia da Universidade de São Paulo e foi aprovado "ad referendum".

We certify that the Research "Kinetic analysis of locomotion applied technique semitendinosus muscle transposition in repairing bilateral perineal hernia in dogs", protocol number 1138/2007, under the responsibility Prof. Dr. Angelo João Stopiglia, agree with Ethical Principles in Animal Research adopted by "Ethic Committee in the use of animals" of the School of Veterinary Medicine and Animal Science of University of São Paulo and was approved "ad referendum" meeting.

São Paulo, 17 de junho de 2010

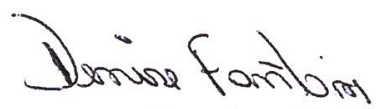

Profa. Dra. Denise Tabacchi Fantoni

Presidente 
FOLHA DE AVALIAÇÃO

Nome: BARBOSA, Procássia Maria Lacerda

Título: Análise cinética da locomoção aplicada á técnica de transposição do músculo semitendinoso na reparação de hérnia perineal bilateral em cães

Tese apresentada ao Programa de Pósgraduação em Clínica Cirúrgica Veterinária da Faculdade de Medicina Veterinária e Zootecnia da Universidade de São Paulo para obtenção do título de Doutor em Ciências.

Data:

\section{Banca examinadora}

Prof. Dr. Instituição:

Assinatura: Julgamento:

Prof. Dr. Instituição:

Assinatura: Julgamento:

Prof. Dr. Instituição:

Assinatura: Julgamento:

Prof. Dr. Instituição:

Assinatura: Julgamento:

Prof. Dr. Instituição: Julgamento: 


\section{DEDICATÓRIA}

Tenho motivos pra te louvar

Tenho motivos pra te adorar

Tenho motivos pra dar a vida por $\mathcal{T}_{i}$

És o motivo de hoje eu existir

O teu amor me alcançou Me trouxe vida, me regenerou E o verdadeiro motivo, me revelou

Está em Jesus o meu Salvador!

$\mathcal{N} a ̃ o$ há lugar melhor pra estar Do que estar sempre ao Teu lado E desfrutar da tua voz Que ao falar aquieta o coração

$\mathcal{N a}$ mais difícil confusão Sei que Tu és o meu amigo Faz me enxergar a solução Fica tão fácil quando Tu estás!!!*

${ }^{\star}$ Tenho motivo- Renascer Praise 9 SEMPRE estás comigo, Senhor. 
Ao meu esposo Valdisnei Barbosa e nossa filhinha Rebeca Barbosa, que são o melhor de Deus na minha vida. Nada é mais importante que tê-los ao meu lado. Com vocês me sinto forte para vencer qualquer batalha, pois lutamos juntos em amor e oração. Amo vocês. 
Aos meus pais Damião Lacerda e Raimunda Lacerda, que sempre serão, em todas as conquistas da minha vida, motivos de orgutho e agradecimentos, pois souberam me conduzir nos caminhos da vida. As minhas vitórias são as suas vitórias, por isso as dedico a vocês. 
Aos meus familiares, pelo amor, carinho, apoio e companheirismo. Sabemos que sempre podemos contar um com o outro. Cada um de vocês sabe o valor na minha vida. A vocês meus amados eu dedico!!! 
A minha sogra Naide Barbosa por ser uma muโher diferenciada, serva de Deus autêntica que sempre nos cobriu em oração. A você minha amada sogra e mãezinha eu também dedico essa conquista, suas orações e cuidado foram confortantes. 


\section{AGRADECIMENTTOS}

Vem e toma o teu lugar

Tens minha vida como altar

Um trono de louvor

Entrego a Ti Senhor meu Deus

Guarda o meu coração No Teu jardim particular Vem regar-me com Tua unção Pra que eu possa exalar Teu ser

Dá-me tuas asas pra te alcançar $\mathcal{N}$ os lugares altos aonde Tu estás Estás assentado acima de todos Tão grande Tu és Mas mesmo assim habitas em mim...

Habitas em mim... Habitas em mim... Habitas em mim... 
Ao meu orientador, Angelo João Stopiglia, homem de muitas qualidades, integridade inquestionável. Alguém que me recebeu como orientada, mas tratou como filha. Obrigada professor, por ter me aceito, ajudado e compreendido. Não há palavras para agradecer-The, mas o senhor sabe tudo o que fez por mim e por essa pesquisa, sem o senhor o meu doutorado teria sido bem difícil. Hoje eu sei onde estou e ande quero chegar. Muito obrigada.

Ao mestre José Fernando Gomes de Al6uquerque, pois sem sua ajuda e incentivo não teria chegado na USP. Tudo começou lá em Mossoró-RN, no laboratório de Anatomia. Nãa há como deixar de agradecer-The em cada etapa, pois o senhor tem a primeira participação.

Valeu a pena

A professora Julia Maria Matera, pela ajuda essencial no desenvolvimento do projeto, pelos ensinamentos, disposição e excelência. Posso dizer que sou privilegiada, tive nesse trabalho a ajuda dos melhores cirurgiões do Brasil, não é para qualquer um. Muito obrigada professora.

A professora Maria Angélica Miglino, por sempre me receber com carinho, acreditar na minha capacidade e incentivar os meus projetos. Obrigada professora por ter sempre um coração disposto a me ajudar, em qualquer lugar que eu esteja.

Aos Professores do Programa de Pós-graduação em Clínica Cirúrgica, pelos ensinos, apoio e exemplos que contribuíram na minha formação profissional.

As Médicas Veterinárias do Serviço de Cirurgia de Pequenos animais - HOVET- FMVZ Andressa Gianotti Campos, Patricia Ferreira Castro, Tatiana Soares da Silva, Viviane Galeazzi pela ajuda, compreensão e encaminhamento dos animais para o projeto. Em especial a veterinária e amiga Sandra Aparecida Rosner, pela amizade que desenvolvemos, a ajuda nas cirurgias, ensinamentos e paciência. Obrigada amiga, sempre vou lembrar tudo o que vocêfez por mim.

Aos funcionários do Serviço de Cirurgia de Pequenos animais - HOVET- FMVZ- Jesus dos Anjos Vieira, José Miron Oliveira e Otávio Rodrigues dos Santos. Vocês são incríveis, como pessoa e como profissionais, muito obrigada por tudo, vocês são fundamentais em todos os projetos desenvolvidos no setor. Em especial Cledson Lelis dos Santos (Lelinho), por seu uma pessoa extraordinária, fez por mim o que ninguém faria, nós sabemos as bombas que pegamos... Sua ajuda foi essencial. Para você não existe tempo ruim, você é muito especial. 
Aos secretários, Belarmino Ney Pereira e Alessandra Souza, pela convivência maravilhosa, pelas risadas, brincadeiras, almoços, enfim, por tudo de bom que vocês são. Profissionais atenciosos e dedicados, pessoas queridas e inesqueciveis. Obrigada por tudo.

A amiga Karla Patrícia pelo tempo que moramos juntas e desfrutamos de uma convivência abençoada, pela pessoa de coração bom que você é e por tudo que vivemos nesse tempo. Deus tem mais para nós, espero que a distância não nos impeça de compartilhar as conquistas e milagres. Somos de JESUS!!! Um beijão e obrigada por tudo.

A Bispa Amanda Baldoni pelo carinho e cobertura espiritual. Você é um exemplo de liderança que quero seguir, não vou esquecer seus ensinamentos, vou seguir sempre em frente, posicionada e confiante na vitória que vem das mãos de Deus. Vm beijão Bispa.

Aos Pastores Cecilia Watanabe, Neci, Elza, Walter e Julhinha, pelos anos de convivência em amor e trabalho, pelas orações, intercessões, Gatalhas e vitórias juntos. Vocês fazem parte da minha história, fui formada em amor, obrigada por cobrir a minha vida. Amo vocês.

A todos da amada Equipe 1 de Diaconia, não tem como citar o nome de cada um de vocês, mas eu tenho muito o que agradecer pela vida de vocês. Quantas alegrias vocês me proporcionaram, sem comentários, sem comparação. A vocês eu agradeço.

Aos amigos preciosos Ricardo e Camila, pessoas inestimáveis, que tem uma participação especial nessa etapa da minha vida, pois sem eles eu não teria conseguido realizar tudo que tinha proposto. Que Deus acrescente 100 vezes mais tudo o que vocês fazem por mim. Beijão

Ao nosso amado R12, Pra Estela, Marilde, Milena, Bianca, Rosana, Romildo, Sandra, Camila, Ricardo, pelo tempo de aprendizado e comunfão que desfrutamos, pelas orações, intercessões e conquistas. Vocês fazem parte da minha história, obrigada.

Ao amigo Alexandre NNavarro Alves de Souza, pela amizade e pela contribuição essencial neste trabalho com as análises cinéticas. Obrigada por todas as análises, por sua disposição e paciência em tirar dúvidas, e pelas colocações pertinentes no desenvolvimento do trabalho.

Aos amigos de pós-graduação pela amizade e convivência, nesse tempo em que estive aqui. 
Aos proprietários que pacientemente compareceram com os cães nos prazos determinados pelo projeto para as avaliações propostas.

Ao Serviço de Radiologia e Ultrassonagrafia do HOVET FMVZ/USP pela atenção e realização dos exames fundamentais ao andamento do projeto

Aos funcionários do setor administrativo do HOVET pela atenção e diligência em atender as necessidades do andamento projeto.

Aos funcionários do da biblioteca da FMVZ-USP, pela agilidade, cortesia e profissionalismo com que conduzem seus trabalhos.

Á Faculdade de Medicina Veterinária e zootecnia da USP, por favorecer o meu desenvolvimento tecnológico e científico, constituindo uma visão diferenciada de profissionatismo.

Á Fundação de Amparo a Pesquisa do Estado de são Paulo- FAPESP, processo $n^{\circ}$ 07/52474-5 por fomentar essa pesquisa, ampliando o conhecimento e proporcionando desenvolvimento. 


\section{RESUMO}

BARBOSA, P. M. L. Análise cinética da locomoção aplicada á técnica de transposição do músculo semitendinoso na reparação de hérnia perineal bilateral em cães. [Kinetic analysis of locomotion applied technique semitendinosus muscle transposition in repairing bilateral perineal hernia in dogs]. 2010. 100 f. Tese (Doutorado em Ciências) - Faculdade de Medicina Veterinária e Zootecnia, Universidade de São Paulo, São Paulo, 2010.

A hérnia perineal é uma das afecções cirúrgicas frequentemente observadas na rotina da clínica cirúrgica de pequenos animais e acometem na sua maioria, cães machos, não castrados e acima de cinco anos. Apresenta elevado índice de recidivas e complicações pós-cirúrgicas, e devido a este fato, muitas técnicas foram preconizadas e utilizadas para a sua correção. Os objetivos do presente estudo foram avaliar a locomoção cinética dos cães com hérnia perineal bilateral, submetidos à técnica de transposição do músculo semitendinoso antes e após a sua transposição; verificar a capacidade de adaptação do membro pélvico operado, após a transposição do semitendinoso, até 90 dias de pós-operatório e analisar a viabilidade dessa técnica de reparação em casos de hérnia perineal bilateral. Foram operados onze cães com diagnostico de hérnia perineal bilateral, no Serviço de Cirurgia de Pequenos Animais junto ao Hospital Veterinário da Faculdade de Medicina Veterinária da Universidade de São Paulo (HOVET-FMVZ / USP). Todos foram submetidos à técnica de transposição do músculo e avaliados com exames baropodométricos antes e após a cirurgia, nos períodos de 30, 60 e 90 dias pós-operatório. As variáveis pico de força vertical (PFV) e impulso vertical (IV) foram utilizadas como parâmetros para a análise de mudanças na locomoção. A PFV e IV não mostraram diferença estatística $(p>0,05)$ entre os membros operados e não operados, respectivamente (18,62 \pm 4,93 e 18,51 \pm 3,75), indicando que não houve alteração na locomoção dos cães após a transposição do músculo semitendinoso. A diferença no comportamento dessas variáveis no período pré-operatório nos permitiu aferir que o desconforto provocado pela hérnia perineal possa interferir na locomoção do animal gerando assimetria, considerando que após o procedimento operatório a simetria da locomoção apresentou valores mais compatíveis dentro do normal. As diferenças em PFV e IV, embora não significativas, nos dá uma idéia da recuperação desses cães e sugere que a transposição não afeta a função locomotora do membro operado.

Palavras chave: Hérnia perineal. Músculo semitendinoso. Análise cinética. Locomoção. 


\begin{abstract}
BARBOSA, P. M. L. Kinetic analysis of locomotion applied technique semitendinosus muscle transposition in repairing bilateral perineal hernia in dogs [Análise cinética da locomoção aplicada á técnica de transposição do músculo semitendinoso na reparação de hérnia perineal bilateral em cães]. 2010. 100 f. Tese (Doutorado em Ciências) - Faculdade de Medicina Veterinária e Zootecnia, Universidade de São Paulo, São Paulo, 2010.
\end{abstract}

A perineal hernia is a surgical lesion frequently observed in surgical clinic for small animals, affecting mainly dogs neutered over five years. Has a high recurrence rate and postoperative complications, and due to this fact, many techniques have been proposed and used for its correction. The objectives of this study were to evaluate the kinetic movement of dogs with bilateral perineal hernia, submitted to the technique of transposition of the semitendinosus muscle before and after its implementation and verify the adaptability of the pelvic limb surgery, after transposition of the semitendinosus 90 days of postoperatively and analyze the feasibility of this technique of repair in cases of bilateral perineal hernia. Eleven dogs were operated with diagnosis of bilateral perineal hernia, on the Surgery Service of the animal small of the Veterinary Hospital of the Faculty of Veterinary Medicine, University of São Paulo (HOVET-FMVZ / USP). All patients underwent the technique of muscle transposition and evaluated baropodometric examinations before and after surgery, in periods of 30, 60 and 90 days postoperatively. The variables peak vertical force (PFV) and vertical impulse (VI) were used as parameters for the analysis of changes in locomotion. The PFV and IV showed no statistical difference ( $>$ > 0.05) between the operated and non operated limbs, respectively (18.62 \pm 4.93 and $18.51 \pm 3.75$ ), indicating that there was no change in locomotion dogs after the transposition of the semitendinosus muscle. The difference in behavior of these variables in the preoperative period allowed us to infer that the discomfort caused by perineal hernia can interfere with the locomotion of the asymmetry animal generating, whereas after the operative procedure, the symmetry of locomotion showed more next values of the normal. The difference in PFV and IV, although not significant, gives us an idea of the recovery of these dogs and suggests that the transposition does not affect the motor function of the limb.

Key words: Perineal hernia. Semitendinosus muscle. Kinetic analysis. Locomotion. 


\section{LISTA DE FIGURAS}

Figura 1 - Sequência operatória do cão n5.A- Posicionamento na mesa cirúrgica B- Correção da hérnia perineal antes da transposição do músculo C- Pedículo da artéria femoral caudal distal; E- Mensuração do músculo semitendinoso;E e F- Transposição do músculo preservando o plano sagital mediano (tunilização); G- Sutura após procedimento cirúrgico; H- Sete dias após o ato operatório, FMVZ/USP - São Paulo - 2007-2010.

Figura 2 - Análise de uma passagem do cão $\mathrm{n}^{\circ} 8$, por meio do sistema de registro de distribuição de força, a partir do software I-scan 5.231, Tekscan., South Boston, MA, USA, FMVZ/USP - São Paulo -2010. .51

Figura 3 - Imagem do cão n² antes do procedimento cirúrgico e cão n 4 com 90 dias de pósoperatório, caminhando com seus respectivos condutores sobre a plataforma de baropodometria - Tekscan ${ }^{\circledR}$ no LAL, FMVZ/USP - São Paulo -20072010 .52

Figura 4 - Análise de uma passagem do cão n8 pela marcação específica para cada membro a partir do software I-scan 5.231, Tekscan., South Boston, MA, USA. As Marcações referem-se as FRS. Verde, membro torácico esquerdo (MTE); vermelho, membro pélvico esquerdo (MPE), Lilás, torácico direito (MTD) e azul, membro pélvico direito (MPD). Passagem registrada no LAL, FMVZ/USP - São Paulo -2007$2010 \ldots . . . .52$

Figura 5 - Mensuração e registro do PFV, IV e TA em Newtons, N/s e s, respectivamente, do cão ${ }^{\circ}$ 8, registrada a partir do software I-scan 5.231, Tekscan., South Boston, MA, USA, no LAL, FMVZ/USP - São Paulo -2007-2010. .53

Figura 6 - Comprimento em centímetros do músculo semitendinoso antes de ser incisado. Acão condrodistrófico, mestiço da raça Daschund $\left(\mathrm{n}^{\circ} 7\right)$ com $6,5 \mathrm{~cm}$; B- cão SRD (n5) com 13cm antes da secção, FMVZ/USP - São Paulo -2007-2010. 58

Figura 7 - A- Cicatrização por segunda intenção com 30 dias de pós-operatório no cão n¹. B- Deiscência de pele após 6 dias do procedimento cirúrgico no cão n8. FMVZ/USP - São Paulo -2007-2010.. 
Figura 8 - Sequência da recuperação do cão n5. A- Aspecto do fechamento da incisão logo após a transposição do músculo semitendinoso. B- Aspecto da ferida sete dias após o ato operatório. C- Recuperação completa do paciente com trinta dias de pósoperatório, FMVZ/USP - São Paulo - 2007-2010.

Figura 9 - Gráfico com os dados estatísticos, evidenciando o comportamento da PFV dos MPO (1- azul) e MPNO (2-verde) nos tempos pré-operatório, 30, 60 e 90 dias de pós-operatório, correspondendo respectivamente aos números 1, 2, 3 e 4 do gráfico, FMVZ/USP, São Paulo - 2007-2010 .64

Figura 10 - Gráfico com os dados estatísticos, evidenciando o comportamento do IV dos MPO (1- azul) e MPNO (2-verde) nos tempos pré-operatório, 30, 60 e 90 dias de pós-operatório, correspondendo aos números 1, 2, 3 e 4 do gráfico, respectivamente, FMVZ/USP - São Paulo -2007-2010. .66

Figura 11 - Análise das forças de reação ao solo no paciente n8 no período pré-operatório, por meio de software e gráfico da PFV e IV para cada um dos quatro membros durante uma das cinco passagens válidas. Em verde (MTD), Vermelho (MTE), Rosa (MPD) e azul (MPE). FMVZ/USP - São Paulo - 2007-2010

Figura 12 - Análise das forças de reação ao solo do cão n8 com 60 dias de pós-operatório, por meio de software e gráfico da PFV e IV para cada um dos quatro membros durante uma das cinco passagens válidas. Em verde (MTD), Vermelho (MTE), rosa (MPD) e azul (MPE). FMVZ/USP - São Paulo - 2007-2010 


\section{LISTA DE TABELAS}

Tabela 1 - Identificação dos cães submetidos à transposição do músculo semitendinoso, atendidos no HOVET, FMVZ/USP, São Paulo, 2010. 56

Tabela 2 - Valores médios do tempo de apoio (TA) em segundos dos membros torácicos e pélvicos operados e não operados, no período pré-operatório, avaliados no LAL, FMVZ/USP, São Paulo, 2010. 61

Tabela 3 - Média dos valores de tempo de apoio (TA) em segundos, dos membros torácicos e pélvicos operados e não operados, no período pós-operatório (30,60 e 90 dias), avaliados no LAL, FMVZ/USP, São Paulo, 2010.

Tabela 4 - Média dos valores do Pico de Força Vertical (PFV) em \%PC no período préoperatório de cada animal, avaliados no LAL da FMVZ/USP, São Paulo, 2010.....63

Tabela 5 - Média dos valores do Pico de Força Vertical (PFV) em \%PC nos períodos pósoperatórios de cada animal, avaliados no LAL da FMVZ/USP, São Paulo, 2010....63

Tabela 6 - Média dos valores Impulso Vertical (IV) considerando cinco repetições válidas dos cães submetidos ao exame de baropodometria no período pré-operatório, LAL da FMVZ/USP - São Paulo - 2010.

Tabela 7 - Média dos valores Impulso Vertical (IV) das cinco repetições de cada um dos pacientes submetido ao exame de baropodometria no período pós-operatório, LAL da FMVZ/USP - São Paulo - 2010 


\section{LISTA DE QUADROS}

Quadro 1 - Parâmetros fisiológicos obtidos dos cães submetidos à transposição do músculo semitendinoso, no seu primeiro dia de atendimento no HOVET, FMVZ/USP - São Paulo -2010. .95

Quadro 2 - Resultado das análises laboratoriais realizadas no período pré-operatório no Laboratório de análises Clínicas do HOVET/FMVZ - São Paulo - 2010. .96

Quadro 3 - Descrição da localização da próstata e bexiga nos laudos emitidos antes do procedimento cirúrgico pelo Serviço de Imagem do HOVET/FMVZ - São Paulo 2010.

Quadro 4 - Descrição das características físicas de cada cão e as respectivas medidas do músculo semitendinoso antes e após a incisão. G- Grande, M- Médio, P- Pequeno, CMComprimento do músculo, CMPI- Comprimento do músculo pós-incisão. Atendidos no HOVET/FMVZ - São Paulo - 2010. .98 


\section{LISTA DE ABREVIATURAS E SIGLAS}

\%BW Porcentagem da body weight

\%PC Porcentagem do peso corpóreo

ALB Albumina

ALP Fosfatase alcalina

ALT Alanina aminotransferase

CHCM Concentração de hemoglobina corpuscular médio

CM Comprimento do músculo

CMPI Comprimento do músculo pós- incisão

CN Caso novo

DH Desidratação

DP Desvio padrão

FAPESP Fundação de Amparo a Pesquisa do Estado de São Paulo

FC Frequência cardíaca

FMVZ Faculdade de Medicina Veterinária e Zootecnia

FR Frequência respiratória

G Grande

H BIL Hérnia Bilateral

H UNI Hérnia Unilateral

HCM Hemoglobina corpuscular média

HG hemoglobina

HI Hidratação

HM Hemácias

HOVET Hospital Veterinário

HT Hematócrito

IC Intervenção Cirúrgica

IV Impulso Vertical

LAL Laboratório do Aparelho Locomotor

LC Leucócitos

LI Linfonodos

M Médio

MPD Membro pélvico direito

MPE Membro pélvico esquerdo 


$\begin{array}{ll}\text { MPNO } & \text { Membro pélvico não operado } \\ \text { MPO } & \text { Membro pélvico operado } \\ \text { MTD } & \text { Membro torácico direito } \\ \text { MTE } & \text { Membro torácico esquerdo } \\ \text { MU } & \text { Mucosas } \\ \text { N/s } & \text { Newton por segundo } \\ \text { NE } & \text { Não especificado } \\ \text { NORMO } & \text { Normal } \\ \text { P } & \text { Pequeno } \\ \text { PFV } & \text { Pico de Força vertical } \\ \text { PLQ } & \text { Plaquetas } \\ \text { POPL } & \text { Poplíteo } \\ \text { PT } & \text { Proteinas totais } \\ \text { RX } & \text { Raio X } \\ \text { SCPA } & \text { Serviço de Cirurgia de Pequenos Animais } \\ \text { SRD } & \text { Sem raça definida } \\ \text { T } & \text { Temperatura } \\ \text { TA } & \text { Tempo de Apoio } \\ \text { US } & \text { Ultrassonografia } \\ \text { USA } & \text { Estados Unidos da América } \\ \text { USP } & \text { Departamento de Cirurgia } \\ \text { VCI } & \text { VCM }\end{array}$




\section{LISTA DE SÍMBOLOS}

$\% \quad$ Porcentagem

* Asterisco

$\leq \quad$ Menor ou igual

$\geq \quad$ Maior ou igual

$\pm \quad$ Mais ou menos

$=$ Igual

- Graus 


\section{SUMÁRIO}

1 INTRODUÇÃO

2 OBJETIVOS

3 REVISÃO DE LITERATURA...........................................................................

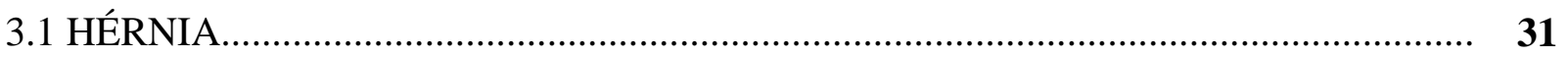

3.2 HÉRNIA PERINEAL ....................................................................................... 31

3.2.1 Considerações Gerais ...........................................................................

3.2.2 Classificação (DORN; CARTEE; RICHARDSON, 1982) ………………….. 32

3.2.3 Epidemiologia ......................................................................................... 33

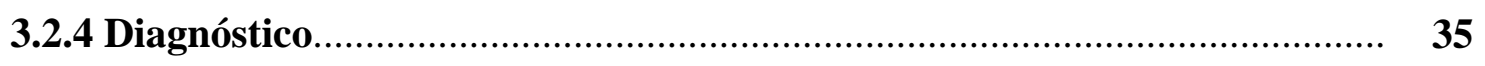

3.2.5 Tratamento Cirúrgico.............................................................................. $\quad 36$

3.3 TRANSPOSIÇÃO DO MÚSCULO SEMITENDINOSO................................................. 38

3.4 ANÁLISE CINÉTICA DA LOCOMOÇÃO.................................................................. 39

3.5 BAROPODOMETRIA..................................................................................... 40

4 MATERIAIS E MÉTODOS.............................................................................. 46

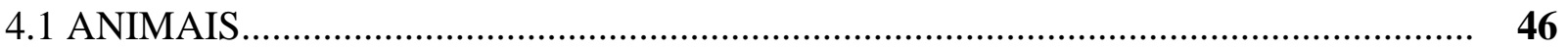

4.2 PERÍODO PRÉ-OPERATÓRIO_............................................................................. 46

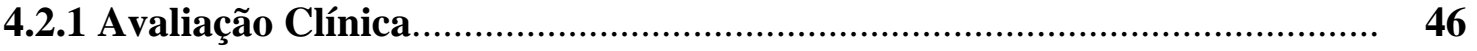

4.2.2 Pré-operatório .......................................................................................... 47

4.2.3 Procedimento Cirúrgico................................................................................ 47

4.3 PERÍODO PÓS-OPERATÓRIO_............................................................................ 5

4.3.1 Pós-operatório Imediato ........................................................................... 50

4.3.2 Avaliação Clínica...................................................................................... 50

4.4 AVALIAÇÃO CINÉTICA BAROPODOMÉTRICA................................................... 50

4.5 AVALIAÇÃO RADIOGRÁFICA E ULTRASSONOGRÁFICA..................................... 53

4.6 ANÁLISE ESTATÍSTICA................................................................................ 54 


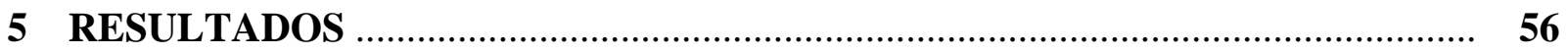

5.1 AVALIAÇÃO CLÍNICA ……………………………………………………... 56

5.2 TÉCNICA CIRÚRGICA...................................................................................

5.2 AVALIAÇÃO PÓS-OPERATÓRIA........................................................................... 58

5.4 AVALIAÇÃO BAROPODOMÉTRICA................................................................... 61

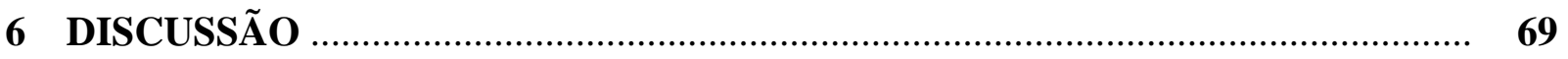

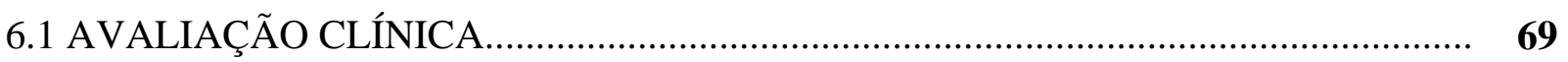

6.2 TÉCNICA CIRÚRGICA..................................................................................... 71

6.3 AVALIAÇÃO PÓS-OPERATÓRIA........................................................................... 73

6.4 AVALIAÇÃO BAROPODOMÉTRICA................................................................. 75

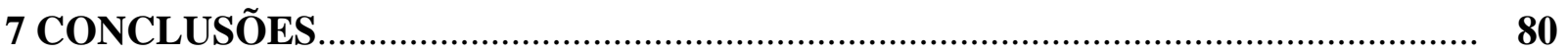

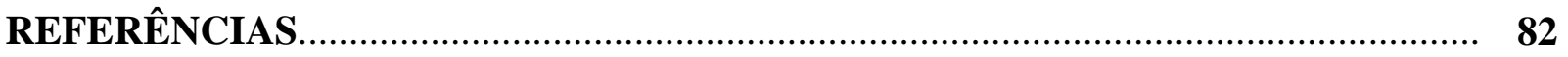

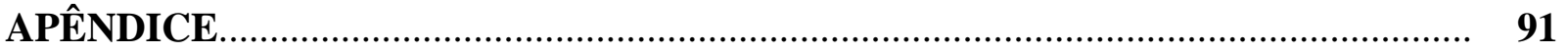

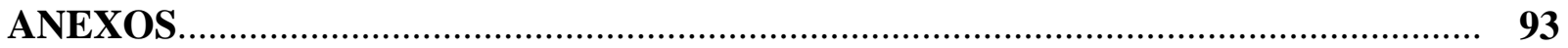




\section{INTRODUÇÃO}




\section{INTRODUÇÃO}

Hérnia é definida como uma protrusão anormal de um órgão ou parte dele causado pelo seu deslocamento através de uma abertura na cavidade anatômica a qual está inserido (BELLENGER; READ, 1998; FERREIRA; DELGADO, 2003). A maioria das hérnias envolve a protrusão de órgãos abdominais através de sua parede ou diafragma e períneo (BELLENGER; READ, 1998). As hérnias perineais ocorrem quando os músculos da região de períneo se separam, permitindo que os conteúdos da cavidade abdominal e/ou pélvica se desloquem para essa região (FOSSUM, 2001).

A hérnia perineal é resultante da atrofia ou enfraquecimento das fáscias e músculos que compõem o diafragma pélvico, que é constituído pelo músculo elevador do ânus, músculos coccígeos e suas fáscias interna e externa (ANDERSON et al., 1998; BELLENGER; READ, 1998)

A ruptura ou atrofia dos músculos do diafragma pélvico permite o deslocamento de estruturas abdominais ou pélvicas em direção caudal, sendo evidenciado por um intumescimento do períneo (COSTA NETO et al., 2006). Esta condição pode-se apresentar uni ou bilateralmente e, mesmo sendo unilateral o lado contralateral geralmente evidencia fragilidade (HEDLUND, 2002).

Os animais machos da espécie canina, de idade superior a cinco anos, principalmente entre sete e nove anos, são os mais acometidos por essa paratopia (HEDLUND, 2002; BELLENGER; READ, 1998), sendo a hérnia perineal caudal o tipo mais comumente encontrado (MANN, 1993).

O tratamento cirúrgico depende do quadro clínico apresentado pelo paciente, uma vez que existe uma grande variedade de procedimentos para o seu tratamento. O método tradicional, que corresponde a suturas entre os músculos esfíncter anal externo e coccígeos (HOLMES, 1964) e a técnica de elevação do músculo obturador interno (ANDERSON et al., 1998; BELLENGER; READ, 1998 MANN; CONSTANTINESCU, 1998) são as técnicas mais utilizadas, no entanto, outras técnicas já foram desenvolvidas, transposição do músculo glúteo superficial (ANDERSON et al., 1998; BELLENGER; READ, 1998); acesso dorsal ao ânus na correção de hérnia bilateral (ACAUI, 2001), uso de membranas biológicas e malhas sintéticas (FRANKLAND, 1986; MATERA et al., 1981; DALECK, 1992; ZERWES, 2005;) e por transposição do músculo semitendinoso (CHAMBERS; RAWLINGS 1991; 
PHILIBERT; FOWLER 1996; CHAMBERS 1999; GALEAZZI et al., 2006; MORTARI et al., 2005)

O músculo semitendinoso forma o contorno caudal da coxa, tem origem na tuberosidade isquiática, descendo por sobre o músculo gastrocnêmio e inserindo-se na face medial da parte proximal da tíbia (EVANS; DELAHUNTA, 1971). Recebe suprimento nervoso do ramo do nervo isquiático e tem como função a extensão das articulações do quadril e tarso, e na flexão da articulação do joelho quando o membro não está suportando o peso (EVANS; DELAHUNTA, 1971).

A correção cirúrgica do diafragma pélvico por transposição do músculo semitendinoso foi descrito em relatos de casos (CHAMBERS, RAWLINGS 1991; PHILIBERT; FOWLER, 1996; CHAMBERS, 1999; GALEAZZI et al., 2006) e, de forma experimental, com cães hígidos (MORTARI et al., 2005). No entanto, nada foi exposto sobre possível interferência dessa transposição na locomoção desses pacientes, considerando que o músculo semitendinoso está diretamente relacionado com a locomoção e postura dos animais.

Alterações na locomoção podem ser analisadas por vários métodos cinéticos e cinemáticos. O sistema de baropodometria permite avaliação cinética do movimento da locomoção de modo quantitativo, sendo uma das mais utilizadas por proporcionar resultados objetivos quanto à locomoção normal do paciente (BUDSBERG et al., 1987; YANOFF al., 1992; JEVENS, 1993), sendo que, a análise baropodométrica quantifica as forças de reação ao solo, descrevendo-as no momento em que o membro toca o solo (RUMPH et al., 1993). 
OBJETIVOS 


\section{OBJETIVOS}

Os objetivos do presente estudo foram:

- Avaliar a locomoção cinética dos cães com hérnia perineal bilateral submetidos à técnica de transposição do músculo semitendinoso, antes e após a sua transposição.

- Verificar a capacidade de adaptação do membro pélvico operado, após a transposição do semitendinoso, até 90 dias de pós-operatório.

- Analisar a viabilidade dessa técnica de reparação em casos de hérnia perineal bilateral. 
REVISÃO DE LITERATURA 


\section{REVISÃO DE LITERATURA}

\subsection{HÉRNIA}

É a passagem anormal de estruturas de uma cavidade para outra, devido a um defeito na parede da cavidade anatômica em que se encontra. Envolve na maioria das vezes, a protrusão do conteúdo abdominal através da parede abdominal, do diafragma, ou do períneo (FERREIRA; DELGADO, 2003). O fator predisponente consiste na presença de defeito ou de abertura na parede muscular, resultado da incapacidade da musculatura em manter o seu conteúdo visceral em seus locais usuais (BELLENGER; READ, 1998; FERREIRA; DELGADO, 2003).

As hérnias podem ser classificadas de várias maneiras, mas duas são mais aplicadas, quanto a sua localização anatômica (hérnias abdominais, diafragmáticas ou perineais) e quanto ao seu tipo (redutíveis, irredutível e estrangulada) (ARCHIBALD; SMITH, 1974; BELLENGER; READ, 1998).

\subsection{HÉRNIA PERINEAL}

Por ser um tema consideravelmente abrangente, resolvemos delinear por tópicos.

\subsubsection{Considerações Gerais}

O períneo é definido anatomicamente como a zona do corpo que recobre caudalmente a pélvis, circundando o canal anal e os canais urogenitais (EVANS; DELAHUNTA, 1971). No plano superficial, seu limite dorsal é a cauda, o limite ventral é o escroto e as laterais são limitadas pela pele que recobre os músculos glúteos superficiais e obturadores internos e as tuberosidades isquiáticas. Profundamente, o períneo é limitado pela terceira vértebra caudal dorsalmente, pelo ligamento sacrotuberoso lateralmente e pelo arco isquiático ventralmente 
(EVANS; DELAHUNTA, 1971).

O diafragma pélvico é constituído pelo músculo elevador do ânus, músculos coccígeos e suas fáscias interna e externa (ANDERSON; CONSTANTINESCU; MASS, 1998; BELLENGER; CANFIELS, 2003). A fossa isquiorretal é descrita como uma depressão cuneiforme cujas paredes são formadas pelo esfíncter anal externo, pelos músculos coccígeo e elevador do ânus medialmente, pelo músculo obturador interno ventralmente, e pela parte caudal do músculo glúteo superficial lateralmente. Ocupam este espaço quantidades variáveis de tecido adiposo, que está incorporado a fáscia perineal superficial (BELLENGER; CANFIELS, 2003).

O enfraquecimento de um ou mais músculos do períneo provoca alterações de sustentação, ocasionando deslocamento de estruturas anatômicas em direção caudal, evidenciado por um intumescimento da região (BELLENGER, 1980; WELCHES et al., 1992). A deterioração da função de sustentação do diafragma pélvico é considerada parte integral ou pré-condição no desenvolvimento da hérnia perineal e, na maioria dos casos, o músculo elevador do ânus está atrofiado ou até ausente (HARVEY, 1977; HAYES; WILSON; TRONE, 1978; BELLENGER; READ 1998).

A fragilidade do diafragma pélvico, freqüentemente, leva a desvio lateral da porção final do reto ipsis lateral a hérnia. Este desvio retal, normalmente, fica internamente repleto de material fecal que não consegue ser evacuado pela tentativa de defecar (BELLENGER; CANFIELS, 2003).

Nas cadelas, a hérnia perineal normalmente não ocorre visto que o músculo elevador do ânus é muito mais forte, mais largo e mais espesso, com maior área de contato com a parede retal do que no macho (DESAI, 1982).

\subsubsection{Classificação (DORN; CARTEE; RICHARDSON, 1982)}

Essa classificação baseia-se nas estruturas do períneo que estão envolvidas na formação da hérnia, caracterizando a sua localização anatômica. Dorn; Cartee e Richardson (1982) dividiram-as em quatro tipos:

Hérnia perineal Ciática: Abrange o ligamento sacrotuberal e o músculo coccígeo. 
Hérnia perineal Dorsal: Envolve o músculo coccígeo e elevador do ânus.

Hérnia perineal Caudal: Músculo elevado do ânus, obturador interno e esfíncter anal externo. Esse tipo é o mais comumente encontrado.

Hérnia perineal Ventral: Neste caso, são os músculos isquiorretal, bulbocavernoso e isquiocavernoso que estão relacionados.

\subsubsection{Epidemiologia}

Hérnia perineal é mais frequente na espécie canina, muitas vezes associada à atrofia neurogênica do músculo elevador do ânus (SJOLLEMA et al., 1993). É esporadicamente diagnosticada no gato, surgindo como complicação secundária a uretrostomia perineal ou ao megacólon idiopático (LEIGHTON, 1979; JOHNSON, GOURLEY, 1980; WELCHES et al., 1992; MANN et al., 1995).

Uma variável epidemiológica que assume especial importância é o sexo do paciente, onde aproximadamente $97 \%$ dos casos ocorrem no cão macho e, destes, 95\% no macho sem castração (MANN, 1993). A explicação para este fato deve-se, por um lado, às frágeis inserções do músculo elevador do ânus no macho e, por outro, à pressão que a próstata, quando hipertrofiada, exerce contra os músculos do diafragma pélvico (FERREIRA; DELGADO, 2003).

A hérnia caudal é o tipo mais comum em cães, se forma entre os músculos elevador do ânus, obturador interno e o esfíncter anal externo (MANN et al., 1995). São geralmente unilaterais, apresentando uma faixa etária de risco elevado entre seis e 14 anos, com incidência máxima entre sete e nove anos de idade (MATERA et al., 1981; WEAVER; OMAMEGBE, 1981; DALECK et al., 1992; RAISER, 1994). A hérnia perineal ventral é rara e mais comum em cadelas, Matera et al. (1981) relataram um caso em cadela. Rochat e Mann et al. (1998) relataram dois casos de hérnia perineal ciática: um Chihuahua macho sexualmente intacto e uma cadela Poodle castrada.

Os fatores etiológicos para o enfraquecimento da musculatura do diagrama pélvico não estão definidos, porém, hipóteses que ligam as hérnias perineais ao esforço na evacuação devido à hiperplasia prostática e às alterações retais que causam constipação crônica 
(SPARKS, 1933; DESAI, 1982), têm sido freqüentemente propostas.

Outros fatores que podem estar associados ao aparecimento de hérnias perineais: a predisposição genética de algumas raças, entre elas o Boston Terrier, Boxer, Collie, Welsh Terrier, Pequinês, Dachshunds e Pastor Alemão (BELLENGER, 1980; ROBERTSON, 1984; SJOLLEMA; VAN SLUIJS, 1991; WASHABAU; BROCKMAN, 1995); alterações hormonais por disfunção nos receptores hormonais prostáticos que, ao aumentarem a testosterona livre no sangue, conduzem a uma hipertrofia prostática, tornando a defecação difícil e dolorosa (MANN et al., 1989; NIEBAUER; DAYRELL-HART; SPECIALE, 1991; MANN, 1993; SJOLLEMA et al., 1993; MANN et al., 1995), enquanto que no gato, esse fator parece ser irrelevante (WELCHES et al., 1992); doenças prostáticas, como prostatites, cistos prostáticos e paraprostáticos, hipertrofia prostática benigna e tumores (MANN et al., 1995; WASHABAU; BROCKMAN, 1995); moléstias intestinais, como constipação crônica, tumores anais, retopatias intercorrentes e diverticulites (MANN et al., 1995; WASHABAU; BROCKMAN, 1995).

Estudos histopatológicos evidenciaram que lesões nos nervos sacrais e/ou pudendos em cães com hérnias perineais podem estar diretamente relacionadas com o seu aparecimento (BELLENGER, 1980; MATTHIESEN, 1989; MANN, 1993; SJOLLEMA et al., 1993). Amostras de biópsias do músculo elevador do ânus, coletadas durante herniorrafia, demonstram atrofia de grupos de fibras musculares, sendo indicativas de atrofia neurogênica (BELLENGER; CANFIELS, 2003).

O aumento da próstata e a presença de enfermidades no reto (desvio, dilatação, flexura e saculação) têm sido implicados como os principais contribuintes para a herniação, por induzir tenesmo, constipação crônica, atrofia e enfraquecimento do músculo elevador do ânus (DORN; CARTEE; RICHARDSON, 1982; RAISER, 1994; HOSGOOD et al., 1995).

O desvio de reto e dilatação da ampola retal são as afecções retais mais comumente encontradas. A presença de divertículo retal não foi constatada em estudo com 100 cães portadores da hérnia perineal em que se realizou herniorrafia ( HOSGOOD et al., 1995).

A gordura retroperitoneal, localizada no canal pélvico, constitui componente principal do conteúdo herniado (LIPOWITZ, 1996), porém, flexura ou saculação retal, próstata, líquido, tecido conjuntivo, vesícula urinária e intestino delgado podem estar presentes (PETIT, 1962). 


\subsubsection{Diagnóstico}

O diagnóstico se baseia na história clínica, exame físico, sinais exibidos, exame radiográfico e ultrassonográfico. Os sintomas mais observados em cerca de 90\% a 95\% dos cães afetados são, tenesmo, disquesia, aumento de volume em posição ventrolateral relativamente ao ânus e constipação crônica (BOJRAB; TOOMEY, 1981; SLOLLEMA; SLUIJS, 1989; MANN, 1993). Presença de vômitos, flatulência, incontinência fecal e prolapso retal, também são mencionados (DALECK et al., 1992).

Quando a bexiga está presente no saco herniário esta afecção torna-se emergência clínica, e os pacientes exibem dor visceral acompanhada de oligúria ou mesmo anúria (RAISER, 1994).

As queixas mais freqüentes, relatadas pelos proprietários, são o aumento de volume em região perineal, tenesmo e disquesia, às vezes mencionam hematúria, incontinência urinária e fecal (SLOLLEMA; SLUIJS, 1989). O esforço e a compressão exercida diversas vezes durante a evacuação resultam eventualmente, em lesão irreversível do nervo pudendo, danificando a função do esfíncter anal (SJOLLEMA et al., 1993).

No cão, o conteúdo do saco herniário é constituído principalmente, por gordura retroperitoneal, seguida por fluido seroso, reto, próstata, bexiga urinária e menos comumente por intestino delgado (MANN, 1993).

Na palpação retal é possível avaliar a existência de afecções como o desvio, a saculação ou o divertículo retal (DIETERICH, 1975). Deste modo pode-se classificar o grau de atrofia/separação muscular do diafragma pélvico e a dimensão/localização da próstata.

O exame radiográfico da região ou mesmo o exame de ultra-som são extremamente úteis para verificar o conteúdo do saco herniário (TANNOUZ; SILVA; ABIDUFIGUEIREDO, 2005). Normalmente a radiografia simples é suficiente, por revelar a posição e as dimensões da bexiga e da próstata. Ao persistir dúvidas, deve-se confirmar radiograficamente a retroflexão da bexiga efetuando uma uretrocistografia de contraste positivo (BOJRAB; TOOMEY, 1981; WHITE; HERRTAGE, 1986; TANNOUZ; SILVA; ABIDU-FIGUEIREDO, 2005).

Os exames de dosagem sérica de uréia e creatinina auxiliam na análise do estado clínico do animal que se encontra com a vesícula urinária retrofletida e provavelmente com 
obstrução do trato urinário (DIETERICH, 1975). Como a maioria dos pacientes são cães geriátricos, é recomendável a avaliação do estado geral do animal por meio do hemograma, acompanhado do perfil bioquímico e da análise de urina (BOJRAB; TOOMEY, 1981). Os animais que sofrem de retroflexão da bexiga podem apresentar azotemia, hipercalemia, hiperfosfatemia e leucocitose neutrofílica com desvio à esquerda (FOSSUM, 2005).

No que se referem aos diagnósticos diferenciais, as possibilidades de neoplasia perineal, hiperplasia das glândulas perianais, inflamação ou neoplasia dos sacos anais, atresia anal e tumores vaginais devem ser excluídas. No caso de existir disquesia, deve-se descartar a hipótese da presença de corpo estranho no reto, fístula perianal, constrição anal ou retal, abscesso dos sacos anais, neoplasia anal ou retal, trauma anal, prolapso anorretal ou ainda de dermatite anal (FOSSUM, 2005).

\subsubsection{Tratamento Cirúrgico}

Segundo Spreul e Franklandl (1980) o tratamento cirúrgico das hérnias perineais consiste em restabelecer a sustentação perdida pela atrofia do músculo elevador do ânus através da oclusão da área triangular limitada pelos músculos coccígeo, esfíncter anal externo e obturador interno. O tratamento recomendado é sempre cirúrgico, exceto quando se o animal apresentar um risco anestésico elevado (HARVEY, 1977; BOJRAB; TOOMEY, 1981).

Embora existam muitas técnicas preconizadas, duas são mais empregadas, a clássica ou de reposição anatômica, que consiste no método tradicional de sutura (PETIT , 1962), e a técnica de elevação do músculo obturador interno e suas modificações (EARLY; KOLATA, 1983; ORSHER; JOHNSTON, 1985; OSHER, 1986; SJOLLEMA; SLUIJS, 1989; MANN; CONSTANTINESCU, 1998).

A principal vantagem da cirurgia clássica é a facilidade de execução, mas como desvantagem, uma maior dificuldade na correção da porção ventral da hérnia, e das deformações anais (HOLMES, 1964; MATERA et al., 1987). A partir da técnica clássica 
desenvolveram-se diversas modificações para diminuir a incidência das recidivas (PETIT, 1962).

A técnica de elevação do músculo obturador interno, apesar de maior dificuldade de execução, origina uma menor tensão nas suturas, uma menor deformação anal e cria um retalho muscular ventral, obliterando a solução de continuidade do diafragma pélvico (SALES LUIS; FERREIRA, 1986; MATERA et al., 1987).

Outras técnicas são citadas como alternativas ao tratamento das hérnias perineais. Obliteração mediante adaptação de estruturas sintéticas como redes protéticas (ZIMMERMAN, 1968); malha de polipropileno (MATERA et al., 1981; CLARKE, 1989), colágeno dérmico suíno (FRANKLAND, 1986); membranas biológicas como centro frênico eqüino (ALVARENGA et al., 1978), peritônio bovino (DALECK et al., 1992), pericárdio eqüino como reforço (ZERWES, 2005); transposição do músculo glúteo superficial (SPREUL; FRANKLANDL, 1980; ANDERSON; CONSTANTINESCU; MASS, 1998; BELLENGER; READ, 1998); acesso dorsal ao ânus na correção de hérnia bilateral (ACAUI, 2001); uso da fáscia lata como reforço (BONGARTZ et al., 2005) ou colopexia e cistopexia através da fixação dos ductos deferentes (BILBREY; SMEAK; DEHOFF, 1990) e transposição do músculo semitendinoso para reconstrução do períneo em casos clínicos (CHAMBERS; RAWLINGS, 1991; PHILIBERT; FOWLER, 1996; CHAMBERS, 1999; GALEAZZI et al., 2006) e experimentais (MORTARI, 2004).

A técnica de acesso dorsal ao ânus na correção de hérnia bilateral, segundo o autor, permitiu o tratamento em um único tempo cirúrgico, sendo de fácil execução por possibilitar boa visibilidade das estruturas que compõem as fossas isquiorretais por aumentar o campo operatório. A evolução e complicações pós-operatórias não fogem ao mencionado na literatura, por tanto, o acesso dorsal ao ânus constitui-se uma alternativa na correção cirúrgica de hérnia perineal bilateral em tempo operatório único, tornando-se uma técnica vantajosa para paciente e proprietário (ACAUI, 2001).

A malha de polipropileno e peritônio de bovino foi usada fixando-as diretamente na musculatura após a redução do conteúdo herniado obtendo resultados satisfatórios, com boa reparação do diafragma pélvico (MATERA et al., 1981; DALECK et al., 1992). As principais complicações pós-operatórias observadas quanto à utilização de membrana biológica são 
semelhantes às demais técnicas, principalmente deiscência de pontos, devido ao processo infeccioso (DALECK et al., 1992).

A castração dos machos é recomendada concomitante com herniorrafia. Reduz os casos de insucesso por diminuir a testosterona circulante e o volume da próstata. Os cães inteiros apresentam uma taxa de recorrência 2,7 vezes superior à dos cães castrados (HAYES; WILSON; TRONE, 1978).

Tanto a retroflexão da bexiga como o encarceramento visceral, são complicações das hérnias perineais e emergências veterinárias, requerendo prévia estabilização do paciente.

\subsection{TRANSPOSIÇÃO DO MÚSCULO SEMITENDINOSO}

O músculo semitendinoso origina-se na tuberosidade isquiática e insere-se na face medial da porção proximal da tíbia, recebe suprimento nervoso do ramo do nervo isquiático (EVANS; DELAHUNTA, 1971). Também contribuem para a flexão do joelho a porção caudal do músculo bíceps femoral, juntamente com o músculo abdutor crural caudal e cabeça caudal do músculo semimembranoso (HERMANSO; EVANS, 1993).

Quando falha a técnica de elevação do músculo obturador interno, duas opções terapêuticas são recomendadas, a reconstrução perineal pela transposição do músculo semitendinoso ou a preservação de estruturas importantes pelo emprego da colopexia, por fixação do ducto deferente (MANN; CONSTATINESCU, 1998). A primeira tem se mostrado útil nos casos em que a porção ventral do períneo encontra-se bastante comprometida, como nas hérnias perineais ventrais, bilaterais e recidivantes (CHAMBERS; RAWLINGS, 1991; PHILIBERT; FOWLER, 1996; CHAMBERS, 1999; GALEAZZI et al., 2006).

Os primeiros casos de utilização da transposição do semitendinoso foram relatados para correção hérnia perineal recidivante, em um cão pastor alemão e em um cão da raça collie de oito anos de idade; este apresentava hérnia perineal unilateral, mas a transposição do músculo obturador interno não era possível de praticar-se devido à fratura antiga da pélvis (CHAMBERS, 1999). O emprego da técnica no Brasil foi descrito por Galleazzi et al. (2006) 
em um cão. Essa técnica também foi utilizada em um gato com cinco anos de idade que apresentava sinais inicias de constipação e tenesmo, sendo diagnosticada presença de hérnia dois meses após a primeira avaliação (VNUK et al., 2005).

O músculo semitendinoso foi pesquisado experimentalmente para verificar possíveis modificações em sua estrutura após a sua transposição na reparação das hérnias perineais, utilizando-se eletromiografia, ultra-sonografia e estudo morfológico (MORTARI et al., 2005). Estes autores observaram que no período de 90 dias, o músculo transposto manteve-se contrátil, mas sofreu processo de atrofia.

\subsection{ANÁLISE CINÉTICA DA LOCOMOÇÃO}

Existem vários métodos de análise da locomoção. O método mais simples é a análise visual durante a locomoção (HARRIS; WERTSCH, 1994). Esta observação clínica e visual, no entanto, é subjetiva e os pesquisadores têm desenvolvido métodos mais objetivos para avaliar o andar quantitativamente (ANDERSON et al., 1993).

A cinética do movimento pode ser estudada por meio do uso de plataformas de força que avaliam as forças de reação ao solo gerado durante o deslocamento e, embora seja uma das muitas formas pelas quais a locomoção pode ser estudada, elas vêm sendo utilizadas com maior frequência e estão preenchendo uma lacuna importante no entendimento da cinesiologia (ANDERSON et al., 1993; BESANCON et al., 2003).

Budsberg; Verstraete; Soutas-Little (1987) introduziram um novo tempo na medicina veterinária, utilizando a metodologia quantitativa da análise de locomoção no cão pelo uso da placa de força.

A locomoção pode ser analisada por seus quatro tipos de apresentação, o passo, a marcha, o trote e o galope, no entanto o galope é uma forma assimétrica de deslocamento, pois os movimentos de um lado não repetem os do outro, assim como os intervalos entre os apoios não são igualmente espaçados, diferindo dos demais tipos de locomoção que 
apresentam movimentos simétricos e os intervalos entre os apoios são igualmente espaçados (NEWTON; NUNAMAKER, 1985).

O ciclo da locomoção pode ser definido como uma série de eventos que envolvem o tipo de locomoção, as fases de apoio e balanço. A fase de apoio é definida como o período no qual a pata toca e permanece no solo, pode ser dividida em uma fase de desaceleração e aceleração, todos envolvidos por variáveis como velocidade, tempo (NEWTON; NUNAMAKER, 1985; RIGGS; DECAMP; SOUTAS-LITTLE, 1993; DECAMP, 1997; RENBERG; JOHNSTON, 1999).

A fase de balanço é definida como o período na qual a pata permanece no ar. A união dessa fase com a fase de apoio caracteriza o passo (DECAMP, 1997).

A velocidade do animal está diretamente relacionada com a fase de apoio, pois a variação na velocidade pode causar a alteração da fase de apoio e distribuição das forças. Em uma velocidade constante a soma da aceleração e da desaceleração é igual a zero, porém durante a claudicação pode gerar uma redução na amplitude da força craniocaudal (RIGGS; DECAMP; SOUTAS-LITTLE, 1993; ROUSH; MCLAUGHLIN, 1994; MCLAUGHLIN; ROUSH, 1995; RENBERG; JOHNSTON, 1999; WEIGEL et al., 2005).

\subsection{BAROPODOMETRIA}

A metodologia da análise da locomoção no cão pelo uso da placa de força foi redefinida em 1987 com a introdução de um novo tempo de análises objetivas do andar na medicina veterinária (BUDSBERG; VERSTRAETE; SOUTAS-LITTLE, 1987).

As plataformas de força têm sido utilizadas em vários estudos na avaliação das forças de reação ao solo, que são forças resultantes da somatória das forças do tronco e do membro do cão (BUDSBERG; VERSTRAETE; SOUTAS-LITTLE, 1987).

Durante a locomoção essas forças podem ser avaliadas de quatro modos, com o animal ao passo, em macha, ao trote e ao galope (BUDSBERG; VERSTRAETE; SOUTAS-LITTLE, 1987; YANOFF; HULSE; HOGAN, 1992; DECAMP et al., 1993; RUMPH et al., 1994; 
BUDSBERG et al., 1995; BERTRAN et al., 1997; KIRPENSTEIJN et al., 2000; FANCHON et al., 2006; WALTER; CARRIER, 2007).

Algumas placas de força mensuram três forças ortogonais de reação ao solo durante a locomoção, força vertical, craniocaudal e mediolateral. A força de reação ao solo (FRS) é representada pela somatória das forças do tronco e membro, transmitidas por um membro ao tocar o solo. A força mediolateral (Fx) apresenta resultados pouco significativos por sua grande variação associada à baixa amplitude inicial. A força craniocaudal (Fy) quantifica a força do membro utilizada para progressão do movimento do animal. A força vertical (Fz) se refere ao apoio do peso. O pico das forças vertical e craniocaudal são parâmetros que avaliam a função do membro; sendo as forças transmitidas no plano craniocaudal (Fy) conhecidas por duas fases, a aceleradora e a desaceleradora (BUDSBERG; VERSTRAETE; SOUTASLITTLE, 1987; DECAMP, 1997).

A força vertical (Fz) mede de forma mais direta a sustentação do peso e tem maior magnitude quando comparada com outras forças ortogonais. Na presença de claudicação esta pode se encontrar reduzida, porém há alterações cinemáticas em que há claudicação sem nenhuma alteração das forças durante o apoio (DECAMP, 1997).

A força craniocaudal (Fy) quantifica a força do membro na progressão da locomoção do animal. De acordo com o sinal positivo ou negativo desta força a fase de apoio pode ser subdividida em desaceleração e aceleração ou propulsão (BUDSBERG; VERSTRAETE; SOUTAS-LITTLE, 1987). No inicio da fase de apoio ocorre à desaceleração, que consiste no impulso necessário para diminuir a quantidade de movimento do cão no inicio dessa fase (BERTRAN et al., 1997). A aceleração é definida como o impulso requerido para aumentar a quantidade de movimento do cão no final da fase de apoio, após a desaceleração (BUDSBERG; VERSTRAETE; SOUTAS-LITTLE, 1987).

A força mediolateral (Fx) tem a menor magnitude das três forças ortogonais, com resultados pouco significativos devido à grande variação desta força associada à baixa amplitude inicial e final, quando observada a andadura de um cão (DECAMP, 1997).

Nas avaliações de locomoção a pico de força vertical (PFV) e impulso vertical (IV) são as mais utilizadas pelos pesquisadores para avaliar a locomoção normal e patológica. $\mathrm{O}$ impulso vertical é a força vertical sobre a área que lhe é a aplicada em função do tempo durante a colisão do membro ao solo descrito pela curva do movimento. Em uma plataforma 
múltipla, o impulso dado por cada membro pode ser encontrado somando o impulso total do animal (BUDSBERG; VERSTRAETE; SOUTAS-LITTLE, 1987; MCLAUGHLIN; MILLER, 1991; RUMPH et al., 1994; BERTRAN et al., 1997)

Cada uma das formas da locomoção do cão (passo, trote, galope e marcha, promove um modelo específico de força de reação ao solo, sendo o passo e o trote as locomoções convencionais mais utilizadas nas avaliações de claudicação (WEIGEL et al., 2005).

Os resultados obtidos utilizando a plataforma de força podem ser afetados pelos métodos utilizados na coleta de dados; fatores como a seleção do cão, a conformação, peso do cão, estrutura músculo esquelética, a forma de trabalho como velocidade e aceleração do cão, número de repetições e condutor podem alterar os dados (BUDSBERG; JEVENS; BROWN, 1993; MCLAUGHLIN; ROUSH, 1995; RENBERG; JOHNSTON, 1999; RUMPH et al., 1994), no entanto, Jevens, Hauptman e Decamp (1993) afirmaram que o condutor não interfere nos dados se seguir corretamente as orientações.

Na análise da locomoção o porte do animal constitui-se um fator a ser considerado, pois a duração da fase de apoio bem como a força vertical e impulso aumentam com o porte do cão (BUDSBERG; VERSTRAETE; SOUTAS-LITTLE, 1987), no entanto, o efeito provocado pela conformação do animal pode ser reduzido na maioria dos estudos da locomoção por padronização da forças de reação ao solo e impulsos pelo peso do corpo do animal (BUDSBERG; VERSTRAETE; SOUTAS-LITTLE, 1987; MCLAUGHLIN; MILLER, 1991; JEVENS; HAUPTMAN; DECAMP, 1993; RUMPH et al., 1993, 1994; JEVENS; DECAMP; HAUPTMAN, 1996).

Outro fator a ser considerado é a velocidade do cão, que deve ser cuidadosamente controlada pelo condutor a fim de reduzir variações atribuídas a este fator. Conforme o animal se move mais rapidamente em uma das formas de andadura ou durante a transição para formas mais rápidas, a velocidade do membro aumenta e, conseqüentemente a amplitude das forças de reação ao solo é afetada (LEACH, 1987; MCLAUGHLIN; ROUSH, 1995).

Por causa da relação de velocidade e aceleração, a força colocada sobre o membro durante a fase de apoio tem um aumento significativo nos valores absolutos, com o aumento da velocidade, nas diferentes formas de locomoção. Em uma velocidade constante a soma da aceleração e da desaceleração é igual a zero, porém durante a claudicação pode gerar uma 
redução na amplitude da força craniocaudal (BUDSBERG; VERSTRAETE; SOUTASLITTLE, 1987; WEIGEL et al., 2005).

McLaughlin e Roush (1995) e Schaefer, Decamp e Hauptnan (1996) sugeriram utilizar a duração da fase de apoio com o intuito de padronizar a prova de locomoção ao invés de controlar a velocidade do cão.

O uso de uma placa única de força convencional consiste na impossibilidade de registrar eventos sucessivos e simultâneos durante a locomoção (ANDERSON et al., 1993). A análise completa da biomecânica da locomoção do cão é impossível quando se tem uma única placa de força, devido à locomoção dos quadrúpedes envolverem contato simultâneo extensivo no solo, com mais freqüência nos membros contralaterais (BERTRAN et al., 1997). Outros problemas referentes ao uso de placas de força convencionais consistem na impossibilidade de registrar eventos sucessivos durante a locomoção e geralmente possuem dimensão extremamente pequena e consequentemente múltiplos passos podem ser necessários para uma coleta representativa de dados (ANDERSON et al., 1993).

A falta de sensibilidade de algumas plataformas de força próxima a periferia, pode causar excessiva variedade nas medidas, assim como serem necessárias repetidas passagens para a realização de um passo na porção central da placa (LEACH, 1987).

Tekscan ${ }^{\circledR}$ é um sistema de registro de redistribuição de pressões de locomoção muito utilizado no homem, debelando vários problemas mencionados ao uso das plataformas de força convencionais, uma vez que o Tekscan ${ }^{\circledR}$ é constituído por um sistema que consegue captar todas as variáveis no processo de locomoção (WHITTLE, 1991). Esse sistema possui uma maior dimensão com múltiplos leitores, portanto passos contralaterais, consecutivos e simultâneos podem ser registrados em única passagem pela plataforma e conseqüentemente menor número de repetições é necessário para promover uma quantidade adequada de dados para comparação.

$\mathrm{Na}$ plataforma de força convencional quando mais de um membro contacta a plataforma em uma única passagem, as forças relatadas tornam-se acumulativas, e, portanto não é possível distinguir as forças que estão sendo originadas separadamente. No sistema Tekscan ${ }^{\circledR}$ cada membro contacta um grupo separado de elementos sensitivos e, conseqüentemente as forças são registradas como eventos distintos pelo sistema de software. Este fato não só diminui o número de repetições necessárias para gerar dados adequados para 
comparação estatística, mas também permite tomar as medidas de todas as forças verticais ocorrendo simultaneamente em um mesmo momento durante o ciclo da locomoção (BESANCON et al., 2003).

A análise da locomoção com o uso de baropodometria já vem sendo bastante utilizado na medicina veterinária, em especial nos casos de distúrbios ortopédicos, entre elas os casos de displasia em cães de diversas raças (McLAUGHLIN; MILLER; TAVIS, 1991; BUDSBERG et al., 1996; OLIVEIRA, 2008; SOUZA, 2009). 


\section{MATERIAIS E MÉTODOS}




\section{MATERIAIS E MÉTODOS}

O estudo foi aprovado pela Comissão de Bioética da FMVZ/USP sob o número de protocolo $\mathrm{n}^{\circ}$ 1138/2007. Todos os procedimentos cirúrgicos foram realizados com aquiescência dos proprietários de acordo com o termo de ciência e autorização que se encontra no anexo A.

\subsection{ANIMAIS}

Foram triados para o procedimento cirúrgico de transposição do músculo semitendinoso vinte cães de diferentes raças e idade acometidos de hérnia perineal bilateral, junto ao Hospital Veterinário (HOVET) da Faculdade de Medicina Veterinária e Zootecnia (FMVZ) da Universidade de São Paulo (USP) para o Serviço de Cirurgia de Pequenos Animais (SCPA) do Departamento de Cirurgia (VCI), no período de agosto de 2007 a julho de 2009. Destes, onze obtiveram indicação para a utilização da técnica de transposição do músculo semitendinoso. Todos os casos de hérnia perineal atendidos pelo HOVET, incluídos ou não no projeto, durante o período supracitado, encontram-se no apêndice A.

\subsection{PERÍODO PRÉ-OPERATÓRIO}

Foi subdividido nas seguintes etapas:

\subsubsection{Avaliação Clínica}

Os cães foram submetidos aos exames clínicos, radiográficos e ultrassonográficos. Foi solicitado hemograma, bioquímica sérica, uréia e creatinina. Na anamnese foram obtidos 
dados quanto ao tempo de evolução da hérnia perineal, sintomatologia e eventuais tratamentos anteriores, medicamentosos, nutricionais ou cirúrgicos.

Realizou-se o exame físico com mensuração dos parâmetros clínicos com palpação digital do reto e palpação externa do aumento de volume herniário para verificar a consistência, o provável conteúdo presente e a possibilidade de redução manual.

Os exames por imagem, laboratoriais e eletrocardiograma foram realizados pelo Serviço de Diagnóstico por Imagem, Serviço de Laboratório Clínico e Serviço de Cardiologia, respectivamente, junto ao HOVET/FMVZ-USP.

O modelo da ficha clínica preenchida para cada paciente encontra-se no anexo B.

\subsubsection{Pré-operatório}

Foi solicitado ao proprietário jejum alimentar do cão no mínimo por 12 horas e restrição hídrica de seis horas antes do procedimento cirúrgico, assim como a higienização da pele e pelagem do animal com sabonete anti-séptico um dia antes do procedimento cirúrgico.

Os animais foram avaliados e anestesiados segundo protocolos elaborados pelo Serviço de Anestesia do Departamento de Cirurgia junto ao HOVET da FMVZ-USP, levando-se em consideração as condições clínicas de cada paciente.

As áreas de interesse foram tricotomizadas e posteriormente as fezes foram removidas manualmente da ampola retal e a bexiga urinária cateterizada com sonda uretral.

\subsubsection{Procedimento Cirúrgico}

Inicialmente foi realizada a castração dos pacientes não castrados previamente. Em seguida, o cão foi posicionado na mesa cirúrgica em decúbito esternal com os membros pélvicos fora da mesma (Figura 1A). Para evitar pressão nos nervos femorais, foi utilizado 
acolchoamento da região inguinal em contato com a mesa, e a cauda atada na direção craniodorsal. A mesa cirúrgica foi colocada em posição de Trendelenburger a fim de elevar a pelve do animal.

Anteriormente a transposição do músculo semitendinoso as hérnias perineais bilaterais eram corrigidas cirurgicamente utilizando a técnica de elevação do músculo obturador interno, suturando-o aos músculos coccígeo e esfíncter anal externo (Figura 1B). Quando necessário foi utilizado pericárdio de equino em glicerina a 95\%, como reforço.

Preconizou-se a transposição do músculo do membro contralateral da região de períneo mais afetada. A incisão partiu da porção final da incisão lateral realizada para correção da hérnia, seguindo distalmente no aspecto caudal do membro pélvico (contralateral ao períneo mais afetado), até a altura do linfonodo poplíteo.

O músculo semitendinoso foi cuidadosamente dissecado das estruturas adjacentes, a fim de evitar injúria ao pedículo proximal vascular e nervoso e a artéria femural caudal distal, que foi localizada na porção distal do músculo e ligada com fio náilon 4-0 (Figura 1C). Após ser mensurado (Figura 1D), o músculo semitendinoso foi seccionado na altura do linfonodo poplíteo e o seu grau de encurtamento foi registrado.

O coto remanescente foi suturado com pontos tipo Sultan, com o propósito de diminuir o sangramento e evitar acúmulo de fluido no período pós-operatório imediato, e a porção seccionada foi mobilizada para a região perianal, sem incisar a pele na região perianal ventral, onde o tecido subcutâneo foi cuidadosamente dissecado formando um túnel no plano sagital mediano do períneo a fim de possibilitar a passagem do músculo a ser transposto (Figura 1E e F), modificando o que foi proposto por Mortari (2005).

A extremidade seccionada do músculo semitendinoso foi suturada aos músculos do diafragma pélvico já corrigido a fim de reforçá-lo. O tecido subcutâneo e pele foram aproximados com suturas em pontos simples separados, ambos com fio de náilon 3-0 (Figura 1G). No membro locomotor aplicou-se penso seco e estéril no pós-operatório imediato. Os pontos foram retirados no prazo máximo de 15 dias após o procedimento cirúrgico (Figura1H). 

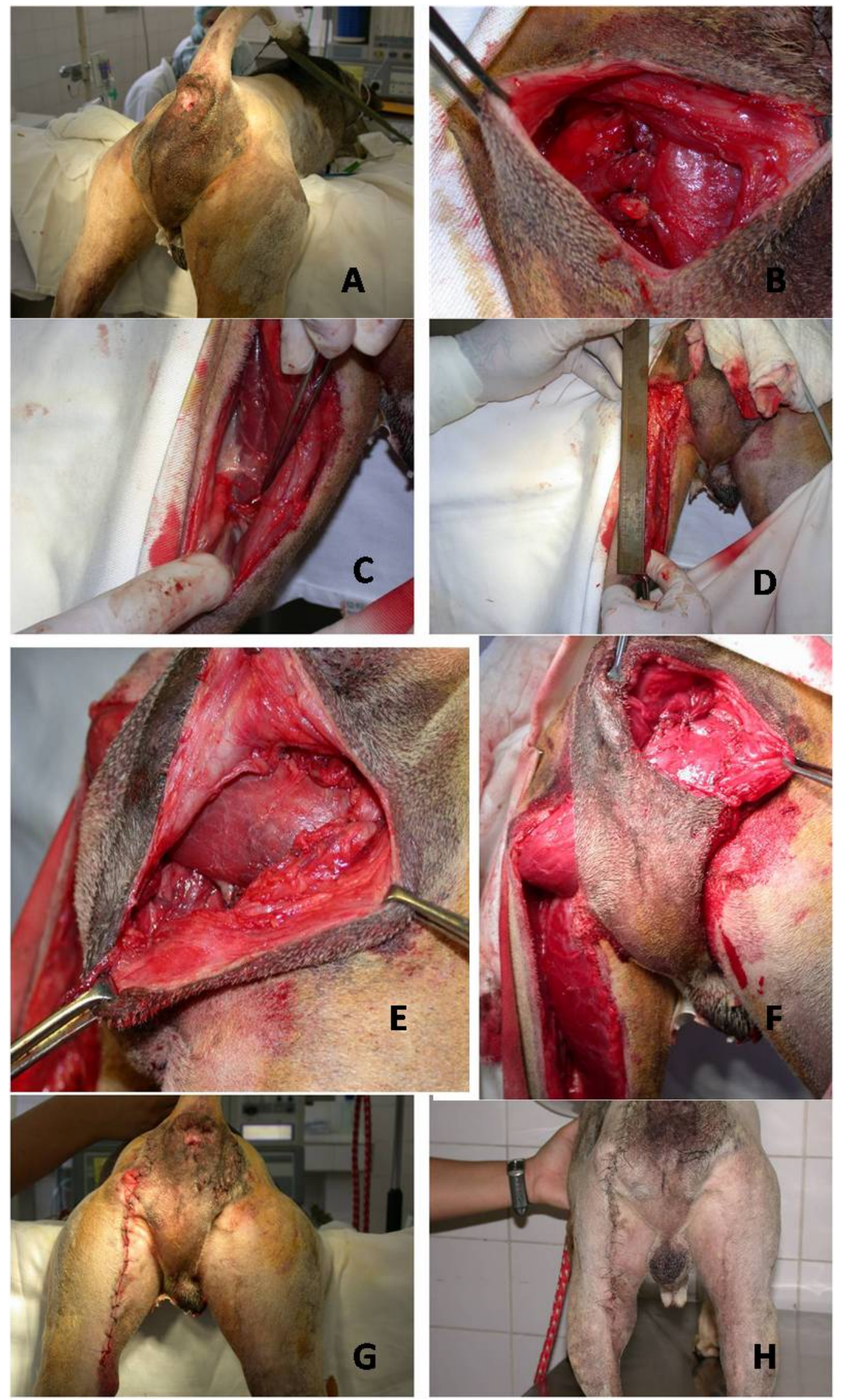

Figura 1 - Sequência operatória do cão n5. A- Posicionamento na mesa cirúrgica B- Correção da hérnia perineal antes da transposição do músculo C- Pedículo da artéria femoral caudal distal; E- Mensuração do músculo semitendinoso;E e FTransposição do músculo preservando o plano sagital mediano (tunilização); GSutura após procedimento cirúrgico; H- Sete dias após o ato operatório - FMVZ São Paulo - 2007- 2010 


\subsection{PERÍODO PÓS-OPERATÓRIO}

Foi subdivido nas seguintes etapas:

\subsubsection{Pós-operatório Imediato}

Após recuperação anestésica os cães foram liberados para o seu domicílio com orientações aos proprietários quanto aos cuidados pós-operatórios. Não foi preconizado um tratamento por via oral padrão, e a prescrição de antibiótico, antiinflamatório e analgésico variou de acordo com a necessidade de cada animal. Para o tratamento externo da ferida cirúrgica foi indicado para todos os pacientes, lavar o local da lesão diariamente com sabonete anti-séptico e em seguida aplicar pomada cicatrizante a base de acetato de clostebol e sulfato de neomicina, três a quatro vezes ao dia e sempre após o animal evacuar.

\subsubsection{Avaliação Clínica}

A avaliação clínica pós-operatória foi realizada às 72 horas, sete; 15; 30; 60 e 90 dias após o procedimento cirúrgico. Em cada período foram considerados os aspectos relacionados na ficha de avaliação clínica (Anexo B) e pautados no quadro de avaliações (Anexo C).

\subsection{AVALIAÇÃO CINÉTICA BAROPODOMÉTRICA}

Todos os animais foram avaliados por meio do sistema de registro de distribuição de pressão (baropodometria) Tekscan ${ }^{\circledR}{ }^{1}$ das forças de reação do solo, antes do procedimento cirúrgico e com trinta, sessenta e noventa dias de pós-operatório (Figura 2).

\footnotetext{
${ }^{1} 7100$ QL Virtual Sensor 3 Mat System, Tekscan Inc. South Boston, MA, USA
} 


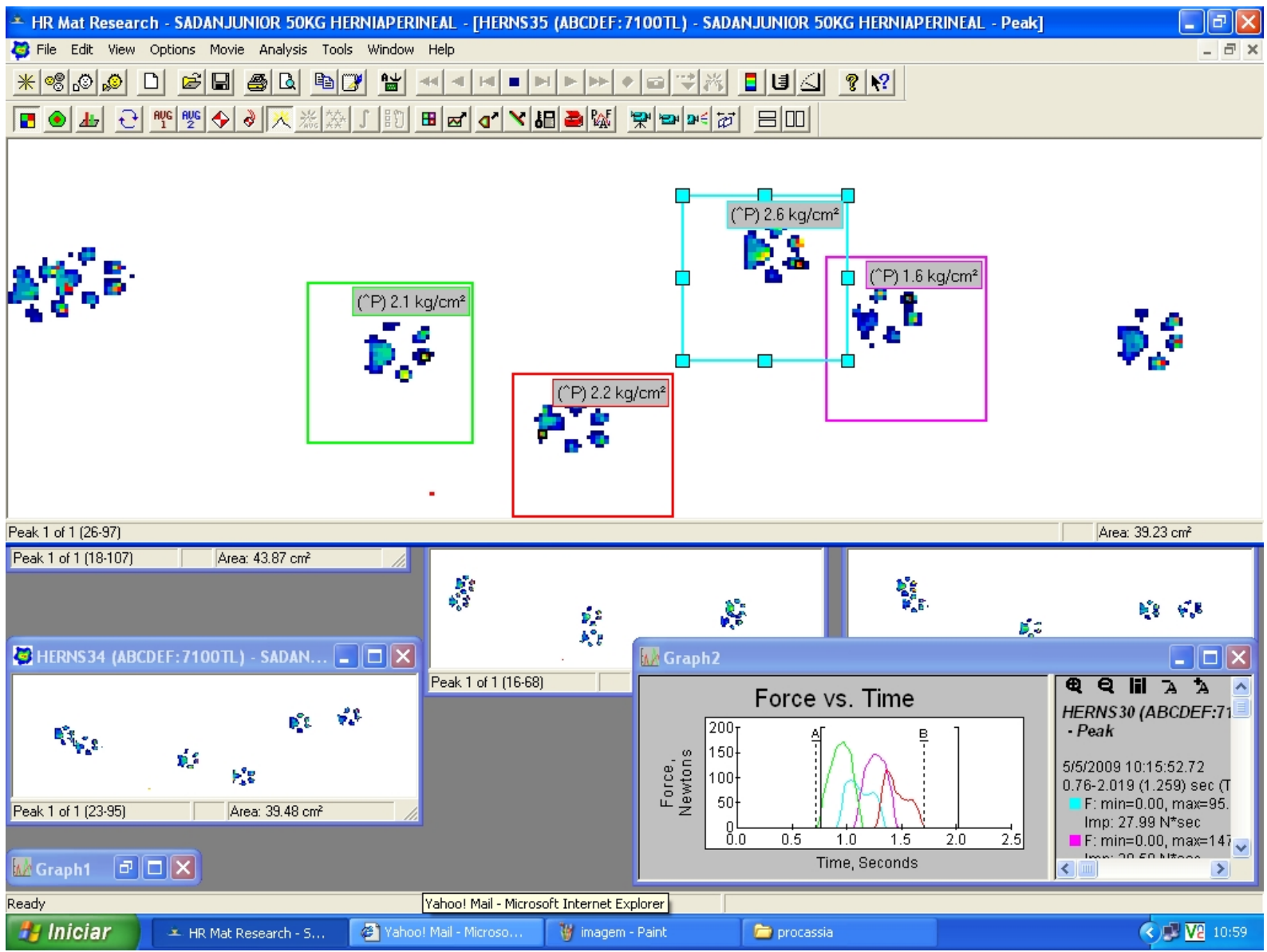

Figura 2 - Análise de uma passagem do cão $n^{\circ} 8$, por meio do sistema de registro de distribuição de força, a partir do software I-scan 5.231, Tekscan, South Boston, MA, USA - FMVZ - São Paulo - 2007-2010

A plataforma utilizada nesse sistema consiste de três placas em série, que geram quadros seriados captados por um software ${ }^{2}$ específico que geram as informações pertinentes a locomoção do animal.

Os cães foram conduzidos sobre a plataforma de baropodometria, ao passo, do lado esquerdo do condutor, de forma a haver contato entre as placas e os membros torácicos e pélvicos do animal (Figura 3). Procurou-se manter a velocidade constante pela razão do comprimento do passo pelo tempo de sua fase, a aceleração foi calculada pela diferença da velocidade final e inicial. A aceleração máxima estimada foi de aproximadamente $0,1 \mathrm{~m} / \mathrm{s}^{2}$.

\footnotetext{
${ }^{2}$ I-scan 5.231, Tekscan Inc., South Boston, MA, USA
} 


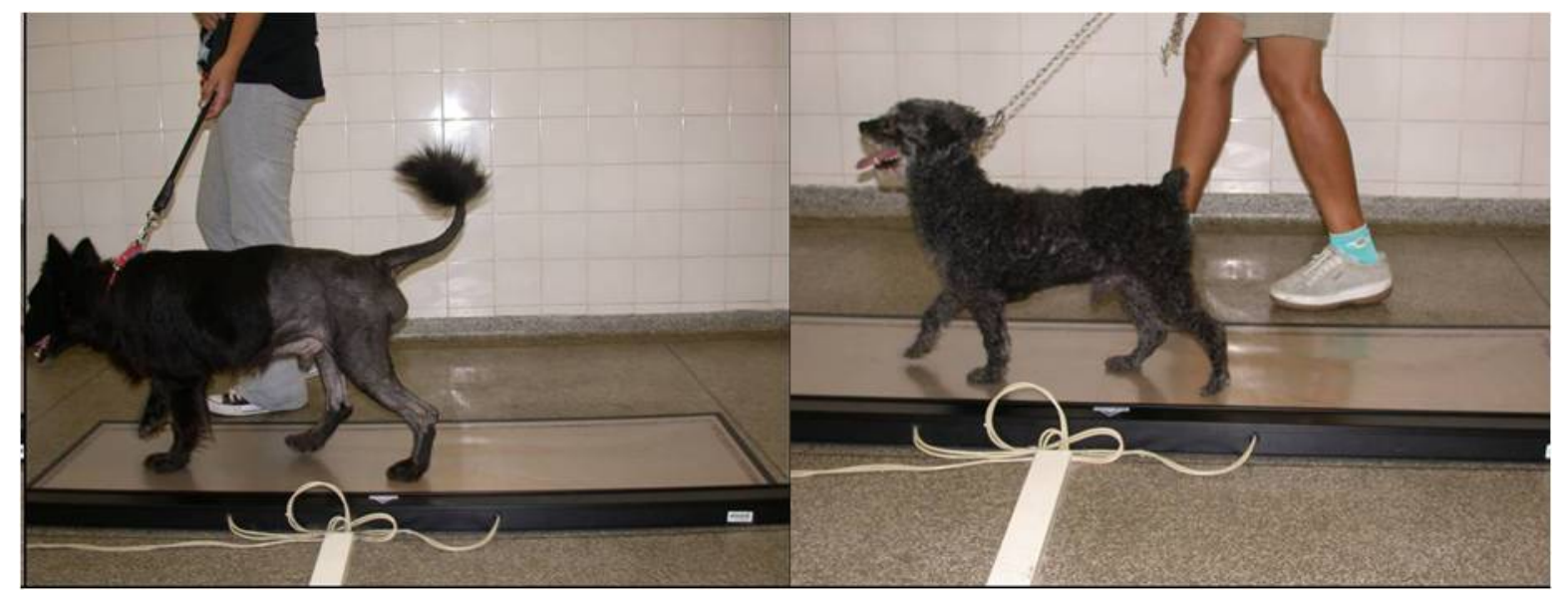

Figura 3 - Imagem do cão $n^{\circ} 2$ antes do procedimento cirúrgico e cão $n^{\circ} 4$ com 90 dias de pós-operatório, caminhando com seus respectivos condutores sobre a plataforma de baropodometria - Tekscan ${ }^{\circledR}$ no LAL - FMVZ/USP - São Paulo 2007-2010

Foram consideradas cinco passagens válidas em um número máximo de vinte repetições. Foram registrados a força máxima vertical expressos em Newton e impulso vertical expressos em N/s e do tempo de fase de apoio e balanço, por meio do software, para membros pélvicos e torácicos desses pacientes (Figuras 4 e 5).

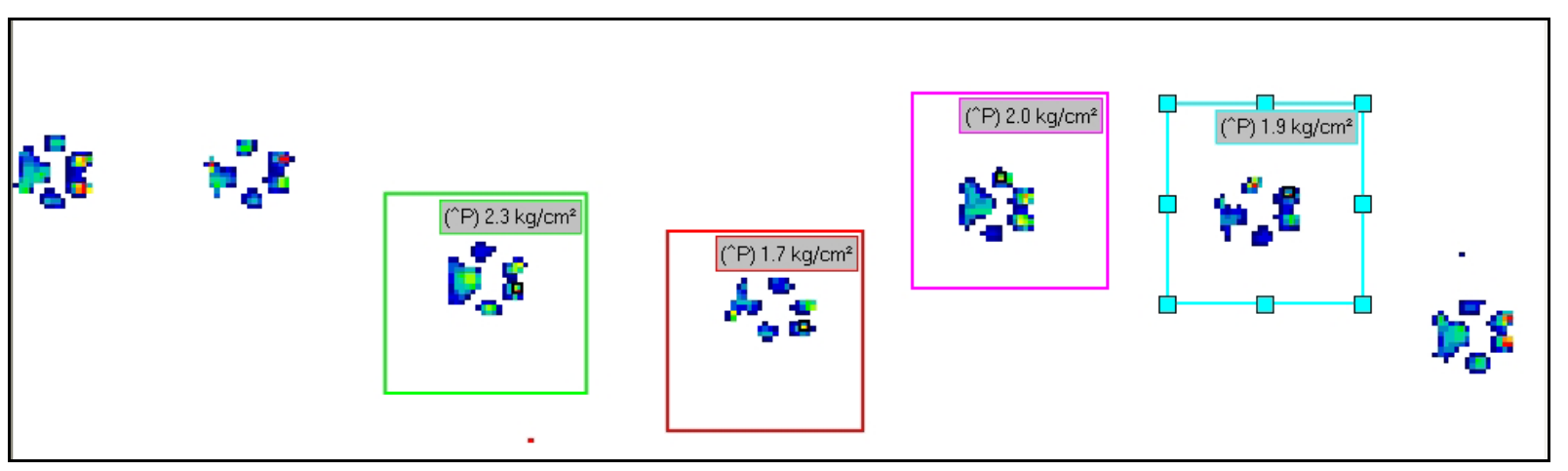

Figura 4 - Análise de uma passagem do cão n8 pela marcação específica para cada membro a partir do software I-scan 5.231, Tekscan, South Boston, MA, USA. As Marcações referem-se as FRS. Verde, membro torácico esquerdo (MTE); vermelho, membro pélvico esquerdo (MPE), Lilás, torácico direito (MTD) e azul, membro pélvico direito (MPD). Passagem registrada no LAL - FMVZ/USP - São Paulo - 20072010 


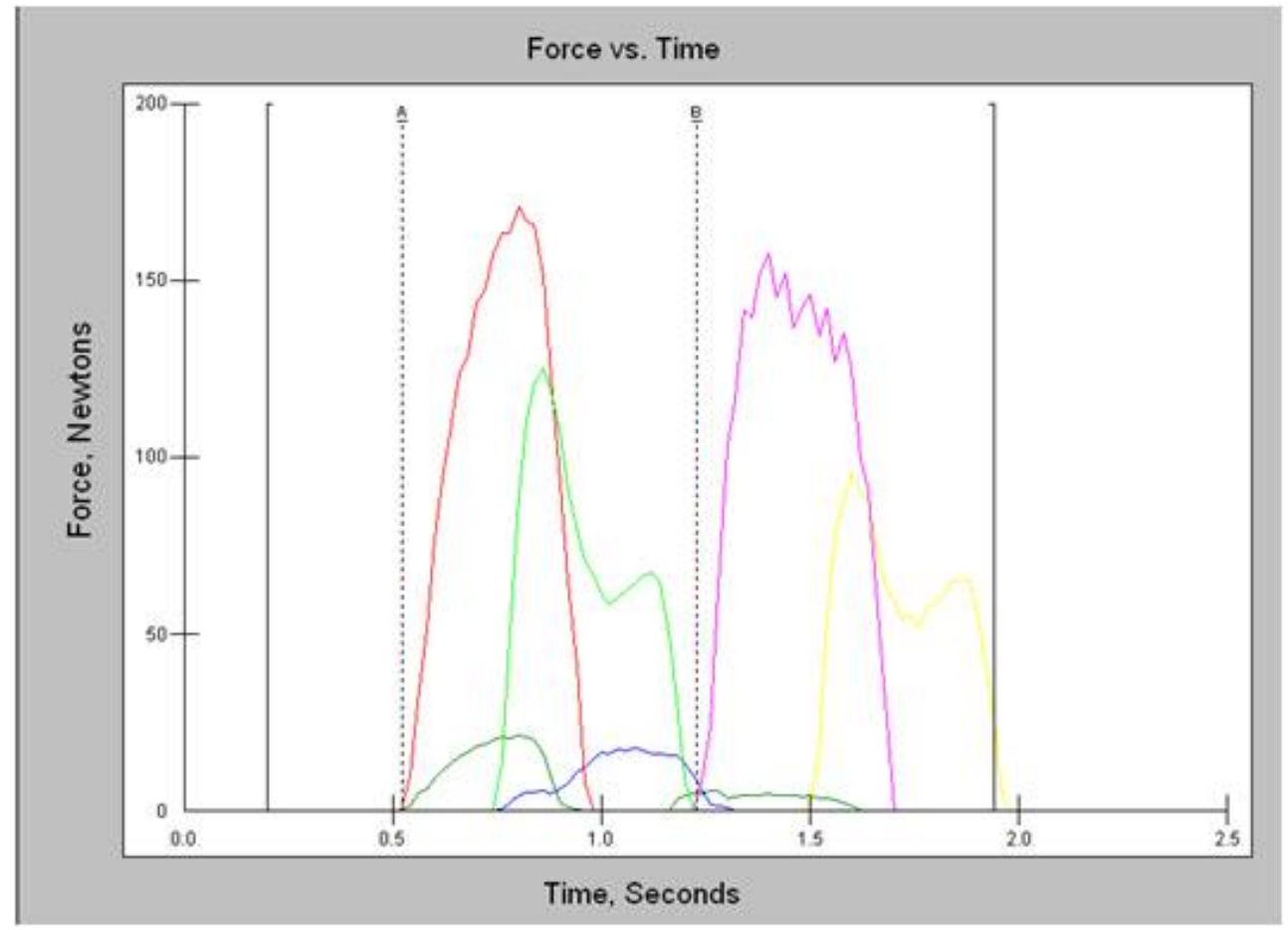

Figura 5 - Mensuração e registro do PFV, IV e TA em Newtons, N/s e s, respectivamente, do cão $n^{\circ} 8$, registrada a partir do software I-scan 5.231, Tekscan, South Boston, MA, USA, no LAL - FMVZ/USP - São Paulo 2007-2010

A força máxima vertical (PFV) e o impulso vertical foram normalizados pelo peso do animal expressando valores em porcentagem corpórea de apoio (\% body weigh - \%BW ou \% peso corpóreo - \%PC)

Todo o sistema foi calibrado de acordo com as especificações do fabricante antes de se iniciarem os registros de dados, a fim de compará-los com os resultados obtidos no período pós-operatório.

\subsection{AVALIAÇÃO RADIOGRÁFICA E ULTRASSONOGRÁFICA}

Os exames radiográficos e ultrassonográficos foram realizados nos períodos pré e pósoperatório com trinta, sessenta e noventa dias, com o intento de acompanhar o posicionamento anatômico das vísceras, assim como diagnosticar possíveis recidivas. 


\subsection{ANÁLISE ESTATÍSTICA}

As variáveis analisadas foram FPV e IV em \%PC, foram considerados os tempos préoperatório e pós-operatório com 30, 60 e 90 dias. Foram consideradas nas análises as cinco passagens válidas nos determinados tempos.

As análises estatísticas focaram os membros pélvicos operados e não operados, se houve ou não significância e o comportamento das variáveis nos tempos propostos.

Foi usado o teste ANOVA para medidas repetidas com dois fatores (operado e o tempo), com nível de significância de 5\%. Aplicou-se primeiramente o teste de Shapiro-Wilks para testar a normalidade dos dados.

Não sendo constatado forte evidencia que os dados não sejam normalmente distribuídos, aplicou-se o teste ANOVA para medidas repetidas. Quando neste teste não foi possível supor esfericidade da matriz de covariância, foi usada uma correção nos graus de liberdade (correção de Lower-bound). 
RESULTADOS 


\section{RESULTADOS}

\subsection{AVALIAÇÃO CLÍNICA}

No período de agosto de 2007 a julho de 2009 foram submetidos ao procedimento cirúrgico de hérnia perineal bilateral no Serviço de Cirurgia de Pequenos Animais do Departamento de Cirurgia, junto ao HOVET/FMVZ, trinta cães da espécie canina de diferentes raças e SRD, machos, de diversas idades.

Vinte animais contemplavam os quesitos de inclusão no projeto, no entanto, durante o período transoperatório decidiu-se por não utilizar a técnica de transposição em nove destes pacientes anteriormente selecionados, por ensejarem possíveis resultados falso-positivos. Contatou-se, nesses casos, que o método convencional de correção da hérnia perineal por elevação do músculo obturador interno com uso de pericárdio de eqüino em glicerina 95\% ou malha de polipropileno como reforço, era suficiente para corrigir a hérnia, evitando serem submetidos à intervenção de maior proporção.

Os dados referentes à identificação de cada animal estão descritos na tabela 1.

Tabela 1 - Identificação dos cães submetidos à transposição do músculo semitendinoso, atendidos no HOVET - FMVZ/USP - São Paulo - 2007-2010

\begin{tabular}{ccccc}
\hline CÃO & N $^{\circ}$ PRONTUÁRIO & RAÇA & IDADE (Anos) & PESO (Kg) \\
\hline 1 & 184802 & SHEEPDOG & 10 & $\mathbf{2 4 , 0}$ \\
\hline 2 & 185564 & SRD & 14 & $\mathbf{1 3 , 0}$ \\
\hline 3 & 186558 & SRD & 11 & $\mathbf{1 7 , 5}$ \\
\hline 4 & 186856 & POODLE & 12 & $\mathbf{6 , 1}$ \\
\hline 5 & 187007 & SRD & 10 & $\mathbf{1 4 , 0}$ \\
\hline 6 & 188402 & ROTTWEILLER & 5 & $\mathbf{3 1 , 7}$ \\
\hline 7 & 164756 & Mestiço DACHSHUND & 11 & $\mathbf{7 , 2}$ \\
\hline 9 & 199233 & ROTTWEILLER & 9 & $\mathbf{4 8 , 6}$ \\
\hline 10 & 199437 & POODLE & 12 & $\mathbf{9 , 4}$ \\
\hline 11 & 190937 & SRD & 12 & $\mathbf{1 8 , 8}$ \\
\hline
\end{tabular}


Os onze cães operados (100\%) eram machos com idade superior a cinco anos, acometidos de hérnia perineal bilateral. No entanto, cinco $n^{\circ} 3, n^{\circ} 7, n^{\circ} 9, n^{\circ} 10, n^{\circ} 11(45,45 \%)$ já haviam sido submetidos à intervenção cirúrgica de hérnia perineal em clínica particular, destes apenas um n³ (9,09\%) não era castrado.

Segundo os proprietários o tempo de evolução das hérnias variou entre um dia a dois anos e as queixas principais foram tenesmo $(81,81 \%)$, disquesia $(81,81 \%)$ e aumento da região de períneo (100\%). Em cinco casos $n^{\circ} 2, n^{\circ} 3, n^{\circ} 4, n^{\circ} 5, n^{\circ} 7(45,45 \%)$, também foi citado dificuldade para urinar e alterações na coloração da urina em três $n^{\circ} 2, n^{\circ} 3, n^{\circ} 4$ (27,27\%) sendo necessária a fixação de sonda uretral em três cães $n^{\circ} 2, n^{\circ} 4, n^{\circ} 7$, após esvaziamento vesical por centese. Em 81,81\% dos casos foi verificada a presença de edema acentuado em toda a região perineal devido ao longo tempo de existência da hérnia, o paciente $\mathrm{n}^{\circ} 10$ apresentava trauma sobre esta.

Os parâmetros fisiológicos de cada animal operado, verificados durante o seu primeiro atendimento no setor de cirurgia do HOVET, estão descritos no anexo D (Quadro 1).

Na palpação externa do aumento perineal o conteúdo mostrou-se redutível em cinco casos $n^{\circ} 1, n^{\circ} 3, n^{\circ} 6, n^{\circ} 7, n^{\circ} 11$ (45,45\%), com consistência macia em seis $n^{\circ} 3, n^{\circ} 5, n^{\circ} 6, n^{\circ} 7$, $n^{\circ} 8, n^{\circ} 11$ (54,54\%); em uma oportunidade $n^{\circ} 8$ (9,09\%) foi possível identificar por esse método de exame, a bexiga urinária na região de períneo, confirmado posteriormente pelo exame de RX e ultra-som. Em todos os pacientes (100\%) foi possível detectar por meio de toque retal o desvio lateral da porção final do reto, no entanto nenhum dos eventos caracterizou a ocorrência de divertículo retal.

Os quadros com os resultados dos exames laboratoriais, hemograma e bioquímica, antes do procedimento cirúrgico estão representados no anexo E (Quadro 2).

Os exames radiográficos e ultrassonográficos possibilitaram verificar a disposição da próstata e bexiga de todos os cães antes de submetidos à transposição do músculo semitendinoso (Anexo F - Quadro 3).

\subsection{TÉCNICA CIRÚRGICA}

Vinte animais foram operados, mas nove (45\%) não foram submetidos à transposição do músculo.

Após a incisão do saco herniário foi possível identificar bexiga urinária no saco herniário esquerdo nos cães $n^{\circ} 2, n^{\circ} 4$ e $n^{\circ} 8$ (27,27\%), sendo que no animal $n^{\circ} 2$ a parede da 
bexiga encontrava-se espessa com sinais de infecção; alças intestinais no animal n4 (9,09\%); próstata no saco herniário direito em outros dois casos $n^{\circ} 3$ e $n^{\circ} 6(18,18 \%)$; cistos prostáticos e abscesso o cão $n^{\circ} 3$ e gordura retroperitonial nos demais casos, $n^{\circ} 1,6,7,9,10$ e 11 (54,54\%).

A extensão longitudinal do músculo semitendinoso variou de acordo o porte de cada animal (Figura 6A, B). As respectivas medidas do músculo antes e após a incisão estão representadas no anexo G (Quadro 4). A média do comprimento foi de $12,20 \mathrm{~cm}$ antes de seccionado e de $8,83 \mathrm{~cm}$ após a secção. A média do encurtamento longitudinal do músculo foi de $3,05 \mathrm{~cm}$.

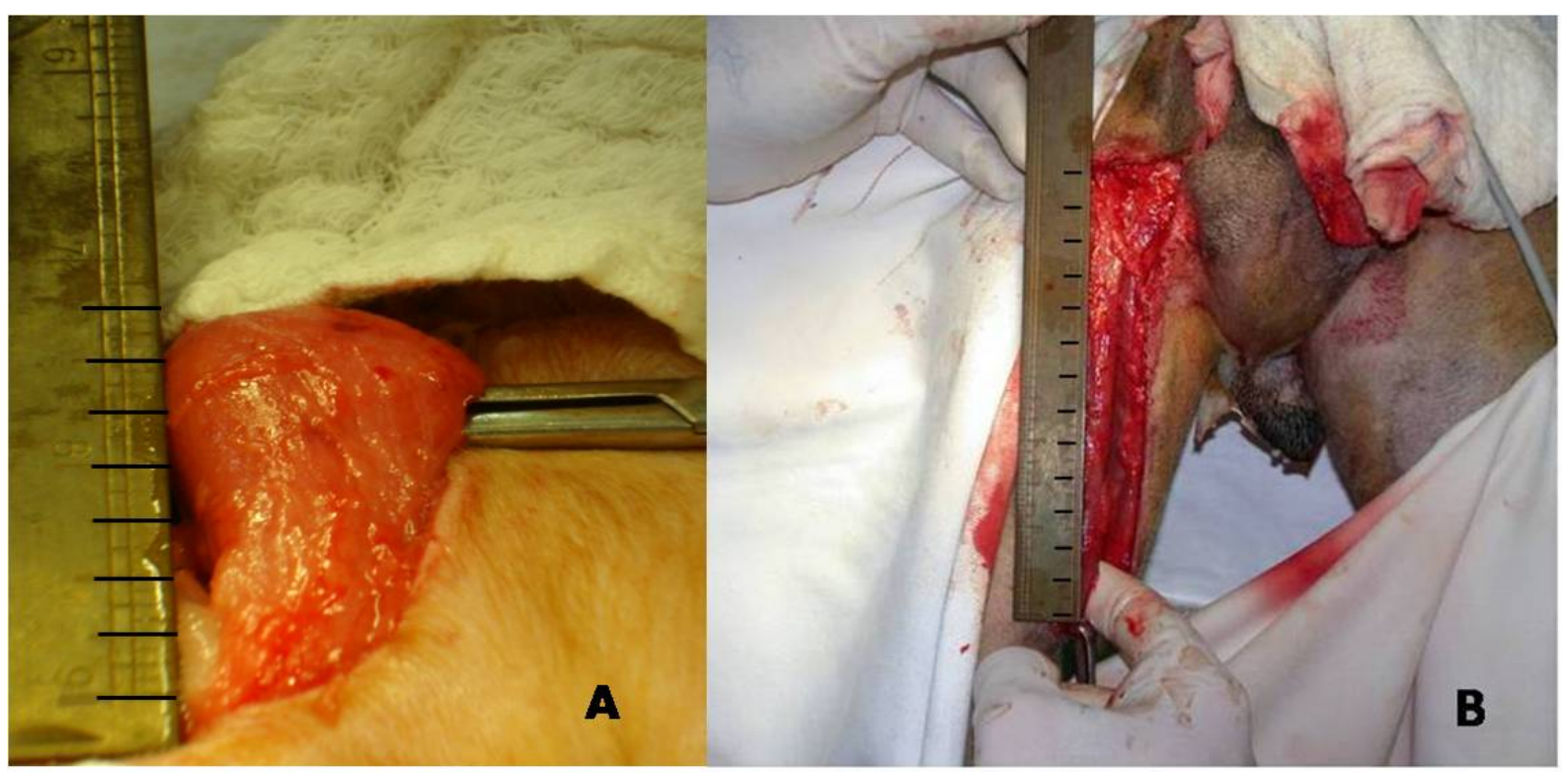

Figura 6 - Comprimento em centímetros do músculo semitendinoso antes de ser incisado. Acão condrodistrófico, mestiço da raça Daschund $\left(\mathrm{n}^{\circ} 7\right) \mathrm{com} 6,5 \mathrm{~cm}$; B- cão SRD $\left(n^{\circ} 5\right)$ com $13 \mathrm{~cm}$ antes da secção - FMVZ/USP - São Paulo - 2007-2010

\subsection{AVALIAÇÃO PÓS-OPERATÓRIA}

A deiscência de pele foi constatada em dois cães, $n^{\circ} 1$ e $n^{\circ} 8(18,18 \%)$, o $n^{\circ} 1$ apresentou complicação pós-operatória nas primeiras 24 horas, com abertura da ferida cirúrgica na região lateral esquerda, o qual foi encaminhado ao centro cirúrgico para correção 
da deiscência. Após 48 horas o paciente retornou com deiscência no mesmo local, sendo indicada cicatrização por segunda intenção (Figura 7A). O cão n8 apresentou deiscência de pele após seis dias de pós-operatório, com focos de contaminação. Foi indicada cicatrização por segunda intenção (Figura 7B).

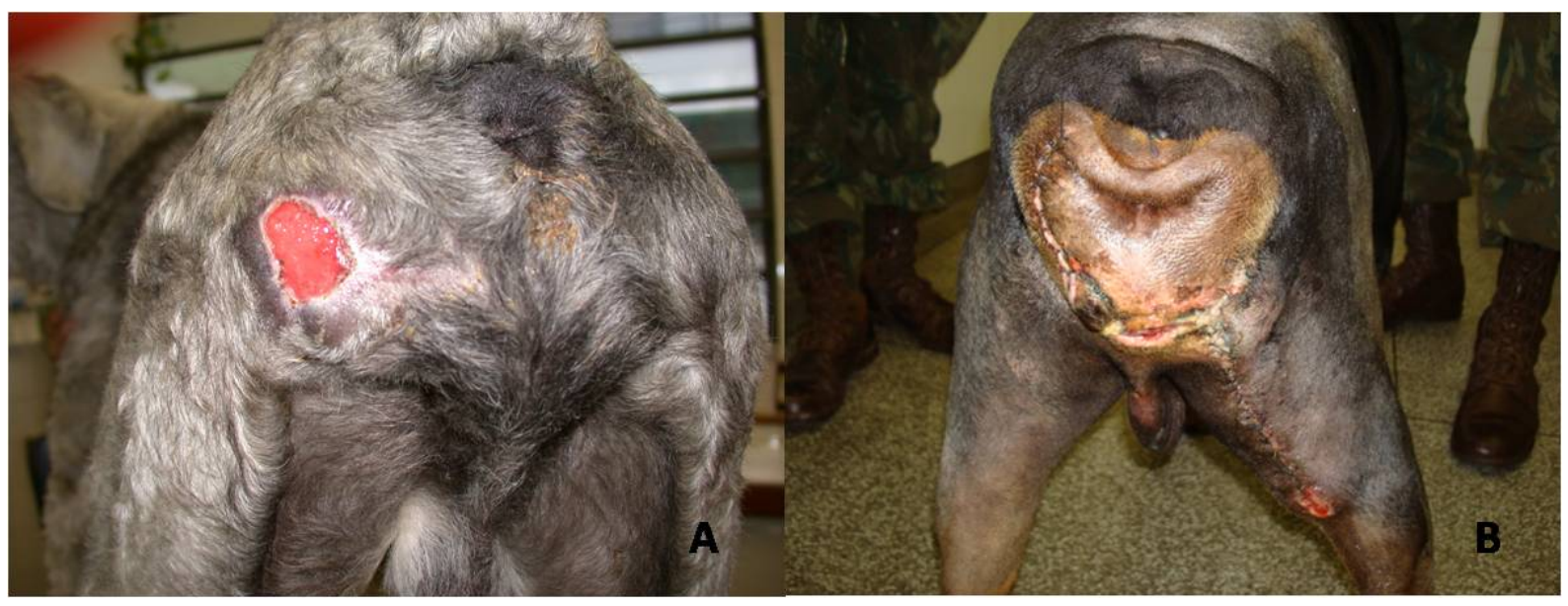

Figura 7 - A- Cicatrização por segunda intenção com 30 dias de pós-operatório no cão $n^{\circ} 1$. B- Deiscência de pele após 6 dias do procedimento cirúrgico no cão n8 FMVZ/USP - São Paulo - 2007-2010

Foram relatados tenesmo e dificuldade para evacuar nos cães $n^{\circ} 3, n^{\circ} 6$ e $n^{\circ} 7$, nos primeiros 15 dias de pós-operatório (27,27\%), persistindo até os 90 dias de avaliação no cão $n^{\circ} 3$. Os animais $n^{\circ} 1, n^{\circ} 2, n^{\circ} 9$ e $n^{\circ} 10$ (36,36\%), apresentaram esses sintomas após 60 dias de pós-operatório. Destes, apenas nos cães $n^{\circ} 1$ e $n^{\circ} 9$ não foram constatadas recidivas durante $o$ período de avaliação. No cão nº 3 (9,09\%) foi relatado prolapso retal ao evacuar.

Nos pacientes onde a dificuldade de evacuar persistiu mesmo após os 60 dias de avaliação, foi indicado manejo alimentar com emolientes e fibras na dieta devido ao seu histórico, e tratamento com acupuntura.

Foram observadas recidivas em oito casos, $n^{\circ} 2, n^{\circ} 3, n^{\circ} 4, n^{\circ} 6, n^{\circ} 7, n^{\circ} 8, n^{\circ} 10$ e $n^{\circ} 11$ (72,72\%), destes, três $n^{\circ} 2, n^{\circ} 4, n^{\circ} 6(27,27 \%)$ foram diagnosticados por meio de exames por imagem, não sendo constatado aumento em região perineal no exame físico e clínico com 90 dias de pós-operatório. As recidivas ocorreram em região dorsal da fossa ísquio retal em dois cães $\left(n^{\circ} 3, n^{\circ} 4\right)$ e em uma das regiões laterais nos demais casos.

Considerando a ausência de recidiva, três pacientes $n^{\circ} 1, n^{\circ} 5$ e $n^{\circ} 9(27,27 \%)$ foram considerados totalmente recuperados após a correção cirúrgica da hérnia perineal com a 
técnica e o período de avaliação propostos. $\mathrm{O}$ cão n 5 apresentou melhor recuperação entre os todos os animais operados (Figura 8 A, B e C).

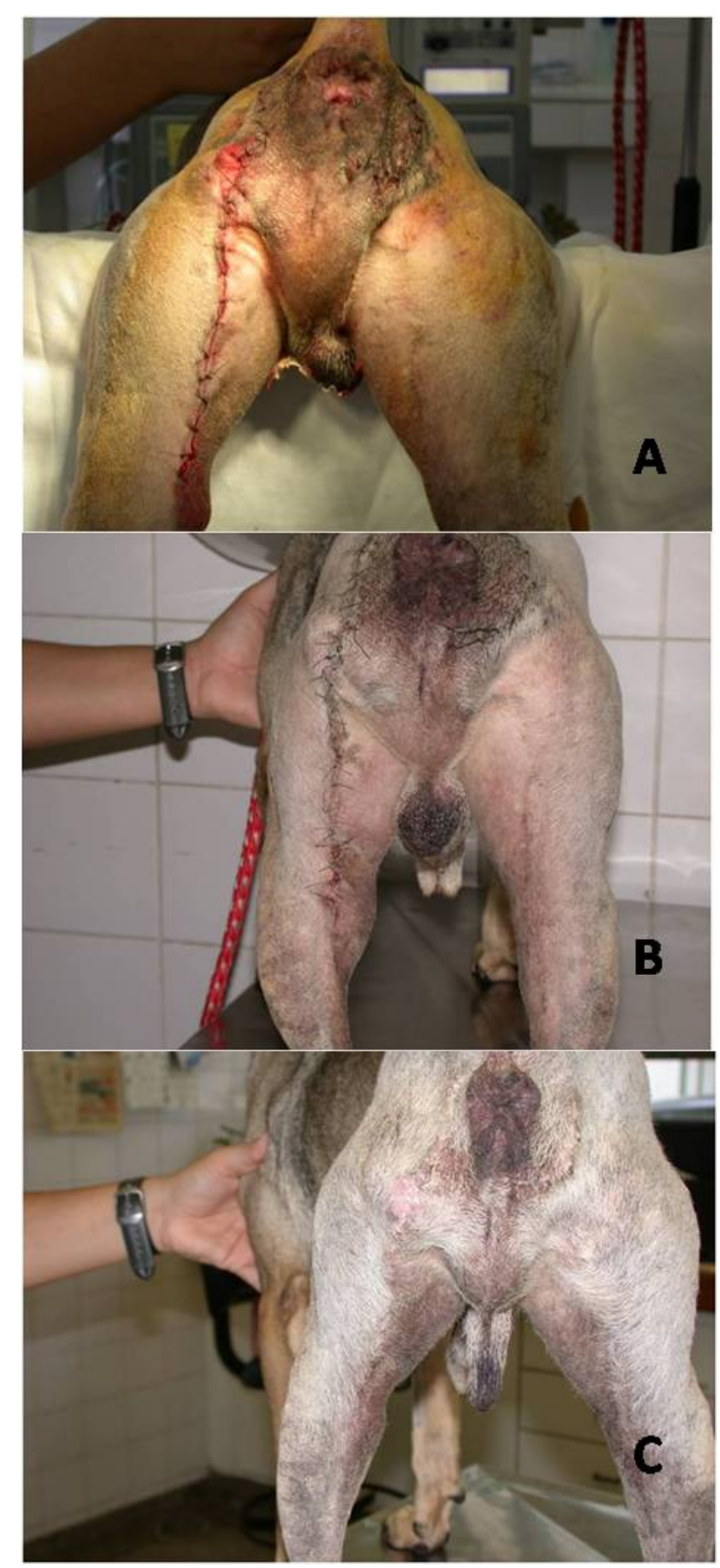

Figura 8 - Sequência da recuperação do cão n5. A- Aspecto do fechamento da incisão logo após a transposição do músculo semitendinoso. B- Aspecto da ferida sete dias após o ato operatório. C- Recuperação completa do paciente com trinta dias de pósoperatório - FMVZ/USP - São Paulo - 2007-2010

Nas avaliações de RX e US com 30, 60 e 90 dias, foram verificadas que em todos os pacientes a bexiga e alças intestinais mantiveram-se em sua localização habitual. Nos cães com aumento de próstata verificados no pré-operatório, apresentaram diminuição da mesma após a castração. 


\subsection{AVALIAÇÃO BAROPODOMÉTRICA}

O tipo de passagem estabelecido para as análises e registros baropodométricos foi o passo.

A média do tempo de apoio (TA) entre os membros torácicos dos pacientes avaliados antes do procedimento cirúrgico foi de 0,349 segundo $\pm 0,029$ e de 0,361 segundo $\pm 0,041$ para os membros pélvicos. Após o procedimento cirúrgico a média das avaliações para os membros torácicos foi de 0,325 segundo $\pm 0,030$ e de 0,321 segundo $\pm 0,029$ para os membros pélvicos. Considerando as médias individuais para o membro pélvico operado e não operado, tempos as seguintes médias, respectivamente, 0,321 $\pm 0,028$ e 0,321 $\pm 0,029$. Os valores individuais de cada membro dos cães analisados nos períodos pré e pós-operatório encontram-se nas tabelas abaixo (Tabelas 2 e 3). Os resultados foram não significativos.

Tabela 2 - Valores médios do tempo de apoio (TA) em segundos dos membros torácicos e pélvicos operados e não operados, no período pré-operatório, avaliados no LAL - FMVZ/USP - São Paulo - 2007-2010

\begin{tabular}{ccccc}
\hline CÃO & MTD(s) & MTE(s) & MPO(s) & MPNO(s) \\
1 & 0,38 & 0,38 & 0,41 & 0,43 \\
2 & 0,45 & 0,45 & 0,45 & 0,45 \\
3 & 0,28 & 0,28 & 0,28 & 0,26 \\
4 & 0,29 & 0,29 & 0,28 & 0,29 \\
5 & 0,50 & 0,50 & 0,60 & 0,60 \\
6 & 0,41 & 0,41 & 0,41 & 0,42 \\
7 & 0,13 & 0,13 & 0,13 & 0,13 \\
8 & 0,43 & 0,43 & 0,45 & 0,45 \\
9 & 0,23 & 0,23 & 0,23 & 0,23 \\
10 & 0,30 & 0,30 & 0,28 & 0,28 \\
11 & 0,44 & 0,44 & 0,44 & 0,44 \\
\hline Média & $\mathbf{0 , 3 4 9}$ & $\mathbf{0 , 3 4 9}$ & $\mathbf{0 , 3 6 0}$ & $\mathbf{0 , 3 6 2}$ \\
\hline DP & $\mathbf{0 , 0 3 0}$ & $\mathbf{0 , 0 2 9}$ & $\mathbf{0 , 0 3 8}$ & $\mathbf{0 , 0 4 5}$ \\
\hline
\end{tabular}


Tabela 3 - Média dos valores de tempo de apoio (TA) em segundos, dos membros torácicos e pélvicos operados e não operados, no período pós-operatório (30,60 e 90 dias), avaliados no LAL, FMVZ/USP - São Paulo - 2007-2010

\begin{tabular}{ccccc}
\hline C̃̃O & MTD(s) & MTE(s) & MPO(s) & MPNO(s) \\
\hline 1 & 0,43 & 0,43 & 0,45 & 0,43 \\
2 & 0,31 & 0,31 & 0,30 & 0,31 \\
3 & 0,30 & 0,30 & 0,29 & 0,29 \\
4 & 0,24 & 0,24 & 0,24 & 0,24 \\
5 & 0,41 & 0,42 & 0,43 & 0,43 \\
6 & 0,42 & 0,42 & 0,4 & 0,4 \\
7 & 0,15 & 0,15 & 0,14 & 0,14 \\
8 & 0,47 & 0,47 & 0,48 & 0,48 \\
9 & 0,23 & 0,22 & 0,21 & 0,21 \\
10 & 0,39 & 0,39 & 0,37 & 0,38 \\
11 & 0,22 & 0,22 & 0,22 & 0,22 \\
\hline Média & $\mathbf{0 , 3 2 5}$ & $\mathbf{0 , 3 2 5}$ & $\mathbf{0 , 3 2 1}$ & $\mathbf{0 , 3 2 1}$ \\
\hline DP & $\mathbf{0 , 0 3 2}$ & $\mathbf{0 , 0 2 9}$ & $\mathbf{0 , 0 2 8}$ & $\mathbf{0 , 0 2 9}$ \\
\hline
\end{tabular}

Não houve diferença estatística $(p>0,05)$ entre os valores médios do pico de força vertical (PFV) em porcentagem de Peso corporal (PC\%), que é a forma corrigida pelo peso do animal, entre os membros pélvicos operados e não operados no período pré e pós-operatório. A média do pico de força vertical (PFV) entre os membros antes e após o procedimento cirúrgico dados em porcentagem de PC\%, está relacionada nas tabelas 4 e 5. 
Tabela 4 - Média dos valores do Pico de Força Vertical (PFV) em \%PC no período préoperatório de cada animal, avaliados no LAL da FMVZ/USP - São Paulo - 2010

\begin{tabular}{clccc}
\hline CÃO & MTD\%PC & MTE\%PC & MPO\% PC & MPNO\% PC \\
\hline 1 & 36,59 & 39,55 & 15,36 & 13,82 \\
2 & 21,40 & 21,12 & 15,05 & 16,08 \\
3 & 40,01 & 42,63 & 26,70 & 26,33 \\
4 & 25,57 & 26,46 & 18,46 & 17,51 \\
5 & 21,77 & 23,96 & 16,47 & 16,66 \\
6 & 35,63 & 33,39 & 22,70 & 21,63 \\
7 & 39,64 & 34,25 & 16,08 & 12,78 \\
8 & 36,05 & 32,31 & 25,45 & 17,84 \\
9 & 35,11 & 37,53 & 21,45 & 21,11 \\
10 & 24,87 & 25,11 & 16,76 & 16,8 \\
11 & 17,63 & 21,37 & 10,33 & 10,69 \\
\hline MÉDIA & $\mathbf{3 0 , 3 8 8}$ & $\mathbf{3 0 , 6 9 8}$ & $\mathbf{1 8 , 6 1 9}$ & $\mathbf{1 7 , 3 8 9}$ \\
DP & $\mathbf{3 , 5 0 7}$ & $\mathbf{3 , 9 0 6}$ & $\mathbf{3 , 1 4 3}$ & $\mathbf{3 , 2 7 2}$ \\
\hline
\end{tabular}

Tabela 5 - Média dos valores do Pico de Força Vertical (PFV) em \%PC nos períodos pósoperatórios de cada animal, avaliados no LAL da FMVZ/USP -São Paulo - 2010

\begin{tabular}{ccccc}
\hline CÃO & MTD\% PC & MTE\% PC & MPO\% PC & MPNO\% PC \\
\hline 1 & 44,27 & 43,07 & 18,71 & 19,61 \\
2 & 32,97 & 33,06 & 21,14 & 23,82 \\
3 & 41,50 & 42,51 & 27,20 & 24,83 \\
4 & 34,54 & 34,97 & 23,90 & 23,01 \\
5 & 23,74 & 24,19 & 16,91 & 19,41 \\
6 & 34,14 & 33,99 & 18,49 & 19,69 \\
7 & 28,15 & 27,39 & 16,4 & 14,21 \\
8 & 30,35 & 31,14 & 18,47 & 15,6 \\
9 & 29,95 & 31,74 & 18,80 & 17,88 \\
10 & 25,18 & 26,15 & 13,19 & 15,38 \\
11 & 29,14 & 31,92 & 16,31 & 17,48 \\
\hline MÉDIA & $\mathbf{3 2 , 1 7 5}$ & $\mathbf{3 2 , 7 3 9}$ & $\mathbf{1 9 , 0 4 3}$ & $\mathbf{1 9 , 1 7 5}$ \\
DP & $\mathbf{3 , 7 1 2}$ & $\mathbf{4 , 1 2 8}$ & $\mathbf{2 , 7 7 0}$ & $\mathbf{2 , 9 1 0}$ \\
\hline
\end{tabular}


Considerando um nível de significância de 5\%, temos que nenhum fator foi significativo. A figura 9 demonstra o gráfico das forças do MPO (1) e MPNO (2) ao longo do tempo, pré-operatório, com 30, 60 e 90 dias de pós-operatório.

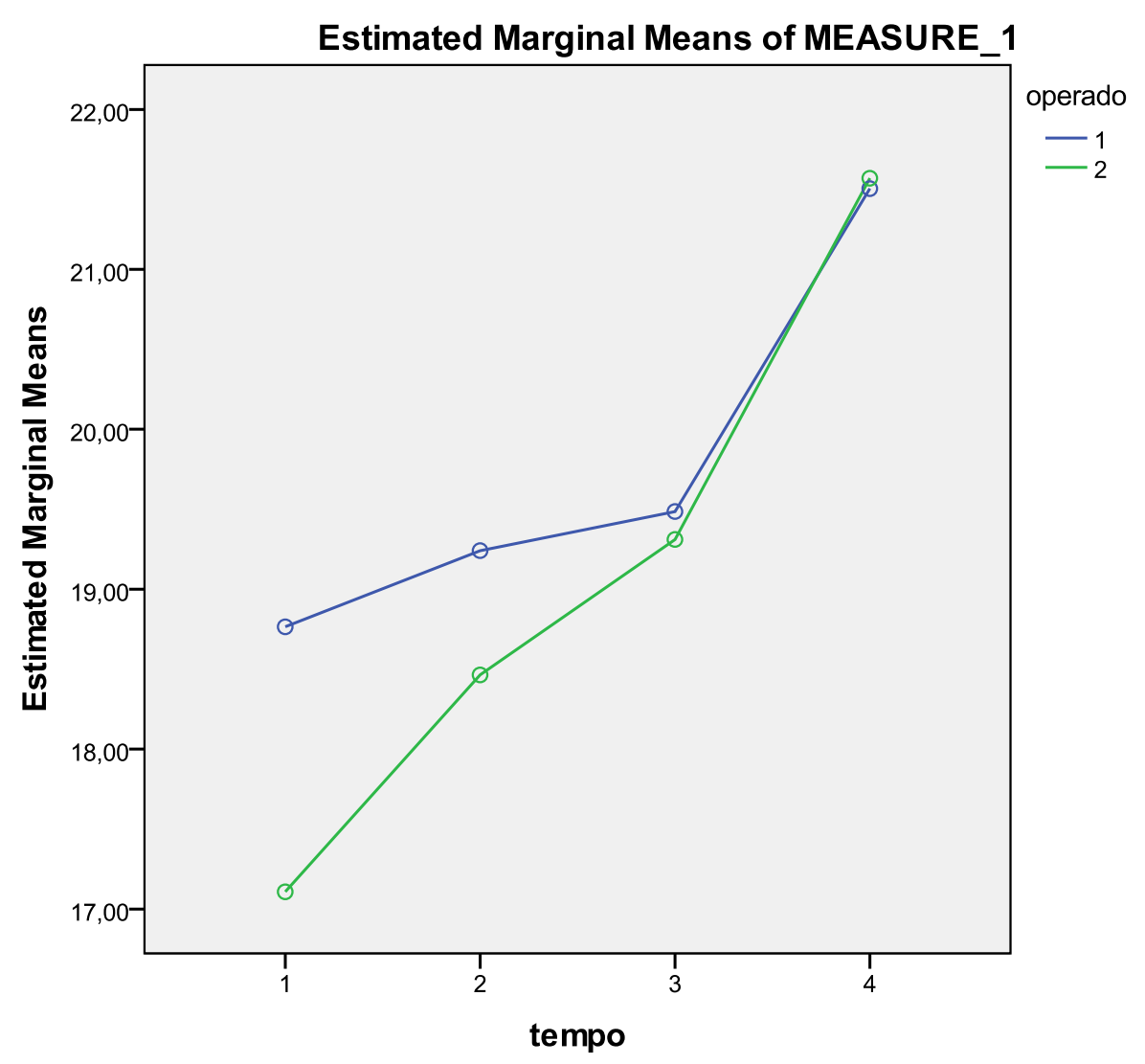

Figura 9 - Gráfico com os dados estatísticos, evidenciando o comportamento da PFV dos MPO (1- azul) e MPNO (2-verde) nos tempos pré-operatório, 30, 60 e 90 dias de pós-operatório, correspondendo respectivamente aos números 1 , 2, 3 e 4 do gráfico - FMVZ/USP - São Paulo - 2007-2010

Os resultados para o impulso vertical estão descritos nas tabelas 6 e 7, sendo que a média para os membros torácicos no pré-operatório foi de 6,681\% \pm 0,966 e de 6,767 \% \pm 0,873 no pós-operatório. Para os membros pélvicos operados e não operados, nos períodos pré e pós-operatório foi de 4,051\% $\pm 1,265$ e de 3,833\% \pm 0,59, respectivamente, sem diferença estatística entre eles. 
Tabela 6 - Média dos valores Impulso Vertical (IV) considerando cinco repetições válidas dos cães submetidos ao exame de baropodometria no período pré-operatório, LAL da FMVZ/USP - São Paulo - 2007-2010

\begin{tabular}{ccccc} 
CÃO & IVMTD\% PC & IVMTE \% PC & IVMPO\% PC & IVMPNO\% PC \\
\hline 1 & 9,72 & 9,62 & 4,05 & 3,88 \\
2 & 7,43 & 6,63 & 4,40 & 4,78 \\
3 & 6,29 & 7,81 & 4,41 & 4,14 \\
4 & 3,97 & 3,54 & 2,36 & 2,46 \\
5 & 7,75 & 8,04 & 6,05 & 6,56 \\
6 & 7,89 & 8,16 & 5,38 & 5,16 \\
7 & 2,89 & 2,86 & 1,39 & 0,97 \\
8 & 9,68 & 9,28 & 6,42 & 5,39 \\
9 & 4,26 & 4,43 & 2,66 & 2,45 \\
10 & 5,05 & 5,16 & 2,79 & 2,86 \\
11 & 5,24 & 5,86 & 2,94 & 3,18 \\
\hline MÉDIA & $\mathbf{6 , 4 9 0}$ & $\mathbf{6 , 7 0 8}$ & $\mathbf{3 , 8 9 5}$ & $\mathbf{3 , 8 0 3}$ \\
DP & $\mathbf{0 , 8 8 6}$ & $\mathbf{0 , 9 5 7}$ & $\mathbf{1 , 1 8 4}$ & $\mathbf{1 , 0 9 4}$ \\
\hline
\end{tabular}

Tabela 7 - Média dos valores Impulso Vertical (IV) das cinco repetições de cada um dos pacientes submetido ao exame de baropodometria no período pós-operatório, LAL da FMVZ/USP - São Paulo - 2007-2010

\section{$\begin{array}{lllll}\text { CÃO } & \text { IVMTD\% PC } & \text { IVMTE\% PC } & \text { IVMPO\% PC } & \text { IVMPNO\% PC }\end{array}$}

\begin{tabular}{ccccc}
\hline 1 & 11,99 & 11,83 & 5,58 & 6,09 \\
2 & 6,06 & 5,84 & 3,79 & 4,18 \\
3 & 6,42 & 6,99 & 3,79 & 3,61 \\
4 & 4,11 & 4,21 & 2,69 & 2,77 \\
5 & 6,34 & 6,66 & 4,46 & 4,74 \\
6 & 9,43 & 9,72 & 4,9 & 5,01 \\
7 & 2,06 & 2,04 & 1,25 & 1,13 \\
8 & 9,93 & 10,18 & 5,57 & 4,85 \\
9 & 3,96 & 4,04 & 2,24 & 2,34 \\
10 & 6,51 & 6,43 & 3,07 & 3,46 \\
11 & 3,56 & 3,73 & 1,92 & 2,02 \\
\hline MÉDIA & $\mathbf{6 , 3 9 7}$ & $\mathbf{6 , 5 1 5}$ & $\mathbf{3 , 5 6 9}$ & $\mathbf{3 , 6 5 5}$ \\
DP & $\mathbf{0 , 8 1 8}$ & $\mathbf{0 , 7 7 8}$ & $\mathbf{0 , 5 1 6}$ & $\mathbf{0 , 5 4 1}$ \\
\hline
\end{tabular}

Também não houve diferença significativa $(\mathrm{p}>0,05)$ do IV entre os membros pélvicos operados e não operados, quando comparados com os tempos de pós-operatório (30, 60 e 90 dias). A figura 10 apresenta o gráfico com o comportamento do Impulso Vertical do MPO e MPNO ao longo do tempo, pré-operatório, com 30, 60 e 90 dias de pós-operatório. 


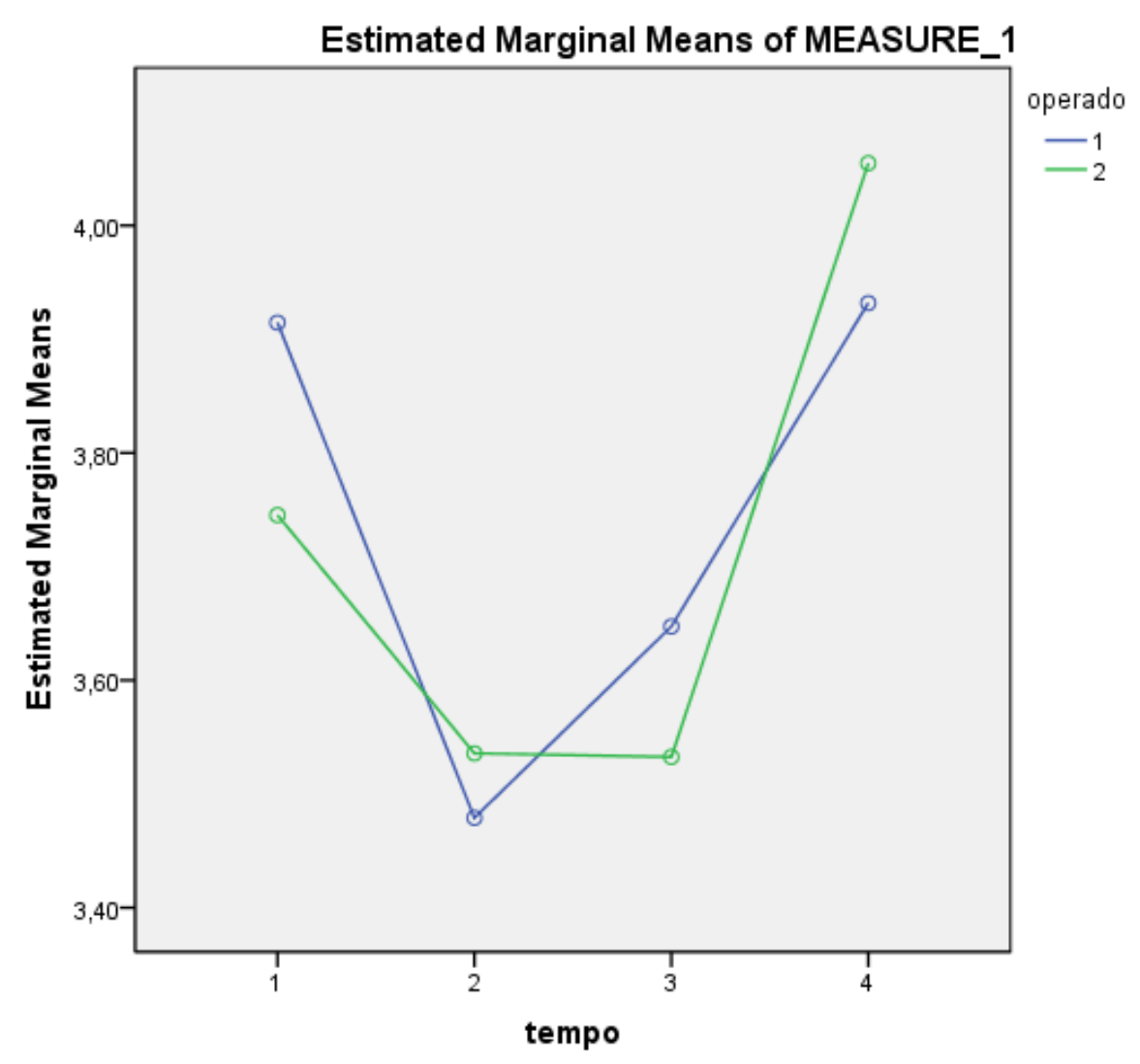

Figura 10 - Gráfico com os dados estatísticos, evidenciando o comportamento do IV dos MPO (1- azul) e MPNO (2-verde) nos tempos pré-operatório, 30, 60 e 90 dias de pós-operatório, correspondendo aos números 1, 2, 3 e 4 do gráfico, respectivamente - FMVZ/USP - São Paulo - 2007-2010

As Forças de reação ao solo expressas em Newtons (sem a normalização de acordo com o peso do animal) que proporcionam as análises da PFV e IV, foram obtidas no período pré-operatório e pós- operatório e estão representadas esquematicamente nas figuras 11 e 12 respectivamente. 


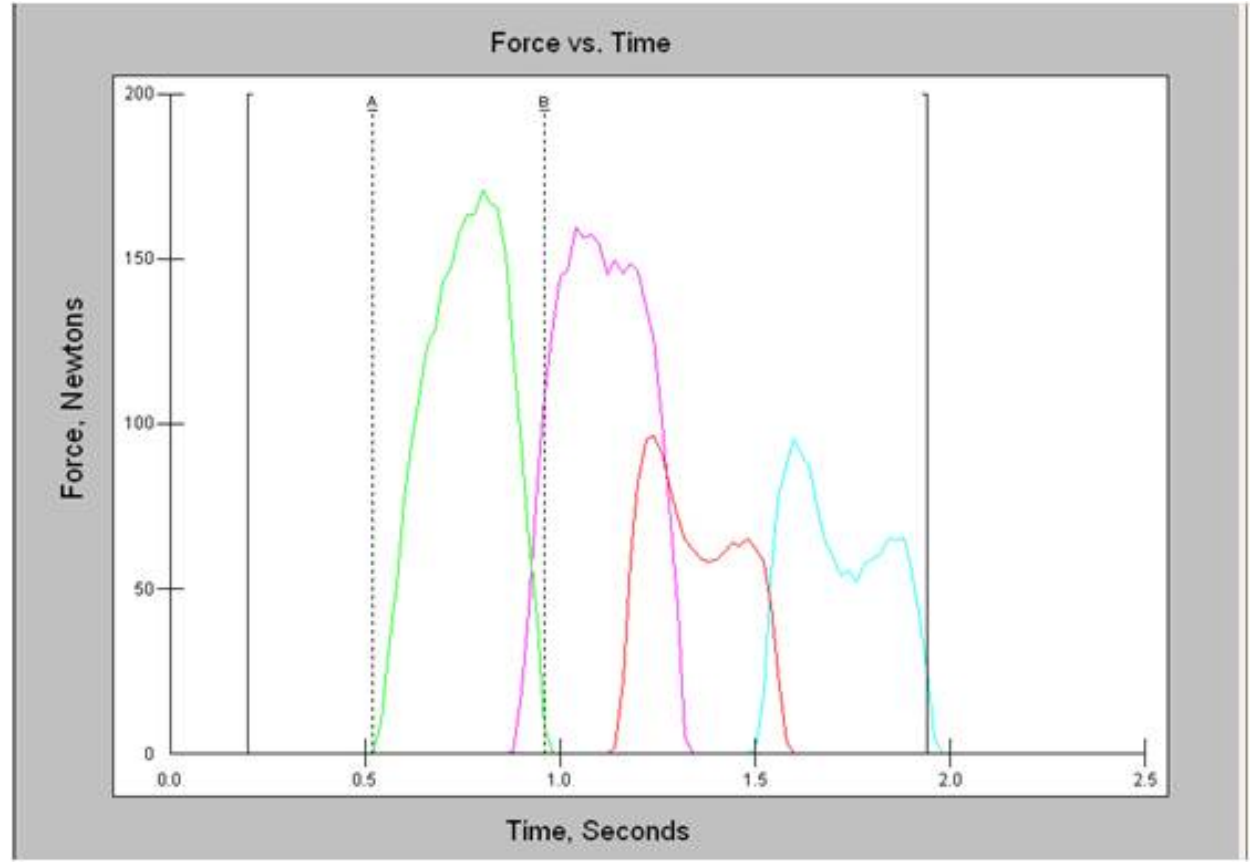

Figura 11 - Análise das forças de reação ao solo no paciente n 8 no período pré-operatório, por meio de software e gráfico da PFV e IV para cada um dos quatro membros durante uma das cinco passagens válidas. Em verde (MTD), Vermelho (MTE), Rosa (MPD) e azul (MPE). FMVZ/USP - São Paulo - 2007-2010

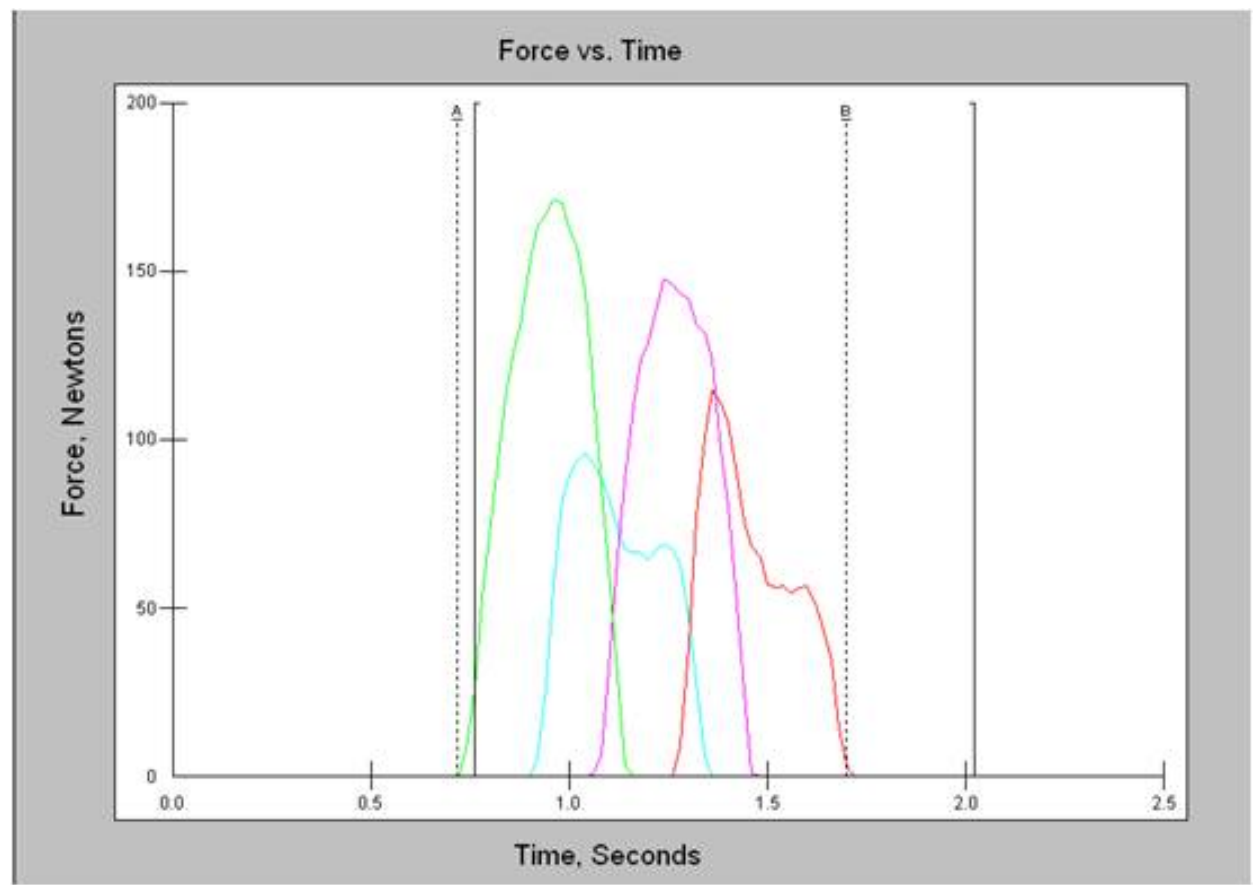

Figura 12 - Análise das forças de reação ao solo do cão n8 8 com 60 dias de pós-operatório, por meio de software e gráfico da PFV e IV para cada um dos quatro membros durante uma das cinco passagens válidas. Em verde (MTD), Vermelho (MTE), rosa (MPD) e azul (MPE). FMVZ/USP - São Paulo - 2007-2010 
DISCUSSÃO 


\section{DISCUSSÃO}

\subsection{AVALIAÇÃO CLÍNICA}

Hérnia perineal acomete com mais freqüência cães machos inteiros e raramente os gatos e as fêmeas (DIETERICH, 1975; LEIGHTON, 1979; JOHNSON, GOURLEY, 1980; ANDERSON et al., 1998), dado evidenciado no presente estudo, onde todos os pacientes atendidos no período de triagem eram cães machos.

Dos onze cães submetidos ao procedimento, cinco ( $\left.n^{\circ} 3, n^{\circ} 7, n^{\circ} 9, n^{\circ} 10, n^{\circ} 11\right)$ haviam previamente corrigido o diafragma, sendo que destes o cão ( $\mathrm{n}^{\circ} 3$ ) encontrava-se inteiro, apesar de ser preconizada a orquiectomia dos cães com hérnia perineal (BELLENGER, 1980; WEAR; OMAMEGBE, 1981; SJOLLEMA; SLUIJS, 1989; RAISER, 1994; HOSGOOD et al., 1995).

Quanto à idade de maior ocorrência desta paratopia em cães, alguns autores citam que ela ocorre entre os sete e nove anos (DIETERICH, 1975; HAYES et al., 1978; ANDERSON et al., 1998), outros afirmam que a incidência maior está a partir dos cinco anos de idade (WEAVER; OMAMEGBE, 1981; HOSGOOD et al., 1995), no entanto, a maioria dos pacientes atendidos neste estudo tinha idade superior a 10 anos, sendo que três casos com a idade inferior a essa faixa, em condizente com a literatura $\left(n^{\circ} 6, n^{\circ} 8\right.$ e $\left.n^{\circ} 11\right)$.

Pouco se relata sobre o tempo de evolução das hérnias perineais (LEIGHTON, 1979; JOHNSON; GOURLEY, 1980; BOJRAB; TOOMEY, 1981; FOSSUM, 2005), tendo em vista ser um dado empírico por está atrelado às informações fornecidas pelos proprietários; em nossa pesquisa um proprietário chegou a relatar que percebeu o aumento de volume na região perineal há apenas um dia (cão $n^{\circ} 8$ ). Segundo alguns proprietários o tempo de evolução da hérnia foi inferior a um mês $\left(n^{\circ} 1, n^{\circ} 5, n^{\circ} 8, n^{\circ} 10\right)$, mas a presença de edema na região perineal na maioria dos cães sugeria período superior ao mencionado.

Os sinais clínicos mais relatados foram tenesmo, disquesia e aumento da região do períneo, o mesmo descrito por Anderson et al. (1998), caracterizando a hérnia perineal como resultado do enfraquecimento, separação dos músculos e fáscia que formam o diafragma pélvico (ANDERSON et al., 1998; BELLENGER; READ, 1998). 
A presença de trauma na região do aumento perineal em um paciente $\left(n^{\circ} 10\right)$ acarretou em demora na realização da intervenção operatória, pois a integridade da pele para a realização do procedimento operatório é primordial. Nenhuma das referências analisadas mencionou a presença de traumas nos casos estudados.

Embora as hérnias perineais apresentem características clínicas peculiares, foi levado em consideração para admissão do diagnóstico, a história clínica, sinais clínicos, exames físicos e exames complementares. É importante ressaltar que em estágios precoces pode ser mais difícil efetuar um diagnóstico preciso (DIETERICH, 1975), fato não deparado nos pacientes em questão, que apresentavam hérnias perineais bilaterais complexas e, às vezes, recidivantes

Os resultados dos exames laboratoriais não constataram alterações fisiológicas que comprometessem a integridade das funções vitais dos pacientes, no entanto, o cão $\mathrm{n}^{\circ} 4$ apresentou quadro de anemia e leucopenia e o cão n³ apresentou redução nos valores de HCM, CHC e plaquetas e aumento da uréia sérica, sendo necessário em ambos os casos, recuperar os cães antes do procedimento operatório, cuidados que os autores solicitam atenção (BELLENGER, 1980; HEDLUND, 2002; BELLENGER; CANFIELD, 2003).

A perda da função do diafragma pélvico freqüentemente leva ao desvio lateral da porção final do reto (CANFIELD; BELLENGER, 1998) e a presença de alguma estrutura nessa região (MANN, 1993). Por isso, além da palpação digital externa e interna, utilizamos os recursos de RX e ultra-som para elucidar o possível conteúdo herniário, não obstante a gordura retroperitonial constituir o componente principal do conteúdo herniado, nos animais do estudo. O mesmo verificado por Lipowitz (1996).

Embora as hérnias perineais unilaterais sejam mais freqüentes (MATERA et al 1981; WEAVER; OMAMEGBE 1981; DALECK et al., 1992; RAISER, 1994), nos detemos a incluir no grupo experimental apenas pacientes com hérnia perineal bilateral com comprometimento da região ventral. 


\subsection{TÉCNICA CIRÚRGICA}

A técnica de transposição do músculo semitendinoso é indicada para cães com diagnóstico de hérnia perineal crônicas, recidivantes (CHAMBER; RAWLINGS, 1991; MANN; CONSTINESCU, 1998). Ao ser considerada uma alternativa na reparação de hérnias perineais nos propomos a verificar a eficácia dessa afirmativa utilizando pacientes da rotina cirúrgica do HOVET/USP, já que todos os episódios descritos até o momento foram casos clínicos isolados (CHAMBERS; RAWLINGS, 1991, MANN; CONSTANTINESCU, 1998; CHAMBERS, 1999) ou em pacientes hígidos (MORTARI et al., 2005).

O músculo semitendinoso é de fundamental importância na dinâmica do movimento de flexão e distensão do membro pélvico e sua transposição poderia acarretar o comprometimento da locomoção destes pacientes. Embora Chambers (1999) e Mortari (2004) afirmarem que cães submetidos experimentalmente ao procedimento de transposição não apresentaram prejuízos na locomoção ou movimentação articular do membro operado, suas análises não foram subsidiadas com o uso de equipamentos específicos para esse fim, que é o que nos propusemos neste estudo.

Dos vinte animais operados, nove (45\%) não foram submetidos à transposição do músculo, pois avaliações nas condições da musculatura da região do períneo durante o período transoperatório contribuíram para modificação no plano inicialmente estabelecido. Cabe frisar, assim, que o cirurgião deve, após cuidadoso exame clínico, poder optar, no momento operatório, por mudar a técnica operatória proposta, se assim pareceu sua análise posterior, a fim de não infringir ao animal maior trauma cirúrgico, que o necessário, pelo emprego da técnica de transposição do músculo semitendinoso, sabidamente de maior dimensão, a sua aplicação, quando comparada às demais técnicas de correção do diafragma pélvico (CHAMBER, 1999).

A técnica cirúrgica que norteou este trabalho foi citada por Mortari (2004), no entanto, durante o procedimento transoperatório empregou-se outra forma de intervenção na região do períneo ventral onde a mesma não foi incisada evitando maior injúria cirúrgica, criando-se túnel cutâneo no plano sagital mediano, local por onde o músculo semitendinoso cursou, evitando-se também, maior tempo para a sutura da região. 
Outra variação na técnica foi a escolha do membro pélvico a ser incisado. Após investigação cuidadosa da sua anatomia (BOYD et al., 1993; EVANS; DELAHUNTA, 2001, DONE et al., 2002;), preconizou-se a transposição do músculo do membro contralateral da região de períneo mais afetada, por incluir que a tuberosidade esquiática onde se insere o músculo semitendinoso encontra-se ventralmente ao diafragma pélvico (EVANS; DELAHUNTA, 1971, 2001), ou seja, mesmo dissecando o músculo até a sua posição de inserção proximal, seria ineficiente para fechamento da hérnia localizada no mesmo antímero do músculo seccionado.

O encurtamento do músculo após a incisão dificulta o processo de transposição à região contralateral, por isso a importância de realizar a incisão na altura do linfonodo poplíteo, o mesmo observado por Mortari (2004).

Constatou-se que a transposição para correção lateral em paciente condroplásico ( $\mathrm{n}^{\circ 7}$ ) fica comprometida devido à redução do comprimento do músculo depois de seccionado, não chegando a contento na região citada, no entanto a fossa ipsilateral da região ventral inclui correção garantida. Neste cão $\left(\mathrm{n}^{\circ} 7\right)$ como o comprimento do músculo não foi suficiente para corrigir a hérnia lateral direita, a mesma foi corrigida pela técnica de elevação do obturador interno e reforçada com o uso de pericárdio eqüino (Puro Sangue Inglês). Esse mesmo paciente foi submetido a uma nova cirurgia após os 90 dias de avaliação, sendo na ocasião utilizado malha de polipropileno para correção de hérnia perineal dorsal contralateral ao antímero do músculo transposto.

Vários conteúdos foram por nós observados no saco herniário, sendo comum a presença de fluido seroso (DIETERICH, 1975) e gordura retroperitonial. Além disso, pôde ser observado bexiga urinária, próstata, saculação, dilatação, flexura, desvio ou divertículo retal, e nódulos de coloração creme a amarelo-âmbar (HOSGOOD et al.; 1995; BELLEGER; CANFIELD, 2003), sendo a bexiga e próstata as outras estruturas encontradas com mais freqüência em nossos pacientes, não sendo constatada, contudo, a presença de divertículo retal, assertiva observada em cem casos por Hosgood et al., (1995).

No paciente em que a bexiga se encontrava no saco herniário esquerdo ( $\left.\mathrm{n}^{\circ} 2\right)$ com as paredes espessadas e com sinais de infecção, foi instituído um tratamento antibiótico diferenciado com enrofloxacino $5 \mathrm{mg} / \mathrm{kg} / \mathrm{BID} / 10$ dias, assim como no cão em que a próstata encontrava-se aumentada de volume com cistos e abscesso na região de saco herniário direito $\left(n^{\circ} 3\right)$. Este mesmo medicamento foi utilizado por Costa Neto et al. (2006) em todos os seus pacientes antes e após o procedimento operatório. Segundo estes autores o uso de 
antibioticoterapia de amplo espectro administrados de forma profilática e terapêutica minimizaram os riscos de infecção pós-operatória.

O transoperatório transcorreu sem complicações, exigindo apenas habilidade manual e conhecimento anatômico para evitar possíveis injúrias ao pedículo neurovascular durante a liberação proximal do músculo semitendinoso (CHAMBERS; RAWLINGS, 1991, MORTARI, 2004).

A presença do edema dificultou a sutura do músculo semitendinoso à região operada, no entanto, esse dado não foi mencionado por outros autores.

Um aspecto não mensurado neste e em outros trabalhos e que merece investigação é a influência do diâmetro do músculo semitendinoso no processo de transposição, pois em um animal da raça Rotweiller $\left(\mathrm{n}^{\circ} 8\right)$, de porte atlético e de guarda, o músculo semitendinoso apresentou-se hipertrofiado, como os demais do seu corpo, o que dificultou bastante a dissecção, a passagem deste pelo túnel no plano sagital mediano e a sutura da pele na região perineal, face ao seu diâmetro. Esse mesmo animal apresentou deiscência de pele no pósoperatório, inicialmente na região de maior tensão da sutura, seguindo para outros pontos, devido à instalação de infecção.

\subsection{AVALIAÇÃO PÓS-OPERATÓRIA}

Altos índices de complicações pós-operatórias têm sido associados em pacientes submetidos à correção cirúrgica de hérnia perineal incluindo recidivas, fístula, abscessos, prolapso retal, incontinência urinária ou fecal e injúria do nervo ciático (HOSGOOD et al., 1985; SJOLLEMA et al., 1989; LIPOWITZ, 1996), estes índices variam conforme o método cirúrgico empregado para a reparação da deformidade perineal (HOSGOOD et al., 1985). As infecções são mencionadas como a mais freqüentemente complicação pós-operatória (BELLENGER, 1980; MATTHIESEN, 1989; LIPOWITZ, 1996; BELLENGER; CANFIELD, 2003; MORTARI, 2004), no entanto essa alteração foi detectada em um (n8) paciente no presente estudo.

Considerar o pós-operatório até os 90 dias de avaliação nos permitiu acompanhar as alterações que ocorreram durante esse período. Os casos de recidivas foram os mais comuns, 
embora a intenção inicial fosse diminuir essas ocorrências com a utilização da técnica de transposição, uma vez que essa é a técnica de escolha quando a face ventral do períneo encontra-se severamente afetada (CHAMBERS; RAWLINGS, 1991; MANN; CONSTINESCU, 1998).

Robertson (1984) relata que as recidivas estão associadas à falha no isolamento das estruturas anatômicas, inadequada colocação de suturas ou escolha inapropriada de materiais de sutura. Estes aspectos foram descartados do nosso estudo, uma vez que todo o procedimento foi cuidadosamente vistoriado, a fim de evitar essas ocorrências.

Cinco cães já haviam sido inicialmente operados, destes, dois apresentaram recidivas antes dos 90 dias de avaliação. A ocorrência das recidivas gerou um maior critério no momento de realizarmos a intervenção, decidindo pela inclusão na pesquisa apenas os pacientes com maior comprometimento das regiões perineais laterais e ventrais a fim de evitar submetê-los a uma injúria dispensável (CHAMBERS; RAWLINGS, 1991; MANN; CONSTINESCU, 1998).

A deiscência de pontos foi observada em dois pacientes $\left(n^{\circ} 1, n^{\circ} 8\right)$ no pós-operatório, mas em um dos casos, especialmente, conjeturamos a possibilidade de o paciente ter se arrastado durante a recuperação da anestesia peridural $\left(\mathrm{n}^{\circ} 1\right)$, uma vez que o mesmo foi removido antes do período mínimo de recuperação estabelecido pelo Serviço de Anestesia. No outro cão $\left(n^{\circ} 8\right)$ a deiscência está relacionada à tensão da sutura provocada pela dificuldade na junção das bordas da ferida devido o diâmetro do músculo transposto. A ocorrência de deiscência, infecções e abscessos variam de 6,4 a 26\% (MATTHIESEN, 1989; LIPOWITZ, 1996; BELLENGER; CANFIELD, 2003).

O esforço e dificuldade de evacuar podem ocorrer no pós-operatório imediato e estar associados ao prolapso retal em alguns casos (ROBERTSON; 1984); prolapsos retais aparecem com freqüência de 2 a 13\% (LIPOWITZ, 1996). Conferimos essa afirmação em um dos pacientes $\left(\mathrm{n}^{\circ} 2\right)$, o qual posteriormente surgiu com recidiva da hérnia em região dorsal. Neste caso não foi indicada uma nova correção cirúrgica devido alguns fatores peculiares ao paciente como o fato de ser a terceira recidiva, apresentar uma degeneração muscular generalizada, já identificada antes do ato operatório, e a idade avançada.

Durante a avaliação dos 60 dias de pós-operatório também foi observado em outros dois pacientes a recidiva da hérnia perineal em sua região mais dorsal, sendo o diagnóstico elucidado com o auxilio do Rx e Ultrassom, uma vez que os pacientes não evidenciavam 
qualquer alteração clínica e física que relevasse a presença de hérnia perineal. Foi estabelecida uma conduta paliativa de manejo do paciente de forma conservativa com o uso de emolientes e fibras na dieta, a fim de tornar o bolo fecal mais macio, o mesmo sugerido por Dieterich (1975).

É indicada a utilização de supositório de glicerina naqueles pacientes que não apresentam trânsito intestinal depois de 48 horas de pós-operatório (DIETERICH, 1975), mas não foi adotada essa conduta em nossos casos por julgarmos desnecessária, no entanto, indicamos para alguns pacientes o uso de laxante natural apenas nos primeiros dias, diferente do que sugeriu Hedlund (2002) quando recomendou a administração de laxantes por período de 1 a 2 meses após a herniorrafia. A utilização de laxantes foi incluída no tratamento devido a queixas do proprietário quanto à presença de disquesia e tenesmo nos primeiros dias após a correção cirúrgica, o mesmo ocorreu com Zerwes (2005) em seus estudos.

A retirada dos pontos foi possível em média 14 dias. Tal período é semelhante ao recomendado por Dieterich (1975) entre 10 e 14 dias.

\subsection{AVALIAÇÃO BAROPODOMÉTRICA}

O músculo semitendinoso possui importância peculiar á locomoção, sua transposição poderia acarretar implicação na caminhada ou postura dos cães submetidos ao procedimento operatório. Por isso utilizamos análises baropodométricas, onde foi estudada a cinética da locomoção, estipuladas por meio do uso de placas de força, avaliando as forças de reação ao solo (FRS), geradas durante esse processo (ANDERSON; MANN, 1993; BESANCON et al., 2003). O PFV e IV foram os parâmetros avaliados e estes são considerados os mais acurados na detecção de claudicação (FANCHON; GRANDJEAN, 2007).

Considerando que a velocidade, aceleração e número de repetições podem introduzir grande alteração na obtenção dos dados (RIGGS; DECAMP; SOUTAS-LITTLE, 1993; BESANCON et al., 2003; WEIGEL et al., 2005), procurou-se controlar esses aspectos da avaliação a fim de minimizar a variação na obtenção dos dados.

Para obter as cinco passagens válidas foi necessário passar o mesmo cão várias vezes na plataforma de força, a fim de obter um maior controle da velocidade e confiabilidade dos 
dados, já que essa variável é de fundamental importância (RIGGS; DECAMP; SOUTASLITTLE, 1993; BESANCON et al., 2003; WEIGEL et al., 2005). Segundo Duncan et al. (2006) o elevado número de passagens sobre a placa pode influenciar os resultados, por isso não ultrapassamos o número de 20 repetições, o mesmo empregado por Souza (2009). O uso da plataforma múltipla com placas sensitivas de leitura nos permite alcançar os resultados esperados pela facilidade de uso (DUNCAN et al., 2006).

A obtenção das FRS dos quatro membros em única passagem foi alcançada por meio do trajeto retilíneo sobre a plataforma, com velocidade, aceleração e tempo padronizados. Para alcançar essa padronização seguimos a descrição de Dulaney et al. (2005), que a obtiveram resultados favoráveis usando até seis metros de distância do primeiro contato do cão com a plataforma baropodométrica. Em nosso estudo o início da caminhada foi a dois metros antes do primeiro contato, o mesmo descrito por Souza (2009).

Os valores de FRS não foram interferidos pela variação dos condutores (cada animal foi conduzido por seu proprietário), embora Budsberg et al. (1993); Mclaughlin e Roush (1995); Renberg et al. (1999) e Rumph et al. (1994), comentem que diferentes condutores podem interferir na obtenção dos dados. Jevens, Hauptman e Decamp (1993) e Souza (2009), citam que a diversidade de condutores não interfere nos valores de FRS, desde que outras variáveis sejam mantidas.

O tipo de passagem estabelecido foi o passo, já que de acordo com Decamp (1997) cada tipo de locomoção gera um padrão específico de forças de reação ao solo. Os padrões estabelecidos por este autor para os membros torácicos e pélvicos foram os mesmos alcançados no nosso trabalho, onde o primeiro pico da força vertical está associado ao toque inicial da pata no inicio da fase de apoio e a o segundo pico, representa a força máxima vertical gerada no final do apoio, associada com a retirada do membro ou propulsão. O mínimo entre estes picos representa o intervalo de tempo entre o toque inicial da pata no solo e sua retirada. É importante lembrar que esse padrão pode não estar presente em condições normais, mesmo que este seja obtido com maior freqüência a velocidade do passo (SOUZA, 2009).

Hottinger et al. (1996) realizaram a análise cinemática em cães de raça de grande porte ao passo e a média de tempo de apoio nos membros encontrada por estes autores foi de

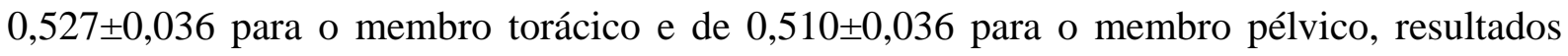
estes superiores ao encontrado no presente estudo, tanto para as avaliações pré-operatória como pós-operatória. 
Não avaliamos estatisticamente se há compensação entre MT e MP, uma vez que utilizamos os resultados descritos por Souza (2009), onde foi verificado que não há sobrecarga significante $(p=0,867)$ entre membros torácicos e membros pélvicos de cães com displasia coxo femoral e hígidos, embora não possamos afirmar que a displasia coxofemoral afete da mesma maneira o centro de gravidade da locomoção do animal com hérnia perineal.

Detemo-nos as análises estatísticas entre os membros pélvicos operados e não operados.

Os valores médios da força pico vertical (PFV) para os membros torácicos de animais hígidos de grande porte estudados por Besancon et al. (2003), foram bem superiores aos encontrados em nosso estudo, tanto nos dados pré como pós-operatório, até mesmo nos pacientes de maior porte com peso superior a $30 \mathrm{~kg}$ os valores ficaram abaixo do mencionado

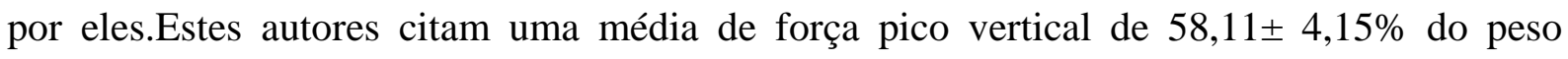
corpóreo ao passo, utilizando o mesmo sistema de baropodometria, contrapondo ao verificado nos cães deste trabalho nas avaliações pré e pós-operatória.

Oliveira (2008) verificou uma média de PFV dos membros torácico e pélvicos de $35,95 \pm 4,55$, dados estes mais próximos do que encontramos. Este autor menciona que o dado inferior de PFV ao citado por Besancon et al. (2003) pode estar relacionado ao fato de ter empregado uma velocidade média inferior a destes autores. No entanto, em nosso trabalho utilizamos uma velocidade média aproximada ao descrita por Besancon et al. (2003), e o valor de PFV foi inferior, logo, não é possível assegurar ser a velocidade o fator preponderante desta diferença.

Outro parâmetro avaliado foram os valores médios de impulso vertical (IV), Duncan et al. (2006) utilizaram o sistema de baropodometria Tekscan® para análises da locomoção de cães normais em trote, sendo os valores de IV encontrados para o torácico e pélvico de $14,7 \% \pm 1,865$ e de 7,775 $\pm 1,195$ respectivamente, já Oliveira (2008) menciona os valores médios do impulso vertical de 12,525\% $\pm 4,047$ para membros torácicos e de 13,086\% $\pm 4,526$ para membros pélvicos. Os resultados encontrados por estes autores diferem ao encontrado em nosso estudo nos dois aspectos de avaliação, ou seja, a média do IV nos pacientes avaliados antes e após a cirurgia observou-se valores bem inferior ao evidenciado pelos autores supracitados.

Riggs et al. (1993) mencionam que o IV diminui com o aumento da velocidade, no entanto, utilizamos velocidade média menor que o citado por Duncan et al. (2006) e IV 
também menor. Já Oliveira (2008) obteve uma velocidade média menor e um IV maior ao verificado em nossos estudos. O impulso vertical assim como o PFV também é influenciado pelo tamanho e conformação do animal, podendo explicar as diferenças nos resultados

Por estarmos realizando transposição do músculo semitendinoso do membro ora direito, ora esquerdo, foi necessária a avaliação dos membros separadamente, o que nos permitiu verificar por meio do gráfico, o desempenho de cada membro.

Os resultados indicaram que a PFV e IV transmitida nos membros pélvicos operados e não operados não apresentam diferenças significativas nos períodos pré e pós-operatório, no entanto, quando analisamos os gráficos das médias observamos que há uma diferença no comportamento dessas variáveis que sugere alterações na dinâmica da locomoção desses cães, estas não relacionadas com a transposição do músculo, pois a diferença ocorre principalmente na avaliação pré-operatória. Com isso podemos aferir que o desconforto provocado pela hérnia perineal possa interferir na locomoção do animal gerando tal assimetria, onde após o procedimento operatório a simetria da locomoção apresentou valores mais compatíveis dentro do normal.

Antes do procedimento cirúrgico a PFV entre os membros pélvicos se comportavam de maneira distinta, vindo a igualar-se a partir dos 90 dias de pós-operatório, no entanto, não encontramos na literatura relatos sobre o comportamento dos membros de forma separada, direito e esquerdo, eles sempre são citados em médias gerais de membros pélvicos ou torácicos.

O IV apresentou um comportamento bem variado nos diferentes tempos, o MPNO no período pré-operatório apresentava um desempenho inferior, chegando a ficar estável e posteriormente superando o MPO em valores médios. Considerando que IV é um parâmetro mais variável e menos acurado para a detecção da claudicação do que o PFV (FACHON, 2007) essas variações podem ser esperadas.

É importante lembrar que essas diferenças em PFV e IV, embora não significativas, nos dá uma idéia da recuperação desses cães e sugere que a transposição não afeta a função locomotora do membro operado. 
CONCLUSÕES 


\section{CONCLUSÕES}

Em face dos resultados obtidos é lícito concluir que:

A técnica de transposição do músculo semitendinoso para reparação de hérnia perineal bilateral não compromete a locomoção dos cães.

O membro pélvico dos cães submetidos ao procedimento operatório não apresentaram qualquer dificuldade de adaptação, favorecendo o uso da técnica.

Embora não haja qualquer alteração na locomoção que comprometa a viabilidade da técnica, esta não se presta favoravelmente a hérnias perineais sem comprometimento ventral. 
REFERÊENCIAS 


\section{REFERÊNCIAS}

ACAUI, A. Avaliação do tratamento da hérnia perineal bilateral no cão por aceso dorsal ao ânus em tempo cirúrgico único. 2001.53 p. Dissertação (Mestrado) - Faculdade de Medicina Veterinária e Zootecnia, Universidade de São Paulo, São Paulo, 2001.

ALVARENGA, J.; BARROS, P. S .M; STOPIGLIA, A. J.; IWASAKI, M. Hérnia perineal no cão (Canis familiares) - Tratamento cirúrgico mediante implante de centro frênico em glicerina. In: CONFERÊNCIA ANUAL DA SOCIEDADE PAULISTA DE MEDICINA VETERINARIA, 35; 1980, São Paulo, Resumo... 1980.

ANDERSON, M. A; CONSTANTINESCU, G. M.; MASS, F. A. Perineal heria repair in dog. In: BOJRAB, M.J.; ELLISON, G.W.; SLOCUM, B. Current techniques in small animal surgery. 4. ed. Baltimore: Williams \& Wilkins, 1998. chap. 35, p. 555-564.

ANDERSON, M. A.; MANN, F. A; MANN, W. C.; HAHN, A. W.; JIANG, B. L.;

TOMLINSON, J. L. A comparison of nonthreaded, enhanced threaded, and Ellis fixation pins used in type I external skeletal fixators in dogs. Veterinary Surgery., v. 22, n. 6, p. 482-489, 1993.

ARCHIBALD J. SMITH, S. G. In:__ Canine Surgery. California: American Veterinary Publications, INC., 1974. cap.12, p. 505-554.

BELLENGER, C. R. Perineal hernia in dogs. Australian Veterinary Journal., v. 56, p. 434438, 1980.

BELLENGER, C.R.; CANFIELD R. B. Perineal hernia. In: SLATTER, D. Textbook of small animal surgery. 3.ed. Philadelphia: Saunders, 2003. p. 487-498.

BELLENGER, C. R.; READ, A. R. Hernia perineal. In: SLATTER, D. Manual de cirurgia de pequenos animais. São Paulo: Manole, 1998. p. 529-5532.

BERTRAN, J. E.; TODHUNTER, R. J.; FOELS, W. S.; WILLIAMS, A. J.; LUST, G. Multiple force platform analysis of the canine trot: a new approach to assessing basic characteristics of locomotion. V.C.O.T., n. 10, p. 160-169, 1997.

BESANCON, M. F.; CONZEMIUS, M. G.; DERRICK, T. R.; RITTER, M. J. Comparison of vertical forces in normal greyhounds between force platform and pressure walkway measurement systems. V.C.O.T., v. 16, n. 3, p.153-157, 2003.

BILBREY, S.A., SMEAK, D.D. E DEHOFF, W. Fixation of the deferent ductus for retrodisplacement of the urinary bladder and prostate in canine perineal hernia. Veterinary Surgery, v. 19, p. 24-27, 1990.

BOJRAB, M. J. TOOMEY, A A. Hernia perineal.In: BOJRAB, M. J. Cirurgia dos pequenos animais. São Paulo: Manole, 1981. p. 436-441 
BONGARTZ, A.; CAROFLIGIO, F.; BALLIGAND, M.; HEIMANN, M.; HAMAIDE, A. Use of autogenous fascia lata graft for perineal herniorrhaphy in dogs. Veterinary Surgery, v. 34,n. 4, p. 405-503, 2005.

BUDSBERG, S. C.; JEVENS, D. J.; BROWN, J. Evaluation of limb symmetry indices, using ground reaction forces in healthy dogs. American Journal Veterinary Research, v. 54, p. 1569-1574,1993.

BUDSBERG, S.C.; JONATAN, N.; LUE, V.L.; FOUTZ, T. L.; REECE, L. Prospective evalution of groud reaction forces in dogs undergoing unilateral total hip repleacement. American Journal of Vetrinary Research, v. 57, n. 12, p. 1781-1785, 1996.

BUDSBERG, S. C.; VERSTRAETE, M. C.; BROWN, J.; REECE, L. Vertical loading rates in clinically normal dogs at a trot. American Journal Veterinary Research, v. 56, n. 10, p. 1275-1280, 1995.

BUDSBERG, S. C.; VERSTRAETE, M. C.; SOUTAS-LITTLE, R.W. Force plate analysis of the walking gait in healthy dogs. American Journal Veterinary Research, v. 48, n. 6, p. 915-918, 1987.

CHAMBERS, J. N. Pedicle muscles flaps In: Manual of canine and feline wound managemente and reconstrution. Surrey, England: 1999. p. 95-103, 152-153.

CHAMBERS, J. N.; RAWLINGS, C. A. Applications of a semitendinous muscle flap in two dogs. Journal American Veterinary Medical Association, v. 199, p. 84-86, 1991.

COSTA NETO, J. M.; MENEZES, V. P.; TORIBIO, J. M. L.; OLIVEIRA, E. C. S.; ANUNCIAÇÃO, M. C.; TEIXEIRA, R. G.; DÁSSIS, M. J. M. H; VIEIRA JUNIOR, A. S. Tratamento cirúrgico para correção de hérnia perineal em cão com saculação retal coexistente. Revista Brasileira de Saúde e Produção Animal, v. 7, p. 07-19, 2006.

DALECK, C. R.; DALECK, C. L. M.; FILHO, J. G. P.; NETO, J. M. C. Reparação da hérnia perineal em cães com peritônio de bovino conservado em glicerina. Ciência Rural, v. 22, n. 2, p. 179-183, 1992.

DECAMP, C. E. Kinetic and kinematic gait analysis and the assessment of lameness in the dog. Veterinary Clinics of North American:Small Animal Practice, v.27, p. 825-841, 1997.

DECAMP, C. E.; SOUTAS-LITTLE, R. W.; HAUPTMAN, J.; OLIVIER, B.; BRADEN, T.; WALTON, A. Kinematic gait analysis of the trot in healthy Greyhounds. American Journal Veterinary Research, v. 54, n. 4, p. 627-634, 1993.

DESAI, R. An anatomical study of the canine male and female pelvic diaphragm and effect of testosterone on the status of levator ani for male dogs. Journal of American animal Hospital Association, v. 18, p. 195-202,1982.

DIETERICH, H. F. Perineal hernia repair in the canine. Veterinary Clinical. North American, v. 5, p. 383-399, 1975. 
DORN, A. S.; CARTEE, R. E.; RICHARDSON, D. C. A preliminary comparison of perineal hernia in the dog and man. Journal of the American Animal Hospital Association, v. 18, p. 624-632, 1982.

EARLEY, D. T.; KOLATA, R. J. Perineal hernia in the dog: na alternative method of Corretion. In: BOJRAB, M. J. Current techniques in small animal surgery. Philadelphia: Lea \& Febiger, 1983. p. 405-407.

EVANS, H. E.; DELAHUNTA, A . Miller's guide to the dissection of the dog. Philadelphia: Saundres, 1971. p. 145-209

FANCHON, L.; VALETTE, J. P.; SANAA, M.; GRANDJEAN, D. The measurement of ground reaction force in dogs trotting on a treadmill. Veterinary and Comparative Orthopedics and Traumatology, v.19, n.1, p. 86-89, 2006.

FERREIRA, F.; DELGADO, E. Hérnias perineais nos pequenos animais. Revista Portuguesa de Ciências Veterinárias, v. 545, p. 3-9, 2003.

FOSSUM, T. W. Perineal hernia. In:__Small animal surgery. Missouri, E. U. A: Mosby; 2005.

FRANKLAND, A. L. Use of porcine dermal collagen in the repair of perineal hernia in dogs a preliminary report. Veterinary Record, v. 119, p. 13-14, 1986.

GALEAZZI, V. S.; MATERA, J. M.; QUEIROZ, G. F.; SILVA, T. S.; CASTRO, P. F. Transposição do músculo semi-tendinoso no reparo de hérnia perineal ventral. Arquivo Brasileiro de Medicina Veterinária e Zootecnia, Belo Horizonte, v. 58, p. 67, 2006. Suplemento, 2.

HARRIS, G. F.; WERTSCH, J. J. Procedures for gait analysis. Archives Physical Medicine and Rehabilitation, v. 75, p. 216-225, 1994.

HARVEY, C. E.. Treatment of perineal hernia in the dog: reassessment. Journal of Small Animal Practice, v. 18, p. 505-511, 1977.

HAYES, H.W.; WILSON, G. P.; TRONE, R. E. The epidemiologic features of perineal hernia in 771 dogs. Journal of the American Animal Hospital Association, v. 14, p. 703707, 1978

HEDLUND, C. Perineal hernia. In: FOSSUM, T. W. Cirurgia de pequenos animais. São Paulo: Roca, 2002. p. 389-394.

HERMANSO, J. W.; EVANS, H. E. The muscular system. In:__Anatomy of the dog. 3. ed. Philadelphia: Saunders, 1993. chap. 6, p. 258-384.

HOLMES, J. R. Perineal hérnia in dog. The Veterinary Record,.v. 76, n. 44,p. 1250-1251, 1964.

HOSGOOD, G.; HEDLUND, C. S.; PEACHMAN, R. D.; DEAN, P. W. Perineal herniorrhaphy: perioperative data from 100 dogs. Journal of the American Animal Hospital Association, v. 31, n. 4, p. 331-342, 1995. 
JEVENS, D. J.; DECAMP, C. E.; HAUPTMAN, J. G. Use of force-plate analysis of gait to compare two surgical techniques for treatment of cranial cruciate ligament rupture in dogs . American Journal Veterinary Research, v. 57, n. 34, p. 389-393, 1996.

JEVENS, D. J.; HAUPTMAN, J. G.; DECAMP, C. E. Contributions of variance in force plate analysis of gait in dogs . American Journal Veterinary Research, v. 54, n. 4, p. 612-615, 1993.

JOHNSON, M. S.; GOURLEY, I. M. Perineal hernia in a cat: a possible complication of perineal urethrostomy. Veterinary Medicine Small Animal Clinician v. 75, p. 241, 1980.

KIRPENSTEIJN, J.; VAN DEN BOS, R.; VAN DEN BROM, W. E.; HAZEWNKEL, H. A. W. Ground reaction force analysis of large breed dogs when walking after the amputation of a limb. The Veterinary Record, v. 146, n. 2, p. 155-159, 2000.

LEACH, D. H. Locomotion analysis technology for evaluation of lameness in horses. Equine Veterinary Journal, v. 19, p. 97-99, 1987

LEIGHTON, R. L. Perineal hernia in a cat. Feline Practice, v. 9, p. 44, 1979

LIPOWITZ, A. L. Perineal surgery. In: LIPOWITZ, A. L.; NEWTON, C. D.; CAYWOOD, D. D.; SCHWARTZ, A. Complications in small animal surgery.

Baltimore:Williams\&Wilkins, 1996. p. 527-540.

MANN, F.A.. Perineal herniation. In: BOJRAB, M. J. (Ed). Disease Mechanisms in small animal surgery. 2. ed. Philadelphia: Lea \& Febiger company, Filadélfia, 92-97, 1993.

MANN, F. A.; BOOTHE, H. W.; AMOSS, M. S.; TANGNER, C. H.; PUGLISI, T. A.; HOBSON, H. P. Serum testosterone and estradiol 17-beta concentrations in 15 dogs with perineal hernia. Journal of the American Animal Hospital Association, v. 194, p. 15781580, 1989.

MANN, F.A.; CONSTANTINESCU, G.M. Salvage techniques for failed perineal herniorrhaphy. In: BOJRAB, M.J. et al. (Eds). Current techniques in small animal surgery. 4. ed. Baltimore: Williams \& Wilkins, 1998. p. 564-570.

MANN, F. A.; NONNEMAN, D. J.; POPE, E. R.; BOOTHE, H. W.; WELSHONS W. V.; GANJAN U. K. Androgen receptors in the pelvic diaphragm muscles of dogs with and without perineal hernia. American Journal Veterinary Research, v. 56, p. 134-139, 1995.

MATERA, A.; BARROS, P. S. M.; STOPIGLIA, A. J.; RANDI, R. E. Hernia perineal no cão- tratamento cirúrgico mediante utilização de malha de polipropileno. Revista da Faculdade de Medicina Veterinária e Zootecnia da Universidade de São Paulo, v. 18, n. 1, p. 37-41, 1981.

MATERA, J. M ; STOPIGLIA, A. J.; ALVARENGA, J.; MATERA, A.; BARROS, P. S. M; SPICCIATI, W. Estudo comparativo para avaliação de diferentes técnicas no tratamento cirúrgico da hérnia perineal do cão.. In: CONGRESSO BRASILEIRO DE CLÍNICOS VETERINÁRIOS DE PEQUENOS ANIMAIS 10², 1987. [Resumo ...].1987, p. 20-20.

MATTHIESEN, D. T. Diagnosis and management of complications occurring after perineal herniorrhaphy in dogs. Continuing Education, v. 11, p. 797-801, 1989. 
McLAUGHLIN, R.; MILLER, C. W.; TAVIS, C. L. Force plate analysis of triple pelvic osteotomy for the treatment of canine hip dysplasia. Veterinary Surgery, v. 20, n. 5, p. 291297, 1991.

McLAUGHLIN, R.; ROUSH, J. K. Effects of increasing velocity on braking and propulsion times during force plate gait analysis in Greyhounds. American Journal Veterinary Research; v. 56, n. 2, p. 159-161, 1995.

MORTARI, C. A. Avaliação da técnica de transposição do músculo semitendinosos no reparo do diafragma pélvico. Estudo experimental em cães. 2004. 101 p. Dissertação (Mestrado) - Faculdade de Medicina Veterinária e Zootecnia, Universidade Estadual Paulista. Botucatu, 2004.

MORTARI, A. C.; RAHAL, S. C.; RESENDE, L. A. L; DAL-PAI-SILVA, M.; MAMPRIM, M. J.; CORREA, M. A; ANTUNES,S. H. S. Hayes, H.W., Wilson, G.P., Trone, R.E. (1978). Electromyographical, ultrasonographical and morphological modifications in semitendinous muscle after transposition as ventral perineal muscle flap. Journal Veterinary Medical. v. 52, n. 7, p. 359-365, 2005.

NEWTON, C. D.; NUNAMAKER, D. M. Normal anda anormal gait. I. In: NUNAMAKER, D.M. Textbook of Small Animal Orthopedics. Philadelphia: Lippincott Company, 1985, p. 1083-1096.

NIEBAUER, G.; DAYRELL-HART, B. L., SPECIALE, J. The potencial role of relaxin in canine perineal hernia. Journal of the Federation of American Societies for Experimental Biology, v. 5A, p. 1639-1642, 1991.

OLIVEIRA, R. M. D. Análise da locomoção de cães portadores de displasia coxofemoral com o sistema de baropodometria. 2008. 75 p. Dissertação (Mestrado) - Faculdade de Medicina Veterinária e Zootecnia Universidade de São Paulo, São Paulo, 2008.

ORSHER, R. Clinical and surgical parameters in dogs with perineal hernia analysis of result of internal obturator transposition. Veterinary Surgery, v. 15, n. 3, p. 253-258, 1986.

ORSCHER, R. J.; JOHNSTON, D. E. The surgical treatment of perineal hernia in dogs by transposition of the obturator muscle. Compendium of Continuing Education Practicing Veterinarian, v. 7, 1985, p. 233-239.

PHILIBERT, D.; FOWLER, J. D. Use of muscle flaps in reconstructive surgery. Compendium of Continuing Education Practicing Veterinarian, v. 18, p. 395-405, 1996.

PETTIT, G. D. Perineal hernia in the dog. Cornell Veterinary, v. 52, p. 261-279, 1962.

RAISER, A. G. Herniorrafia perineal em cães - análise de 35 casos. Brazilian Journal Veterinary Reserach Animal Science, v. 31, n. 3/4, p. 252-260, 1994.

RENBERG, W. C.; JOHNSTON, S. A.; YE, K. Comparison of stance time and velocity as control variables in force plate analysis of dogs. American Journal Veterinary Research, v. 60, n. 8, p. 814-819, 1999. 
RIGGS, C. M.; DECAMP, C. E.; SOUTAS-LITTLE, R. W. Effects of subjet velocity on force plate measured ground reaction forces in healthy Greyhounds at the trot. American Journal Veterinary Research v. 54, n. 12, p. 1523-1526, 1993.

ROBERTSON, J. J. Perineal hernia repair in dogs. Modern Veterinary Practice, v. 65, p. 365-368, 1984.

ROCHAT, M. C.; MANN, F. A. Sciatic perineal hernia in two dogs. Journal of Small Animal Practice, v. 39, p. 240-243, 1998,.

ROUSH, J. K; MCLAUGHLIN JR., R.M. Effects of subject stance time and velocity on ground reaction forces in clinically normal Greyhounds at the walk. American Journal of Veterinary Research, v. 55, n. 12, p. 1672-1676, 1994.

RUMPH, P. F.; LANDER, J. E.; KINCAID, S. A.; BAIRD, D. K.; KAMMERMANN, B.S. Ground reaction force profiles from force platform gait analyses of clinically normal mesomorphic dogs at the trot. American Journal Veterinary Research, v. 55, n. 6, p. 756761, 1994.

RUMPH, P. F.; KINCAID, S. A; BAIRD, D. K.; KAMMERMANN, B. S.; VISCO, D. M.; GOETEL, L. F. Vertical ground reation force distribution during experimentally induced acute synovitis in dogs. American Journal Veterinary Research, v. 54, n. 3, p. 365-369, 1993.

SALES LUIS, J. P. FERREIRA, F. Ensaio de técnica alternativa para a hérnia perineal do cão, por transposição do músculo obturado interno. O Med. Vet, v. 1, p. 40-44, 1986.

SAS. STATISTICAL ANALISYS SYSTEM. SAS, User’s Guide: basic and statistic. Cary: SAS, 1995. $1.686 \mathrm{p}$.

SCHAEFER, S. L.; DECAMP, C. E.; HAUPTNAN, J. G. Use of cinematic gait analysis to evaluate hind limb symmetry of the trot in healt dogs. Veterinary Surgery, v. 25, p. 437-439, 1996.

SJOLLEMA, B. E.; VAN SLUIJS, F. J. Perineal hernia in the dog: developments in its treatment and retrospective study in 197 patients. Tijdschr. Diergeneeskd, v. 116, p. 142147, 1991.

SJOLLEMA, B. E.; VAN SLUIJS, F. J. Perineal hernia repair in the dog by transposition of the internal obturator muscle. Part II. Complications and results in 100 patients. Veterinary Questions, v. 11, p. 18-23, 1989.

SJOLLEMA, B. E.; VENKER-VAN HAAGEN, A. J.; VAN SLUIJS, F. J.; HARTMAN, F.; GOEDEGEBUURE, S.A. Electromyography of the pelvic diaphragm and anal sphincter in dogs with perineal hernia. American Journal Veterinary Research, v. 54, p. 185-190, 1993.

SLOLLEMA, B. E.; SLUIJS, F. J. Perineal hernia repar in the dog by transposition of the internal obturador muscle. II Complications and results in 100 pacients. Veterinary

Questions, v. 11, n. 1, p. 18-23, 1989. 
SOUZA, A. N. A. Correlação entre o grau de displasia coxofemoral e análise cinética da locomoção de cães da raça Pastor Alemão. 2009.153p. Dissertação (Mestrado) - Faculdade de Medicina Veterinária e Zootecnia Universidade de São Paulo, São Paulo, 2009.

SPARKS, E. R. Prostatectomy in the reduction of perineal hernias in the dog. Veterinary Medicine,v. 28, n. 12, p.508-511, 1993.

SPREU, J. S. A.; FRANKLAND, A. L. Transplanting the superficial gluteal muscle in the treatment of perineal hernia and flexure of the rectum in the dog. Small Animal Practical, v. 21, p. 265-278, 1980.

TANNOUZ, V. G. S.; SILVA, B. X.; ABIDU-FIGUEIREDO, M. Hérnia perineal em cães: aspectos anatômicos e ultra-sonográficos. Revista Universidade Rural, Sér. Ci. Vida. Seropédica, v. 25, 2005. Suplemento.

VNUK, D.; BABÍC, M.; STEJSKAL, D.; CPAX, I.; HARAPIN, B.; PIRKÍC. Application of a semitendinosus muscle flap in the treatment of perineal hernia in cat. Veterinary Record. $v$. 156, p. 182-184, 2005.

WALTER, J. P.; CARRIER, D. R. Ground forces applied by galloping dogs. Journal of Experimental Biology, v. 210, p. 208-216, 2007.

WASHABAU, R. J.; BROCKMAN, D. J. Recto-anal disease. In: ETTINGER S.J.; FELDMAN E.C. Textbook of Veterinary Internal Medicine, 4. ed. Filadélfia: WB Saunders company, 1995.p. 1398-1409.

WEAVER, A. D.; OMAMEGBE, J. O. Surgical treatment of perineal hernia in the dog. Journal of Small Animal Practice, v. 22, p. 749-758, 1981.

WEIGEL, J. P.; ARNOLD, G.; HICKIS, D. A.; MILLIS, D. L. Biomechanics of joint. Veterinary Clinics on North American: Small Animal Practice, v. 35, n. 6, p. 1255-1287, 2005.

WELCHES, C. D.; SCAVELLI, T. D.; ARONSOHN, M. G.; MATTHIESEN, D. T. Perineal hernia in the cat: a retrospective study of fourty cases. Journal of the American Animal Hospital Association, v. 28, p. 431-438, 1992.

WHITE, R. A.; HERRTAGE, M. E. Bladder retroflexion in the dog. Journal of Small Animal Practice, v. 27, p. 735-746, 1986.

WHITTLE, M. W. Gait analysis: an introduction. Boston: Butterworth-Heinemann, 1991.

YANOFF, S. R.; HULSE, D. A.; HOGAN, H. A.Measurements of vertical ground reaction force in jumping dogs. Veterinary Compendium of Orthopedics and Traumatology, v. 5, p. 44-50, 1992.

ZERWES, M. B. C. Avaliação comparativa do tratamento cirúrgico da hérnia perineal em cães pela técnica de elevação do músculo obturador interno com ou sem reforço de retalho de membrana de pericárdio eqüino preservado em glicerina a 98\%. 2005. 91 p. Dissertação (Mestrado) - Faculdade de Medicina Veterinária e Zootecnia.Universidade de São Paulo, São Paulo, 2005. 
ZIMMERMAN, L. M.. The use of prosthetic materials in the repair of hernia. Surgical Clinics of North America, v. 48, p. 143, 1968. 
APÊTNDICE 


\section{APÊNDICE A}

\begin{tabular}{|c|c|c|c|c|}
\hline \multicolumn{5}{|c|}{ ATENDIMENTO HOVET- AGOSTO 2007 A JULHO DE 2008} \\
\hline & PARCIAL 1 & H BIL & H UNIL & NE \\
\hline $\mathrm{CN}$ & 64 & 21 & 17 & 26 \\
\hline IC & 46 & 20 & 24 & 2 \\
\hline \multicolumn{5}{|c|}{ ATENDIMENTO HOVET- AGOSTO 2008 A JULHO DE 2009} \\
\hline & PARCIAL 2 & H BIL & H UNI & $\mathrm{NE}$ \\
\hline $\mathrm{CN}$ & 42 & 15 & 10 & 17 \\
\hline IC & 25 & 10 & 13 & 2 \\
\hline \multicolumn{5}{|c|}{$\begin{array}{l}\text { TOTAL DE ATENDIMENTOS NO HOVET } \\
\text { AGOSTO } 2007 \text { A JULHO DE } 2009\end{array}$} \\
\hline & TOTAL & H BIL & H UNIL & NE \\
\hline $\mathrm{CN}$ & 106 & 36 & 27 & 43 \\
\hline IC & 71 & 30 & 37 & 4 \\
\hline
\end{tabular}

Descrição de Todos os casos de hérnia perineal atendidos no HOVET, incluídos ou não no projeto, durante o período de Agosto de 2007 a Julho de 2009. CN- Caso Novo; ICIntervenção Cirúrgica, HBIL- Hernia Bilateral, HUNIL- Hérnia Unilateral, NE- Não Especificado. 
ANEXOS 


\author{
ANEXO A \\ HOSPITAL VETERINÁRIO \\ DA \\ FACULDADE DE MEDICINA VETERINÁRIA E ZOOTECNIA DA USP
}

\title{
TERMO DE CIÊNCIA E AUTORIZAÇÃO
}

\begin{abstract}
EU, responsável pelo animal da espécie , raça , com (De Idade), registrado no Hospital Veterinário da FMVZ sob n ${ }^{\circ}$ , ESTOU CIENTE de que o animal de minha propriedade fará parte do protocolo de pesquisa intitulado: Aplicação da técnica de transposição do músculo semitendinoso na reparação de hérnias perineais em cães com acompanhamento sistematizado do pós-operatório e uso do sistema de baropodometria no estudo da locomoção, em desenvolvimento no Serviço de Cirurgia desta Faculdade, sob a responsabilidade do Professor Doutor Ângelo João Stopiglia, do Departamento de Cirurgia, da Faculdade Faculdade de Medicina Veterinária e Zootecnia da Universidade de São Paulo.
\end{abstract}

Outrossim, declaro ter sido cientificado de forma pormenorizada sobre os procedimentos que serão aplicados nesse animal.

Por estar plenamente concorde firmo o presente.

São Paulo, de de

NOME: ASSINATURA

RG n ${ }^{\circ}$ : 


\section{ANEXO B \\ UNIVERSIDADE DE SÃO PAULO \\ FACULDADE DE MEDICINA VETERINÁRIA E ZOOTECNIA \\ SERVIÇO DE CIRURGIA- HOVET \\ HÉRNIAS PERINEAIS}

IDENTIFICAÇÃO

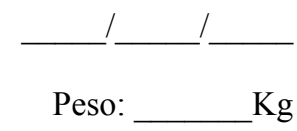

ANAMNESE:

Normoquesia ( ) Aquesia ( ) Disquesia ( ) Diarréia ( ) Hematoquesia ( ) Tenesmo ( )

Outros:

Normorexia ( ) Anorexia ( ) Hiporexia ( ) Polifagia ( ) Emese ( )

Outros:

Normodipsia ( ) Adipsia ( ) Oligodipsia ( ) Polidipsia ( )

Outros:

Urina cor/asp. Normais ( ) Anúria ( ) Oligúria ( ) Poliúria ( ) Disúria ( ) Hematúria ( )

Outros:

Animal interiro ( ) Castrado ( )

Outros:

Alimentação caseira ( ) ração ( ) Caseira /ração ( )

Outros:

Contactantes: Sim ( ) Não ( )

Quais:

Imunização ética ( ) Não Vacinado ( ) Atrasada ( )

Outros:

Antecedente Mórbidos: Sim ( ) Não ( )

Quais:

EXAME CLÍNICO:

Temperatura:

Hidratação:

Mucosas: Linfonodos :

Auscultação: FR: FC: TPC:

Palpação Abdominal:

Palpação Retal: 
Sensibilidade:

Deformidades retais:

Próstata: Palpável ( ) Não palpável ( )

Outros:

\section{EXAME EXTERNO:}

Consistência: Macia ( ) Firme ( ) Flutuante ( )

Outros:

Sensibilidade: Sim ( ) Não ( )

Outros:

Provável Conteúdo: Bexiga ( ) Próstata ( )

Outros:

OBSERVAÇÕES: 


\section{ANEXO C}

\section{Avaliações em cada período}

\section{Identificação:}

\begin{tabular}{|l|c|}
\hline Periodo/Aval & Exame Clínico/ Exame Físico/ Baropodometria/ Raio X/ Ultra-som \\
\hline & \\
\hline Período/Aval & Exame Clínico/ Exame Físico/ Baropodometria/ Raio X/ Ultra-som \\
\hline & \\
\hline Período/Aval & \\
\hline & \\
\hline & Exame Clínico/ Exame Físico/ Baropodometria/ Raio X/ Ultra-som \\
\hline & \\
\hline
\end{tabular}




\section{ANEXO D}

\begin{tabular}{|c|c|c|c|c|c|c|}
\hline CÃO & T ${ }^{\circ} \mathbf{C}$ & FC (bpm) & FR (mpm) & MU & LI & HI \\
\hline 1 & 38,9 & 132 & $*$ & NORMO & NORMO & ADEQUADA \\
\hline 2 & 39,4 & 228 & 28 & NORMO & NORMO & DH. LEVE \\
\hline 3 & 38,4 & 140 & 40 & NORMO & NORMO & ADEQUADA \\
\hline 4 & 38,6 & 100 & $*$ & NORMO & POPL $\uparrow$ & ADEQUADA \\
\hline 5 & 39,2 & 160 & 36 & CONGESTAS & NORMO & DH. LEVE \\
\hline 6 & 39,7 & 120 & $*$ & NORMO & POPL $\uparrow$ & ADEQUADA \\
\hline 7 & 39,3 & 120 & 140 & NORMO & NORMO & ADEQUADA \\
\hline 8 & 38,1 & 90 & 40 & NORMO & NORMO & ADEQUADA \\
\hline 9 & 38,1 & 188 & 48 & NORMO & NORMO & ADEQUADA \\
\hline 10 & 39,2 & 100 & 61 & NORMO & POPL $\uparrow$ & DH. LEVE \\
\hline 11 & 36,7 & 147 & 40 & NORMO & NORMO & ADEQUADA \\
\hline
\end{tabular}

Quadro 1 - Parâmetros fisiológicos obtidos dos cães submetidos à transposição do músculo semitendinoso, no seu primeiro dia de atendimento no HOVET, FMVZ/USP - São Paulo - 2007-2010 


\section{ANEXO E}

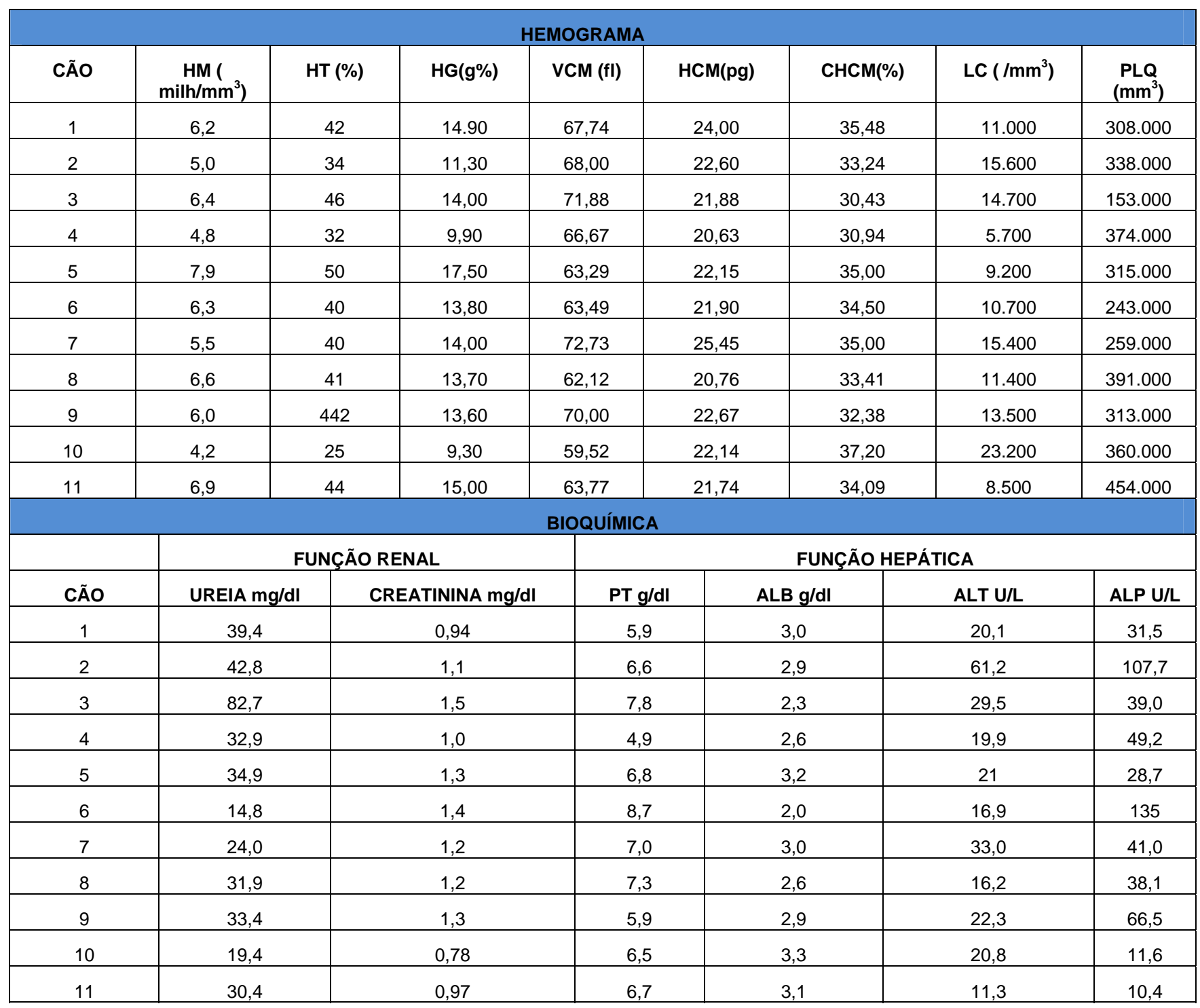

Quadro 2 - Resultado das análises laboratoriais realizadas no período pré-operatório. Laboratório de análises Clínicas - HOVET-FMVZ - 2007-2010 


\section{ANEXO F}

\begin{tabular}{|c|c|c|}
\hline CÃO & US & $\mathbf{R X}$ \\
\hline 1 & Próstata aumentada, topografia habitual. & Reto em região de períneo \\
\hline 2 & $\begin{array}{l}\text { Próstata aumentada em região de períneo, bexiga } \\
\text { visualizada no aumento de volume perineal. }\end{array}$ & $\begin{array}{l}\text { Próstata aumentada em região de } \\
\text { períneo, bexiga no canal pélvico. }\end{array}$ \\
\hline 3 & $*$ & $\begin{array}{l}\text { Próstata aumentada em região de } \\
\text { períneo, bexiga em canal pélvico. }\end{array}$ \\
\hline 4 & $\begin{array}{l}\text { Próstata não visualizada, alças intestinal em hérnia } \\
\text { direita, bexiga em hérnia Esquerda. }\end{array}$ & $\begin{array}{l}\text { Próstata não visualizada, bexiga } \\
\text { deslocada caudalmente. }\end{array}$ \\
\hline 5 & $\begin{array}{l}\text { Próstata aumentada em região de períneo, bexiga } \\
\text { deslocada caudalmente. }\end{array}$ & $\begin{array}{l}\text { Próstata aumentada em região de } \\
\text { períneo e bexiga não visualizada. }\end{array}$ \\
\hline 6 & $\begin{array}{l}\text { Próstata aumentada em região de períneo direito, } \\
\text { bexiga deslocada caudalmente. }\end{array}$ & $\begin{array}{l}\text { Próstata aumentada em região de } \\
\text { períneo, bexiga deslocada caudalmente. }\end{array}$ \\
\hline 7 & $\begin{array}{l}\text { Próstata não observada, alças em região de períneo, } \\
\text { bexiga comprimida pelas alças. }\end{array}$ & Indefinição da bexiga. \\
\hline 8 & $\begin{array}{l}\text { Próstata aumentada em região de períneo esquerdo. } \\
\text { Bexiga deslocada caudalmente. }\end{array}$ & $\begin{array}{l}\text { Bexiga deslocada caudalmente, próstata } \\
\text { aumentada na região de períneo. }\end{array}$ \\
\hline 9 & Próstata não visualizada. & $\begin{array}{l}\text { Próstata deslocada caudalmente e bexiga } \\
\text { em posição habitual. }\end{array}$ \\
\hline 10 & $\begin{array}{l}\text { Próstata e bexiga localizada em região hipogátrica. } \\
\text { Não identificado estruturas em região de aumento } \\
\text { perineal. }\end{array}$ & $\begin{array}{l}\text { Próstata em região de períneo, bexiga } \\
\text { deslocada caudalmente. }\end{array}$ \\
\hline 11 & $\begin{array}{l}\text { Seguimento de alça intestinal em conteúdo herniário da } \\
\text { região perineal esquerda. }\end{array}$ & $\begin{array}{l}\text { Bexiga e uretra prostática com } \\
\text { retroflexão em região perineal esquerda. }\end{array}$ \\
\hline
\end{tabular}

Quadro 3 - Descrição da localização da próstata e bexiga nos laudos emitidos antes do procedimento cirúrgico pelo Serviço de Imagem do HOVET/FMVZ - São Paulo 2007-2010 


\section{ANEXO G}

\begin{tabular}{|c|c|c|c|c|c|c|}
\hline CÃO & RAÇA & PORTE & IDADE (Anos) & PESO (Kg) & CM (cm) & CMPI(cm) \\
\hline 1 & SHEEPDOG & G & 10 & $\mathbf{2 4 , 0}$ & $\mathbf{2 0 , 0}$ & $\mathbf{1 5}$ \\
\hline 2 & SRD & M & 14 & $\mathbf{1 3 , 0}$ & $\mathbf{1 5 , 0}$ & $\mathbf{9 , 5}$ \\
\hline 3 & SRD & M & 11 & $\mathbf{1 7 , 5}$ & $\mathbf{1 3 , 0}$ & $\mathbf{1 0 , 0}$ \\
\hline 4 & POODLE & P & 12 & $\mathbf{6 , 1}$ & $\mathbf{9 , 0}$ & $\mathbf{5 , 0}$ \\
\hline 5 & SRD & M & 10 & $\mathbf{1 4 , 0}$ & $\mathbf{1 1 , 0}$ & $*$ \\
\hline 6 & ROTTWEILLER & G & 5 & $\mathbf{3 1 , 7}$ & $*$ & $*$ \\
\hline 7 & Mestiço DACHSHUND & P & 11 & $\mathbf{7 , 2}$ & $\mathbf{6 , 5}$ & $\mathbf{4 , 5}$ \\
\hline 8 & ROTTWEILLER & G & 9 & $\mathbf{4 8 , 6}$ & $\mathbf{1 7 , 5}$ & $\mathbf{1 3 , 5}$ \\
\hline 9 & POODLE & P & 12 & $\mathbf{9 , 4}$ & $\mathbf{9 , 0}$ & $\mathbf{6 , 5}$ \\
\hline 10 & SRD & M & 12 & $\mathbf{1 8 , 8}$ & $\mathbf{1 1 , 0}$ & $\mathbf{8 , 0}$ \\
\hline 11 & SRD & M & 9 & $\mathbf{1 3 , 4}$ & $\mathbf{1 0 , 0}$ & $\mathbf{7 , 5}$ \\
\hline
\end{tabular}

Quadro 4 - Descrição das características físicas de cada cão e as respectivas medidas do músculo semitendinoso antes e após a incisão. G- Grande, M- Médio, P- Pequeno, CMComprimento do músculo, CMPI- Comprimento do músculo pós-incisão. Atendidos no HOVET/FMVZ - São Paulo - 2007-2010 